\title{
Kernos
}

Revue internationale et pluridisciplinaire de religion grecque antique

18 | 2005

Varia

\section{Chronique archéologique de la religion grecque (ChronARG)}

\section{(2) OpenEdition}

Journals

\section{Édition électronique}

URL : http://journals.openedition.org/kernos/1835

DOI : 10.4000/kernos. 1835

ISSN : 2034-7871

Éditeur

Centre international d'étude de la religion grecque antique

\section{Édition imprimée}

Date de publication : 1 janvier 2005

Pagination : 475-530

ISSN : 0776-3824

\section{Référence électronique}

"Chronique archéologique de la religion grecque (ChronARG) », Kernos [En ligne], 18 | 2005, mis en ligne le 29 juin 2011, consulté le 15 septembre 2020. URL : http://journals.openedition.org/kernos/ 1835 


\section{Chronique archéologique de la religion grecque (ChronARG)}

La présente chronique couvre essentiellement les publications de 2003, tout en tenant compte des années antérieures pour les régions qui n'ont pas systématiquement fait l'objet d'une chronique annuelle. Plusieurs régions, qui étaient jusqu'à présent traitées chaque année, passent provisoirement à un traitement bisannuel (Athènes, Péloponnèse). Nous ne désespérons pas de couvrir les régions qui n'ont pas encore été associées à cette chronique depuis sa création (Béotie, Eubée, Phocide, Locride, Étolie), mais ce n'est pas encore le cas cette année.

Par contre, nous renouons avec une pratique inaugurée lors de la première livraison de la Chronique archéologique en publiant le compte rendu d'une fouille par ses auteurs. Il s'agit de la mise au jour d'un ensemble exceptionnel de trois animaux découpés et enterrés tels quels à l'angle nord-est de l'agora de Thasos. C'est par cette découverte remarquable que s'ouvre la chronique.

Didier Viviers \& Vinciane PIRENNE-DeLForge 


\section{Un rituel d'engagement à Thasos : archéologie et textes}

À l'occasion d'un sondage destiné à contrôler une relation stratigraphique, dans l'angle nord-est de l'agora de Thasos, a été mis au jour un ensemble ostéo-archéologique exceptionnel ${ }^{1}$ : dans une grande fosse allongée, on a retrouvé les squelettes d'un taurillon, d'un verrat et d'un bélier, coupés en deux et disposés en deux amas bien séparés, comprenant l'un l'avant du bélier, l'arrière du porc et du bovin, l'autre l'arrière du bélier, l'avant du bovin et du porc. Il s'agit de trois mâles, deux d'entre eux plutôt jeunes, énergiquement mais soigneusement coupés en deux comme le suggère la trace de la lame qui s'observe sur les vertèbres et les côtes du bovin. Dans chacune des moitiés, les os sont restés en parfaite connexion, ce qui signifie que les carcasses ont été disposées telles quelles dans la fosse, sans autre dépeçage ni prélèvement de chairs. La datation de cette trouvaille repose uniquement sur du matériel céramique : celui, très pauvre, du comblement de la fosse qui renvoie au $\mathrm{IV}^{\mathrm{e}}$ siècle, sans autre précision, et celui, plus riche et caractéristique, du comblement d'une fosse postérieure dont le terminus post quem est de ca 330 av. J.-C.

L'interprétation de cette trouvaille demande que soient pris en compte ses deux éléments constitutifs: l'association de trois animaux d'une part, la division des corps et leur disposition en deux ensembles distincts d'autre part. La première donnée nous renvoie à une association bien connue et attestée dans la documentation épigraphique et littéraire pour différents rituels

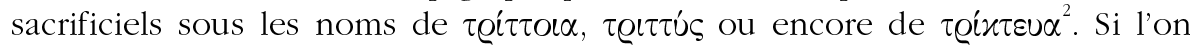
s'en tient à la définition par espèces, le complexe retrouvé à Thasos correspond très exactement à la trittoia dans la composition qu'en donne Callimaque $^{3}$ et qui est confirmée par la plupart des sources écrites, même si d'autres associations sont attestées par ailleurs.

\footnotetext{
${ }^{1}$ Voir Fr. Blondé, A. Muller, D. Mulliez, BCH 124 (2000), p. 520 et, avec Fr. Poplin, AErgoMak 15 (2001), p. 67-73 et BCH 127/2 (2003), sous presse. Le groupe de recherche sur la religion grecque des Universités de Liège, Louvain et Bruxelles, nous a accueillis en novembre 2001 au Musée royal de Mariemont, pour la présentation alors bien provisoire de cette trouvaille. Nous remercions la rédaction de Kernos de faire place aujourd'hui à une interprétation plus élaborée. - Pour le détail de l'établissement des données et de l'argumentation avec l'exploitation des textes, nous renvoyons à notre article à paraître dans le BCH 129 (2005). Tous nos remerciements vont aux nombreux collègues qui nous ont aidés à faire progresser la compréhension de notre trouvaille.

${ }^{2}$ Les textes principaux désignant cet assemblage de trois animaux à des fins rituelles ont été commodément réunis dès 1939 par L. ZIEHEN, s.v. «trittoia », RE VII A1 (1939), col. 328-330.

3 Callimaque, fr. 578 (éd. R. Pfeiffer, 1949).
} 
En l'occurrence, si le nombre rehausse l'importance du rituel, c'est le découpage des bêtes et leur séparation en deux tas qui lui donnent sens. Cette pratique, attestée dans une aire géographique extrêmement large et à des périodes très diverses, intervient dans des rituels qui, pour l'essentiel, ont reçu dès l'Antiquité deux interprétations principales: on y a vu soit une façon solennelle de sceller une forme d'engagement (traité, alliance ou serment), soit un rituel de purification ${ }^{4}$. Le réexamen de l'ensemble des sources nous amène à privilégier pour la trouvaille thasienne la première de ces interprétations, la seconde n'intervenant de manière explicite en contexte grec qu'assez tardivement, dans des textes de Quinte-Curce et de Tite-Live ${ }^{6}$ relatifs à des lustrations de l'armée macédonienne que l'on fait passer entre les parties d'un animal coupé en deux. Plutarque mentionne un rituel de purification similaire chez les Béotiens, en dehors de tout contexte militaire ${ }^{7}$. La question se pose de savoir s'il ne s'agit pas à chaque fois d'un rite dont le sens fondamental échappait. En tout état de cause, si elle devait être retenue, il conviendrait d'expliciter la dimension lustrale de ces rites militaires; et cette dimension ellemême serait-elle recevable qu'elle ne nous paraitrait aucunement exclure la signification que d'autres sources élucident pleinement.

En effet, en dehors du contexte proprement grec, deux ensembles de textes donnent clairement l'interprétation du rituel comme une manière, parmi d'autres, de préfigurer le sort qui attend l'éventuel parjure: le premier regroupe des traités du vIII ${ }^{\mathrm{e}}$ et du VII ${ }^{\mathrm{e}}$ siècle provenant de l'empire assyrien et de ses marges ${ }^{8}$; le deuxième réunit deux extraits de l'Ancien Testament, l'un évoquant l'alliance que Iahvé passe avec Abraham, l'autre la rupture de l'alliance conclue entre Iahvé et Jérusalem?. Dans ces textes, le découpage des bêtes est donné comme la préfiguration du sort dont est menacé le parjure. En contexte grec, trois textes évoquent de façon tout aussi explicite la malédiction appelée sur les parjures, avec une mise en scène différente, mais d'interprétation identique : le premier est un serment homérique que l'on scelle en répandant du vin comme sera répandue la cervelle du parjure ${ }^{10}$; le second décrit le rituel du serment molosse avec découpage d'un bœuf en

\footnotetext{
${ }^{4}$ Voir en particulier M.P. NILSSON, Geschichte der griechischen Religion I³, Munich, 1967, p. 106-107 (sur le rituel de purification et la contamination entre Reinigungs- et Eidopfer), et p. 139-141 (sur le Eidopfer); W. BuRKERT, Greek Religion, Harvard, 1985, p. 250-254 (serment) et p. $82-84$ (purification)

5 Quinte-Curce, X, 9, 11-12. - La lustration a lieu au lendemain de la mort d'Alexandre, en 323.

Tite-Live, XL, 6. - La lustration que décrit Tite-Live a lieu en 182.

7 Plutarque, Quaest. rom., 290d.

${ }^{8}$ Voir A. LEMAIRE, J.-M. DURAND, Les inscriptions araméennes de Sfiré et l'Assyrie de Shamshiilu, Genève/Paris, 1984, et Ch. A. FARAONE, "Molten wax, split wine and mutilated animals: sympathetic magic in Near Eastern and Early Greek oath ceremonies », JHS 113 (1993), p. 60-80, qui commente les textes les plus intéressants de notre point de vue.

9 Respectivement Génèse 15, 7-10 et 17, et Jérémie 34, 17 sq.

10 Iliade III, 299 : "Quels que soient ceux qui transgresseront les premiers ces serments, que leur cervelle comme ce vin soit répandue sur la terre. »
} 
petits morceaux et vin répandu ${ }^{11}$; le troisième est le fameux serment de Cyrène par lequel les colons qui partaient pour l'Afrique et les habitants de la métropole Théra s'engageaient réciproquement : il fut scellé en jetant au feu des figurines de cire, rituel prédéterminant la liquéfaction des parjures ${ }^{12}$. Le découpage de bêtes en deux était cependant la pratique la plus courante dans le serment grec, à en croire de nombreux autres textes, tant épigraphiques que littéraires. Ils se contentent de la simple mention, à l'occasion de prestations de serments dans le cadre politique ou judiciaire, des tó $\mu \alpha$ ou des $\sigma \varphi \alpha^{\prime} \gamma\llcorner\alpha$ des bêtes immolées : les prestataires du serment ou les partenaires de l'alliance ou les parties qui prêtent serment les prennent en main, ou se tiennent sur elles ou encore passent entre elles, selon les cas ${ }^{13}$. Jamais ces chairs ne sont consommées : elles sont tantôt enfouies, tantôt entièrement brûlées ou encore jetées à la mer. Les Grecs, pas plus que les Hébreux ou les Assyriens, n'avaient manifestement besoin d'aucune autre explication sur le sens de ce rituel, désigné par des expressions équivalentes dans plusieurs langues : «couper une alliance » en hébreu, «couper un serment» dans les langues sémitiques ou chez Homère ${ }^{14}$.

La trittoia partagée de Thasos nous parait donc devoir être interprétée comme le témoignage archéologique - à notre connaissance, le premier jamais identifié - d'un engagement solennel. Cette trouvaille nous permet d'abord d'écarter avec certitude l'interprétation souvent soutenue depuis le début du $\mathrm{Xx}^{e}$ siècle selon laquelle les tomia seraient les testicules de l'animal immolé $^{15}$ : il s'agit bien de grandes pièces, des moitiés de la bête. D'autre part, elle nous invite à revenir sur l'interprétation comme rite de purification de plusieurs textes décrivant le passage d'une armée (hittite, perse, grecque, macédonienne), entre les moitiés d'une victime (homme, femme, chien, porcelet, chèvre $)^{16}$, interprétation que suggéraient notamment les deux textes

11 Proverbia Coisliniana, Paroemiographi Graeci I 225 (texte cité par BuRKeRT, o.c. [n. 4], p. 251-252, n. 18) : «lorsque les Molosses prêtent un serment, ils apportent un bœuf et une coupe remplie de vin; ils découpent le bøuf en petits morceaux et prient pour que le parjure soit découpé de la sorte; puis ils versent le vin de la coupe et prient pour que le sang des parjures soit répandu de la sorte. »

${ }^{12}$ Inscription R. MEIGGS, D. LEWIS, A Selection of Greek Historical Inscriptions to the end of the fifth century $B C$, Oxford, $1988^{2}$, p. 5-9 $\mathrm{n}^{\circ}$ 5, se terminant par la formule de malédiction : " que celui qui sera infidèle à ce serment se liquéfie et disparaisse, lui, sa race et ses biens. »

13 Entre autres nombreux exemples dont on trouvera les références dans les ouvrages cités ci-dessus n. 4 ou dans G. Glotz, s.v. «jusjurandum», Dictionnaire des Antiquités III (1899), p. 748-769, signalons Démosthène, Contre Aristocrate, 67-68.

14 E.J. BICKERMAN, "Couper une alliance ", Studies in Jewish and Christian History (1976),

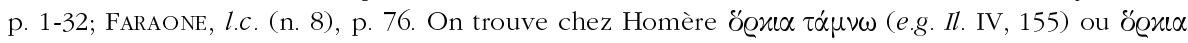
$\pi \iota \sigma \tau \dot{\alpha} \tau \alpha \dot{\alpha} \mu \nu \omega$ (e.g. Il. II, 124; Od. XXIV, 483); l'expression finit par signifier "prêter serment » : voir Hérodote, IV, 70 et VII, 13, 2; Polybe, XXI, 24, 3 et XXI, 32, 15; SIG ${ }^{3}$, 45, 1. 44). FARAONE, l.c. (n. 8), renvoie aussi au latin foedus ferire.

15 P. STENGEL, «Zu den griechischen Schwuropfern. Tomia, Hiera teleia », Hermes 49 (1914) p. 90-101. Voir NiLSSON, o.c. (n. 4), p. 139-141.

16 Apollodore, III, 13, 7; Keilschrifttexte aus Boghazköi (1921), XVII.28 iv 55-56; Hérodote, VII, 39, 3; Quinte-Curce, X, 9, 11-12; Tite-Live, XL, 6. Voir S. EITREM, « A purificatory rite and some 
tardifs mentionnés ci-dessus. Nous sommes très tentés de penser que ces "purifications » d'armées défaites ou menacées de mutineries relèvent en fait du même cas de figure que celui que nous venons de décrire. Il s'agit de restaurer ou d'instaurer une cohésion, sous la menace : celui qui ne respecte pas son engagement de soldat et met en péril la cohésion du groupe subira le sort de la victime coupée. Et c'est encore la même explication qu'il faut avancer lorsque Platon décrit la troisième phase de la procédure de désignation des magistrats, où "chacun élit le candidat de son choix parmi les cent [retenus], en passant entre les parties d'une victime coupée en deux ${ }^{17}$, ce qui nous parait plutôt relever d'un rituel d'engagement que de purification. Il nous semble que c'est la prégnance du rituel bien mieux connu, à la fois dans les textes et l'iconographie, de la purification par le sang d'une victime ${ }^{18}$ qui est à l'origine d'un certain nombre de contaminations et d'interprétations fautives, chez les Anciens aux époques tardives d'abord, chez les exégètes contemporains ensuite.

Reste à essayer de préciser le cadre de cette cérémonie thasienne. Des indices archéologiques - succession de fosses observées dans la stratigraphie et restes dispersés d'ossements de verrats étrangers à notre trittoia - suggèrent que cette région de l'angle nord-est de l'agora de Thasos aurait pu voir se répéter de tels rituels à l'époque classique au moins et constituer en quelque sorte l'horkomosion de Thasos. Tout serment comporte la prise à témoins de divinités, qui sont les garants : Glaukos, héros de la fondation de Thasos, dont le cénotaphe est immédiatement voisin, mais aussi les Charites, déesses de la concorde civique, qui avaient leur sanctuaire dans le Passage des Théores tout aussi proche ${ }^{19}$, pourraient à notre sens avoir été ces garants. En revanche, il faut évidemment se résoudre à l'ignorance sur la nature précise de l'engagement pris ici (alliance, traité, réconciliation civique, serment judiciaire ou privé...) et à la totale impossibilité de le rattacher à un épisode quelconque de l'histoire de Thasos au Iv siècle.

$\begin{array}{cccc}\text { Francine BLONDÉ } & \text { Arthur MULLER } & \text { Dominique MULLIEZ } & \text { François PoPLIN } \\ \text { CNRS } & \text { Univ. Lille 3 } & \text { École française } & \text { Muséum national } \\ \text { Halma - UMR 8142 } & \text { Halma - UMR 8142 } & \text { d'Athènes } & \text { d'Histoire naturelle } \\ & & & \text { UMR 5197 }\end{array}$

\footnotetext{
allied rites de passage», SO 25 (1947), p. 36-53, ainsi que FARAONE, l.c. (n. 8), p. 60-80. En revanche, nous excluons de la discussion le rituel décrit par Pausanias (II, 34, 2) au cours duquel on promène les moitiés d'un coq autour d'une vigne pour la protéger du vent : il ne s'agit ni de serment ni de purification, mais d'un rite prophylactique.

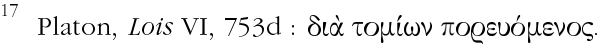

18 Voir les références ci-dessus n. 4.

19 Sur ces monuments de l'angle nord-est de l'agora, voir Y. GRANDJEAN et Fr. SALVIAT (dir.), Guide de Thasos, École française d'Athènes, 2000 (Sites et monuments, 3), p. 69-70 (mnèma de Glaukos) et p. 82-87 (Passage des Théores).
} 


\section{[01. Athènes, Attique, Mégaride]}

\section{[02. Péloponnèse]}

\section{[03. Béotie, Eubée]}

\section{[04. Phocide, Locride, Étolie]}

\section{Acarnanie, Épire, Illyrie méridionale, îles ionien- nes (François QuANTIN)}

\section{Acarnanie}

05.01 - Palairos - La découverte, en 1988, d'un autel au sommet de la colline du Prophète-Élie, est à l'origine d'une prospection, qui a permis d'identifier l'itinéraire des processions entre la ville et le sanctuaire, même si le tracé ne peut pas toujours être situé avec précision. Le temple est localisé au S de l'autel.

M. BerTele, in Acheloos. Schriften der Oberhummer Gesellschaft e.V. München 2, 2000, p. 716; G. TOuCHaIs et alii, BCH125 (2001) [2002], Chr., p. 887.

\section{Épire}

05.02 - Ambracie - XII Éphorie des antiquités prébistoriques et classiques - Les fouilles de sauvetage et les interventions programmées conduites à Arta fournissent comme chaque année de nombreux renseignements sur l'urbanisme d'Ambracie. On signale les découvertes suivantes : au pied de la colline Péranthis, hors contexte d'habitat, des figurines en terre cuite et des fragments de plaques, dont un exemplaire présente une scène de banquet (rue Papagou); à l'angle d'une maison, au niveau des fondations, de nombreux petits vases associés à des restes animaux et des indices de combustion dans une fosse (rue Manoliassis) : le dispositif, déjà connu à Ambracie, suggère la pratique d'un rite de consécration des fondations - $c f$. I. et E. ANDREOU, in $E^{\prime}$

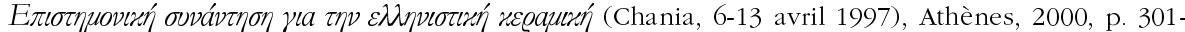
310, pour une étude de ces dépôts votifs, en particulier les vases miniatures, dans les fondations de maisons ambraciotes de l'archaïsme à l'époque hellénistique; dans une maison, des figurines féminines d'époques classique et hellénistique, et des appliques à relief en terre cuite dont l'iconographie évoque un banquet funéraire (rue Stamatelopoulou); près des vestiges du grand théâtre d'Ambracie, une stèle votive gravée d'une inscription en alphabet corinthien archaïque : KOTENOE ANE@EKE (rue Tsakalof).

Aux abords d'un nouveau tronçon des remparts antiques de la ville situé près du kastro byzantin, on note la découverte de plusieurs constructions et dépôts datés de l'archaïsme à l'époque hellénistique, qui sont interprétés comme les vestiges d'un sanctuaire (rues Mostraion et Agia Paraskevi). À quelques mètres à l'extérieur du rempart sont conservées les fondations d'un mur d'enceinte plus ancien, mais de même direction; au droit de ce nouveau mur, on découvre les vestiges plus ou moins rectangulaires d'une aire dallée limitée par des murs, vraisemblablement un lieu de culte, dont sont distinguées deux phases, toutes deux d'époque hellénistique. L'interprétation cultuelle est fondée sur la découverte de sept figurines taurines en bronze, auxquelles s'ajoutent de nombreux fragments qui appartiennent au même type d'offrande. V. Karatzeni propose à juste titre d'attribuer ces vestiges hors-les-murs à un sanctuaire de Poséidon, ou du fleuve Arachthos [AD 52 (1997) [2003], Chr. B'2, p. 564-566, fig. 8, pl. $209 \alpha$ et $\beta$ ]. Un sanctuaire de Poséidon est connu sur le territoire des Ambraciotes, mais il est situé aux confins de la chôra (cf. ChronARG [2002], 05.03), et ne peut donc être confondu avec ce lieu de culte associé aux remparts de la ville. 
A. Angeli, $A D 52$ (1997) [2003], Chr. B'2, p. 561; V. KARATZEni, ibid., p. 562-566; Th. KondoGIANNI, ibid., p. 573; J. WHITLEY, AR 2002-2003 (2003), p. 57-58.

05.03 - Phanari [plaine du] - Université de Boston, École américaine d'Athènes, XII Éphorie des antiquités prébistoriques et classiques, VIII Éphorie des antiquités byzantines - Les A. reconstituent l'évolution du paysage de la plaine du Phanari, et précisent les modifications qui ont affecté la baie, le lac Achérousia et le cours de l'Achéron, en particulier pendant la période antique. La colline de l'édifice de Mésopotamon, interprété par S.I. Dakaris comme un nekyomanteion, est donc dans l'Antiquité un promontoire dominant la baie du Phanari, dont le comblement est bien postérieur (pour des conclusions similaires, cf. ChronARG [2001], 05.00).

M.R. Besonen, G. RAPP et Z. Jing, "The Lower Acheron River Valley: Ancient Accounts and the Changing Landscape », in J. WisEmAN, K. ZACHOS (éds), Landscape Archaeology in Southern Epirus, Greece I, American School of Classical Studies, Athènes, 2003, p. 198-234 (Hesperia, Supplément 32).

05.04 - Agia Paraskevi (Thesprôtie) - VIIt Éphorie des antiquités prébistoriques et classiques K. Preka signale la découverte des vestiges d'une construction hellénistique de plan rectangulaire, peut-être associée à l'E à un autel. La stratigraphie a permis d'identifier clairement une couche de destruction due à un incendie. Le matériel - des figurines et des protomés féminines, des os d'animaux, des vases miniatures certainement votifs, une boucle d'oreille en or et une monnaie d'Alexandre III -, associé à une construction rectiligne, suggère que le site était un lieu de culte.

K. Preka, AD 52 (1997) [2003], Chr. B'2, p. 610; J. Whitley, AR 2002-2003 (2003), p. 59.

05.05 - Dodone - Université de Ioannina - Sous la responsabilité de Ch. Tzouvara-Souli, d'A. Vlachopoulou et K. Gravani, la campagne 1999 avait permis de mieux connaître la partie S de l'édifice interprété comme un prytanée. Vestiges architecturaux et matériel archéologique sont datés dans cette zone des époques romaine et paléochrétienne. Pour les fragments de tuile estampillés $\Delta$ iò Nóov, cf. SEG 50 (2000) [2003], n 545. En 2000, les fouilles ont continué le dégagement du couloir de l'aile $\mathrm{O} 2$ dans la partie $\mathrm{S}$ de cet édifice. La construction du mur $\mathrm{N}$ de ce diadromos semble être postérieure au passage destructeur de Paul-Émile en 167. Les A. estiment que ce mur, dans lequel sont remployés des fragments de chapiteaux, pourrait avoir succédé à une colonnade de même axe.

- L'équipe de l'Université de Ioannina a aussi travaillé en 2000 dans le secteur du portique découvert par K. Karapanos dans la partie occidentale du sanctuaire. Devant la stoa, on a mis au jour six bases de statues: quatre sont parallélépipédiques, une porte un cylindre mouluré à la

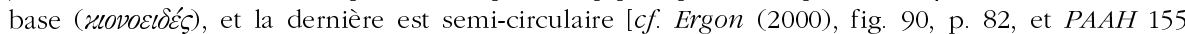
(2000) [2003], p. 147, fig. 2]. Lors de la campagne 2002 - cette zone n'est pas fouillée en 2001 -, on signale le long de la façade orientale six autres soubassements de bases de statues. La même année, la fouille de la stoa a découvert deux bases supplémentaires appartenant à la colonnade intérieure, a continué le dégagement du «stéréobate » qui portait la colonnade en façade, et a atteint la limite S-E du portique, où est conservé un escalier de six marches permettant l'accès à l'édifice [cf. Ergon (2002), fig. 39, p. 44]. Un emmarchement plus modeste est observé approximativement au milieu de la façade E. Au S du portique, une partie du péribole a été fouillée, ainsi que les fondations d'une tour qui signale peut-être un accès au sanctuaire. À l'O, un grand mur parallèle au tracé du péribole pourrait correspondre selon les A. à un gymnase. En 2003, on continue l'étude de la stoa $(79 \times 10,50 \mathrm{~m})$ : découverte de quatre nouvelles bases de colonnes appartenant au portique axial (4,3 $\mathrm{m}$ d'entrecolonnement), d'une inscription datée par la forme des lettres du v ${ }^{e}$ ou du Iv s. av. J.-C. [PAAH 50 (2003) [2004], p. 55, fig. 53], d'une tête de taureau - sans indication de la matière -, et de fragments de statues en bronze. Notons que ces fouilles illustrent une fois de plus la qualité des travaux de K. Karapanos (Dodone et ses ruines, Paris, 1878, pl. III, VI et VII, et p. 26-27, 125-128, en particulier pour les bases en façade du portique; cf. ChronARG [2002], 05.05).

Ch. Souli, A. Vlachopoulou et K. Gravani, PAAH 154 (1999) [2002], p. 147-154; 155 (2000)

[2003], p. 145-150; 156 (2001) [2004], p. 113-117. Ergon 48 (2001) [2002], p. 62-63; 49 (2002)

[2003], p. 43-45; 50 (2003) [2004], p. 52-56. 
- À partir de deux kylikes - traditionnellement identifiés comme des phiales - et d'un skyphos en bronze découverts à Dodone lors des fouilles de K. Karapanos, l'A. tente de mieux définir une série typologique de vases à boire, dont Corinthe est sans doute le centre de production, et s'interroge sur le contexte festif et religieux d'utilisation de cette vaisselle souvent gravée d'une inscription dédicatoire.

A. SIDERIS, «Bronze Drinking Vases Bearing Dedicatory Inscriptions », Eirene 38 (2002), p. $167-201$.

- Grâce aux textes de quelques lamelles oraculaires découvertes dans le sanctuaire de Dodone, l'A discute le sens de l'épiclèse Naios et commente le rôle de l'eau dans le sanctuaire épirote sur ce sujet $c f$. aussi Ch. Chandezon, L'élevage en Grèce (fin $V^{\prime}-$ fin $I^{e r}$ s. a.C.), Bordeaux, 2003 (Ausonius-Scripta Antiqua, 5), p. 104-105. Fondée sur les préoccupations commerciales ou coloniales de certaines questions posées aux dieux de Dodone, et sur une restitution favorable de l'environnement antique du sanctuaire, cette interprétation «aquatique » de Dodone, ancienne, permettrait de démontrer l'intérêt du sanctuaire pour les affaires maritimes.

A.M. Prestiani Giallombardo, "Dodona e la Sicilia : frammenti di un dialogo », in Múotos.

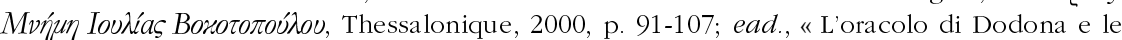
navigazioni adriatiche nei secoli VI-IV a.C. », in I Greci in Adriatico 1, Hesperia 15 (2002), p. 123-136.

05.06 - Passaron - N. Katsikoudis reprend l'étude d'un relief découvert dans le sanctuaire de Zeus Aréios près de la ville molosse de Passaron. Un aurige seulement vêtu d'une chlamyde conduit un char attelé à des félins. Une inscription mentionnant Zeus accompagne cette œuvre énigmatique. L'A. parcourt la bibliographie, et, au terme d'une réflexion iconographique et stylistique, estime que le relief est une consécration à Zeus, ce qui est très vraisemblable, et qu'il doit être situé dans le seconde moitié du IV s. av. J.-C.

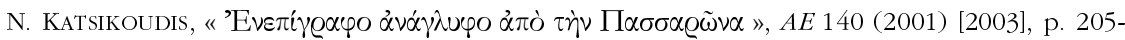
216.

05.07 - Phoinikè - Università degli studi di Bologna (Dipartimento di archeologia), Institut archéologique albanais (Département de l'Antiquité) - Depuis 2000, une mission dirigée par $\mathrm{S}$. De Maria et Sh. Gjongecaj a repris les recherches à Finik, et sur le territoire de l'antique capitale des Chaones. Ces travaux font l'objet de publications régulières depuis 2001, ouvrages dont la qualité et la rapidité d'édition sont remarquables.

- Découverte par L.M. Ugolini en 1926 (Albania antica II, L'acropoli di Fenice, Roma/Milano, 1932, p. 93-109), une petite chapelle, cosiddetta "thesauros»-l'archéologue italien n'attribuait pas une fonction précise à cet édifice qu'il datait au $\mathrm{IV}^{\circ} \mathrm{s}$. av. J.-C., mais insistait sur son caractère public: sa fonction religieuse ne lui paraissait pas certaine -, est sise sur un point haut de l'acropole de Phoinikè (area A22). Elle a fait l'objet d'une seconde fouille, et d'urgents travaux de restauration. Le monument est associé à l'E à un mur à gradins, et a connu plusieurs phases d'occupation, avant sa transformation en baptistère associé à une église à l'époque paléochrétienne. Les murs de l'édifice sont de très belle facture, et diffèrent des vestiges domestiques découverts à Phoinikè, en particulier par l'usage d'orthostates. Le plan sommaire levé par l'architecte de L.M. Ugolini est amélioré par M. Zaccaria, qui donne une très précise description des vestiges, à partir de la reconstitution de l'état de l'édifice à la fin des fouilles de L.M. Ugolini. La forme est incontestablement celle d'un naos, tel que l'archéologie épirote en connait tant, distyle in antis, vraisemblablement sans colonnade prostyle, et sans doute d'ordre dorique ( $c f$. une restitution graphique hypothétique). La construction de ce petit temple est datée à la charnière des $\mathrm{IV}^{e}$ et III ${ }^{e}$ s. av. J.-C. par S. De Maria. La divinité est inconnue.

S. De Maria (éd.), E. Giorgi et G. Lepore, Phoinike. La città e il suo territorio, Bologna, 2001 (Percorsi di archeologia 1), p. 20-21; S. DE MARIA, "Il Thesauròs: una revisione », in S. DE Maria et Sh. GJONGeCaj (éds), Phoinike I. Rapporto preliminare sulla campagna di scavi e ricerche 2000, Bologna/Firenze, 2002, p. 55-61; M. ZACCARIA, « Ricerche e restauri nel tempietto prostilo (thesauròs) », in S. DE MARIA, Sh. GJONGECAJ (éds), Phoinike II. Rapporto preliminare sulla campagna di scavi e ricerche 2001, Bologna, 2003, p. 63-72. 
- Sh. Gjongecaj et I. Pojani abordent l'iconographie religieuse, à partir de deux découvertes réalisées en 2000 et en 2001 : une statuette en bronze d'Hermès $(\mathrm{H}: 7 \mathrm{~cm})$, vraisemblablement datable au $\mathrm{I}^{\text {er }}$ s. av. J.-C., augmente le nombre de représentations de la divinité en Épire d'un bel exemplaire, sans doute une offrande; un fragment de statue, sans doute féminine, en marbre blanc (H conservée : $37,5 \mathrm{~cm}$ ), vêtue d'une nébris, d'un chiton, et d'un himation replié sur le bras gauche. Dotée d'une mortaise dans le dos, cette statue pourrait appartenir à un ensemble tympanal. L'A. propose de reconnaitre Artémis chasseresse, mais n'exclut pas Dionysos, grâce à une comparaison de la statue de Phoinikè avec une stèle à naïskos découverte à Dermenas, près d'Apollonia d'Illyrie (Musée archéologique d'Apollonia, $\mathrm{n}^{\circ}$ inv. 3465; cf. Albanien. Schätze aus dem Land der Skipetaren, Mainz am Rhein, 1988, n 328).

Sh. GJONGECAJ, « Ritrovamenti fortuiti da Phoinike », in Phoinike II, p. 109-114, en particulier "Un Hermes/Mercurio di bronzo », p. 111-112, et un appendice de N. Civici et F. STAMATI : «Mercurio o Hermes? Analisi e restauro »; I. PojanI, « Artemide o Dioniso ? », in Phoinike II, p. $115-117$.

- En 2001 et en 2002, la Mission italo-albanaise a effectué une première reconnaissance topographique du territoire de Phoinikè. Les vestiges de Metoqi, au S/O de Phoinikè en direction de Saranda, sont très comparables à ceux de Çuka et, à une autre échelle, à ceux de Malathre, c'est-à-dire des complexes composés d'une enceinte plus ou moins fortifiée qui abrite au centre un édifice en forme de tour. Ils ne correspondent donc pas à un sanctuaire composés de deux temples datés au IV ${ }^{e}$ s. av. J.-C., identification proposée par L.M. UgolinI, Albania Antica, I, Ricerce archeologiche, Roma/Milano, 1927, p. 150. Dh. BuDina avait repris les observations de L.M. Ugolini : son étude des vestiges en modifiait considérablement le plan et l'interprétation, ce que confirment parfaitement les travaux actuels d'E. Giorgi (Dh. BUDINA, « Harta arkeologiike e bregdetit Jon dhe e pellgut të Delvinës [Carte archéologique du littoral ionien et du bassin de Delvina] », Iliria I [1972], p. 292-293, fig. 9 et 10). En revanche, on signale un édifice antique vraisemblablement cultuel près de l'église Saint-Nicolas à Mesopotamon dans la plaine de la Bistrica.

S. De Maria (éd.), E. Giorgi et G. Lepore, Phoinike. La città e il suo territorio, p. 30-31; E. GIORGI, «Ricerche e ricognizioni nel territorio », in Phoinike I, p. 121-131; id., " Ricerche e ricognizioni nel territorio », in Phoinike II, p. 91-98.

05.08 - Boutbrôtos en Chaonie - Fouilles et travaux albano-britanniques (Butrint Foundation et Institut Archéologique albanais) - La fouille du théâtre de Butrint a été menée par L.M. Ugolini entre 1928 et 1932, avec des levés réalisés par l'architecte de la Mission italienne Carlo Ceschi en 1931 et 1932. Le manuscrit était pratiquement achevé en 1934, mais n’a pas été publié. Conservé au Museo della Civiltà Romana à Rome, cet ouvrage, le volume IV de la série Albania Antica, voit donc le jour, grâce à un accord entre la Fondation Butrint et le musée romain. L'ouvrage, fondé sur un considérable travail d'archive et de recherche bibliographique, n'est donc pas une publication du théâtre, mais l'édition du manuscrit de L.M. Ugolini, enrichi de commentaires et de contributions sur le monument, la Mission archéologique italienne et son directeur. Cette belle publication, destinée à faire le point sur l'édifice et son environnement immédiat, permet d'aborder quelques aspects importants de la topographie cultuelle grecque de Bouthrôtos, puisque le thêâtre fait partie du sanctuaire d'Asclépios.

L'ouvrage livre des informations sur la relation archéologique entre le koilon et le petit temple attribué à Asclépios, découvert et étudié par L.M. Ugolini (p. 80, \$ B2.1; $c f$. p. 117) : le petit naos $(6,55 \times 8.45 \mathrm{~m})$, doté au fond d'une anfractuosité naturelle [cf. p. 166-167, et G. PANI, «Arkitektura e dy tempujve në Butrint dhe puniment restauruese ne to ", Monumentet 1 (1988), p. 23-24] appelée «favissa»-, a été respecté lors de la construction du théâtre, de la parodos O - plus courte que la parodos $\mathrm{E}$ (fig. 6.1, p. 108, et 6.16, p. 120; pour la phase romaine, $c f$. fig. 6.50 , p. 149) -, où étaient gravés les actes d'affranchissement (P. CABANES, «Les inscriptions du théâtre de Bouthrôtos ", Actes du colloque 1972 sur l'esclavage, Besançon/Paris, 1974, p. 105-209). Les deux édifices ne sauraient en effet s'ignorer, puisqu'une inscription gravée sur la face antérieure du second rang de gradins indique que le théâtre a été construit grâce aux revenus du dieu [p. 89, §B17.5; cf. L. MORricone, « Le iscrizioni del teatro di Butrinto », PdP 41 (1986), p. 172-174] : 
'A italienne au sujet du petit temple attribué à Asclépios, un naos distyle in antis, sans doute dorique, dont la construction, datée au IV s. av. J.-C., est comparée à celle du Trésor des Athéniens à Delphes ( $c f$. fig. 6.74, p. 171). À l'intérieur, l'anfractuosité pourrait correspondre à un ancien écoulement d'eau sulfureuse. Un second temple est succinctement abordé, situé sur une terrasse au $\mathrm{N}$ qui domine le petit temple et le théâtre, près des remparts de l'acropole. Ajoutons que cet édifice est lui aussi découvert par L.M. UGouns pendant la fouille du théâtre (Butrinto. Il mito d'Enea. Gli scavi, Roma, 1937, p. 122-123; cf. fig. 71, p. 126). La krepis $(7,8 \times 11,7 \mathrm{~m})$ et les premières assises des murs sont bien conservées, et permettent de restituer une chapelle tétrastyle ionique comparée au naos de Zeus à Dodone. À l'époque romaine, le sol est couvert d'une mosaïque polychrome (pour les activités édilitaires romaines, $c f$. maintenant J. BERGEMAnn, Die römische Kolonie von Butrint und die Romanisierung Griechenlands, Munich, 1998, en particulier p. 47-66). Selon J. Wilkes, ce temple in summa cavea est « evidently dedicated to Aphrodite ». Or en 1999, en l'absence de matériel épigraphique et archéologique associé au monument - absence toujours d'actualité -, N. Ceka reconnaissait que la divinité logée dans ce temple était inconnue et proposait sans argument précis une attribution à Dionysos (Butrint. A Guide to the City and its Monuments, Butrint Foundation, London, 1999, p. 39; cf. ChronARG [2001], 05.12). Notons que les cultes d'Aphrodite et de Dionysos sont en effet attestés à Bouthrôtos, comme ceux d'Artémis, d'Hygie, de Zeus Cassios, et, peut-être, d'Athéna. Il est donc périlleux de choisir un candidat, d'autant plus que l'édifice oblong à deux chambres immédiatement à l'O de la chapelle attribuée à Asclépios - bien visible sur le plan de L'Institut archéologique albanais à la fig. 6.73, p. 170 -, non attribué, doit être pris en compte dans ces réflexions, et qu'un dieu important dont est attestée à Bouthrôtos la prêtrise, Zeus Sôter, n'est pas encore domicilié. Il est évident que cet ensemble forme une aire cultuelle importante, et que le théâtre vient compléter le dispositif topographique en le perturbant partiellement.

F. Sear confirme la relation chronologique entre le petit temple attribué à Asclépios et le thêâtre proposée par L.M. Ugolini (p. 182), et montre que cette association topographique ne manque pas de parallèles dans le monde grec (p. 191), en particulier dans les sanctuaires d'Asclépios (Épidaure, Balagrae en Cyrénaïque, Pergame, Messène, Nea Paphos à Chypre, Lissos en Crète, Smyrne; $c f$. p. 192). L'hypothèse d'un odéon couvert avait été formulée par R. MEINEL (Das Odeion. Untersuchungen an überdachten Antiken Theatergebäuden, Francfort, 1980), mais une série d'arguments de nature technique conduit F. SEAR à penser que le théâtre de Bouthrôtos n'était pas couvert (p. 192-194).

I. Pojani propose un catalogue commenté des sculptures découvertes par L.M. Ugolini lors de la fouille du théâtre. Nous signalons celles qui ont sans doute un rapport avec le culte : une tête masculine barbue datée de la basse époque hellénistique, peut-être celle d'Asclépios selon l'archéologue italien, qui n'exclut pas néanmoins Zeus ou Poséidon (Cat. n 4, p. 219-221; cf. le commentaire de l'A., p. 249); un fragment de pilier hermaïque appartenant à une statue, Hermès selon L.M. Ugolini (Cat. $n^{\circ} 14$, p. 240-241; cf. le commentaire d'I. Pojani, p. 251, qui reconstitue le lieu exact de provenance, et, en se fondant en particulier sur des exemples régionaux, rappelle à juste raison que le pilier " hermaïque » peut correspondre à la représentation d'autres dieux, dont Asclépios); un autel cylindrique daté de l'époque impériale (Cat. n 18, p. 243-244).

O.J. Gilkes (éd.), A.M. Liberati, L. Miraj, I. Pojani, F. Sear, J. Wilkes et B. Polci, The Theater at Butrint. Luigi Maria Ugolini's Excavations at Butrint 1928-1932 (Albania Antica IV), Britisch School at Athens, 2003 (Supplementary Volume $\mathrm{n}^{\circ} 35$ ).

- Dans le cadre d'une réflexion sur les offrandes en numéraire dans les sanctuaires de héros guérisseurs et les Asclepieia, un dispositif découvert par L.M. Ugolini dans la chapelle attribuée à Asclépios est interprété à juste titre par les A. comme un thesauros (p. 262-263). Il s'agit de deux blocs superposés creusés de deux cavités symétriques et communicantes; le bloc supérieur est doté d'une fente destinée à introduire des monnaies [L.M. Ugolini, L'acropoli di Butrinto, Rome, 1942, p. 96-97, pl. 88, fig. 2 : «ara di Filisto», en raison de l'inscription gravée sur l'un des deux blocs = 'E $i$ i i̊géoç $\Phi(\lambda i \sigma \tau O U)$. Signalons que ce thesauros n'est en effet pas pris en compte dans la synthèse de G. KAMINSKI, "THESAUROS. Untersuchungen zum antiken Opferstock », JdI 106 (1991), p. 63-181], dont la typologie montre néanmoins que le dispositif de Bouthrôtos a de 
nombreux parallèles, et que sa présence dans un édifice naomorphe ne fait pas nécessairement de ce dernier un trésor ou un temple-trésor ( $c f$. «Im Tempel bzw. Kultraum », p. 118-120).

M.E. GorRini et M. Melfi, "Archéologie des cultes guérisseurs : quelques observations », Kernos 15 (2002), p. 247-265.

\section{Illyrie méridionale}

05.09 - Apollonia - Mission épigraphique et archéologique française en Albanie, Institut archéologique albanais - Grâce aux travaux de la campagne 2001, il est maintenant assuré que l'« édifice à mosaïque » ne peut correspondre à l'atrium d'une domus à péristyle, car la cour centrale n'est pas hypèthre - absence d'un dispositif d'évacuation des eaux. Il pourrait s'agir d'un édifice cultuel (cf. ChronARG [2003], 05.09). La façade monumentale oriente le monument vers l'E, en direction de la grande rue qui mène aux deux points hauts de la ville. L'hypothèse d'un pompeion d'où partiraient des processions sacrées n'est pas exclue. À l'E de la fouille, les constructions complexes situées au $\mathrm{S}$ du mur 12, qui marque la limite méridionale de la grande rue, doivent peut-être être interprétées comme le podium d'un temple, qui pourrait avoir été transformé en basilique paléochrétienne. L'éboulis découvert dans la rue, en contrebas de ce dispositif, contenait en effet de très nombreux fragments architecturaux signalés dans les précédentes chroniques.

P. Cabanes, J.-L. Lamboley, B. VReKaj et alii, « Apollonia d'Illyrie (Albanie) », BCH 126 (2002) [2003], p. 646-658; J.-L. LAMBOLEY, « La nuova documentazione archeologica di IV secolo ad Apollonia ", in La Sicilia dei due Dionisî (Atti della settimana di studio, Agrigento 24-28 febbraio 1999), Roma, 2002, p. 217-221 (p. 220); id., " Les fouilles franco-albanaises d'Apollonia : résultats récents et perspectives », in M. BuORA et S. SANTORO (éds), Progetto Dürres. L'indagine sui beni culturali albanesi dell'Antichità e del Medioevo: tradizioni di studio a confronto (Parme-Udine, 19-20 aprile 2002), Trieste, 2003 (Antichità altoadriatiche, 53), p. 323-351.

- Description et analyse de 18 stèles funéraires apolloniates antérieures à l'époque impériale; $c f$. notamment deux couronnements de stèles : une Nikè sacrifiant ( $n^{\circ} 17$, p. 227-228) et une probable représentation d'Aphrodite ( $n^{\circ} 18$, p. 228-229).

I. Pojani-Dhamo, « Relieve të stelave funerare apoloniate të periudhës klasike dhe helenistike », Iliria (1997) [1999], 1-2, p. 205-241.

\section{îles ioniennes}

05.10 - Corcyre - VIII Éphorie des antiquités prébistoriques et classiques - À Palaiopolis, K. Preka signale la découverte de fragments de figurines d'époque archaïque, associées à un «trésor» de monnaies d'argent (rue Nafsikas).

- Selon K. Kanta-Kitsou, le kouros et le «bétyle » de Kanoni (terrain Pouriki, cf. ChronARG [2001], 05.16), sont vraisemblablement associés à un sanctuaire d'Apollon Agyieus.

K. Preka, AD 52 (1997) [2003], Chr. B'2, p. 606; J. Whitley, AR 2002-2003 (2003), p. 59;

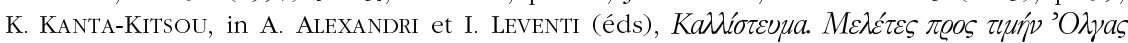

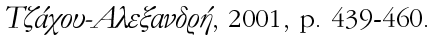

05.11 - Leucade - I. Andréou publie une étude archéologique et historique du centre urbain de l'ancienne Leucade, en insistant sur les aspects urbanistiques et édilitaires, et ainsi complète parfaitement l'étude de S.P. MORRIS, «The Towers of Ancient Leukas: Results of a Topographic Survey, 1991-1992», Hesperia 70-73 (2001), p. 285-347, les réflexions de M. FIEDLER, AJA 105 (2001), p. 278, et les informations fournies par G. Pliakou et V. KARATZENi, AD 52 (1997) [2003], Chr. B'2, p. 595-598. Dans ce cadre, l'A. propose une synthèse sur les sanctuaires urbains (p. 178181). Après avoir rappelé la découverte de figurines en terre cuite dans les maisons, I. Andréou retient que trois grands sanctuaires sont connus par les sources, ceux d'Apollon, d'Aphrodite Aineias, et d'Héra; par ailleurs, l'épigraphie et l'iconographie monétaire font aussi connaître les cultes d'Athéna, d'Artémis, d'Hermès, d'Achélôos et d'Héraclès. Aucun de ces sanctuaires n'est 
actuellement situé de manière satisfaisante. L'A, qui compare la forme du terrain et l'organisation spatiale des sanctuaires de Leucade à celles d'Apollonia d'Illyrie, propose de situer le sanctuaire d'Apollon sur le promontoire nord-occidental de la ville. Aphrodite Aineias, sans doute honorée en dehors de la ville, avait très vraisemblablement un lieu de culte urbain, où son épiclèse était sans doute différente. Le sanctuaire d'Héra, côtier ( $c f$. Tite-Live, XXXIII, 17), doit vraisemblablement être situé près d'un port, au $\mathrm{N}$ ou au $\mathrm{S}$, selon une situation topographique comparée à celle du sanctuaire de la déesse à Pérachôra. Le sanctuaire urbain d'Athéna, connue à Leucade par une dédicace archaïque provenant du S de l'île (LSAG, 1961, p. 227 et 229), ne peut encore être situé. Une inscription découverte dans une tombe pourrait, avec prudence et foi en la restitution proposée, suggérer l'existence d'un culte de Thétis. Le culte d'Achélôos, attesté par les monnaies de Leucade, pourrait être situé auprès de deux sources jaillissant respectivement au $\mathrm{N}$ et au $\mathrm{S}$ de la ville (Megali Vrisi et Spasmeni Vrisi), où ont été découvertes de nombreuses figurines féminines en terre cuite, comparées au matériel votif découvert dans le sanctuaire du dieu-fleuve à Messène. Enfin, le culte des Nymphes, non attesté en ville, est en revanche très présent dans la chôra, principalement dans des grottes ou de plus modestes anfractuosités : Agia Kiriaki à Nidri, Asvotripa à Phrini (cf. ChronARG [2001], 05.17), Choirotripa à Apolpaina, Charalavi Tripa à Platistoma, et Borliatsos à Kakalo (ces deux toponymes correspondent très vraisemblablement à Voliatso et Kavallo, où une grotte cultuelle a été explorée par l'Éphorie de paléoanthropologie et de spéléologie en 1994, cf. ChronARG [2002], 05.08, et J. WHiTLEy, AR 2003-2004 [2004], p. 41, pour la découverte de figurines votives en terre cuite : Pan, Héraclès, Hermès, Silènes et Satyres). L'activité cultuelle dans ces sanctuaires naturels remonte au vi s. av. J.-C. et doit être attribuée aux colons corinthiens.

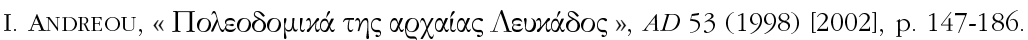

05.12 - Ithaque - VI Éphorie des antiquités prébistoriques et classiques, King's College (London) - Dans le cadre de la prospection dirigée par C. Morgan et A. Sotériou, une étude paléotopographique de la grotte de Polis et de ses environs a été menée. Elle met en cause l'existence même d'une «cave-like structure » pendant l'Antiquité, en montrant que l'effondrement du plafond est plus ancien. Les recherches de la campagne 2003 confirment cette conclusion, mais apportent une nuance : un abri ouvert et étroit existait vraisemblablement.

J. WhitLey, AR 2002-2003 (2003), p. 42-44; AR 2003-2004 (2004), p. 38-39.

- Découvert à Magnésie du Méandre, l'unique décret connu de l'État d'Ithaque mentionne à la fin du III $^{\mathrm{e}}$ s. av. J.-C. les deux sanctuaires où des copies du textes devaient être exposées sous la responsabilité d'un même magistrat, l'epidamiorgos : l'Odysseion et le hieron d'Athéna (O. KERN, Die Inschriften von Magnesia am Meander, Berlin, 1903, 27, $\mathrm{n}^{\circ}$ 36, 1. 29-30). J.M. FossEY tente de localiser ces deux sanctuaires et rappelle à cette occasion la découverte dans le secteur de Polis d'une inscription très restituée mentionnant une offrande - disparue dans une lacune au début du texte -, peut-être faite par des peripoloi, et, au génitif, Athéna Polias et Héra Téléia (LSAG, p. 213, $\mathrm{n}^{\circ} 3$, et M.L. LAZZARINI, Le formule delle dediche votive nella Grecia arcaica, Rome, 1976, $\mathrm{n}^{\circ} 945$ ). Il propose donc de situer l'Odysseion dans le centre urbain, et le sanctuaire d'Athéna près de la grotte de Polis, qui, d'après le matériel, serait plus particulièrement consacrée aux Nymphes (pour un culte d'Ulysse bien antérieur à l'époque hellénistique, $c f$. I. MALKIn, The Returns of Odysseus. Colonization and Ethnicity, Berkeley et al., 1998, p. 94-119; id., "Ithaka, Odysseus and the Euboeans in the eighth century ", in M. BATs, B. D'AGostino (éds), Euboica. L'Eubea e la presenza euboica in Calcidica e in Occidente, Naples, 1998 [CJB, 16 / AION(ArchStAnt), 12], p. 110). Notons que cette localisation des deux lieux de culte s'accorde parfaitement avec les conclusions, non exploitées par J.M. Fossey, de S. SyMEONOGLOU (PAAH 1995 [1998], p. 211-215, pl. 92-93; cf. ChronARG [2002], 05.09), qui pense avoir découvert l'Odysseion lors de ses fouilles à Alalkomenai. La prospection menée par C. Morgan et A. Sotériou apportera sûrement des informations utiles à la localisation de l'Athénaion (cf. J. WHITLEY, AR 2002-2003 [2003], p. 42-44). L'A. s'interroge aussi sur le caractère exceptionnel de la double exposition, l'expliquant par la nécessité de déposer le texte dans le lieu de culte le plus important pour l'identité insulaire des habitants d'Ithaque, l'Odysseion - son prêtre fait partie des magistrats éponymes, ce qui témoigne de l'importance du culte du héros -, mais aussi dans un sanctuaire d'une divinité dont la diffusion 
est panhellénique («the need for a divine participation in the act of recognition »). À la manière du poème odysséen, les monnaies d'Ithaque associent en effet étroitement Ulysse et Athéna au faîte du panthéon insulaire [ $c f$. aussi L. RADIF, « Una fantageografia realistica: la 'grotta delle Ninfe' omerica », Maia 54 (2002), p. 27-32].

J.M. FossEy, «Ithaka and Magnesia-on-the-Maiandros », AncW 32-2 (2001), p. 171-181.

05.13 - Céphalonie - VI Éphorie des antiquités prébistoriques et classiques et Éphorie de paléoanthropologie et de spéléologie - L'étude de la grotte de Drakaina à Poros (cf. ChronARG [2002], 05.10) a montré que du Néolithique au Bronze Ancien l'abri est un habitat; du XV ${ }^{e} s$ au VII s. av. J.-C., la grotte est semble-t-il abandonnée, et devient au vi s. un lieu de culte consacré à Pan et aux Nymphes, dont l'activité cesse avec la conquête romaine en 188 av. J.-C. Sur ce sanctuaire, $c f$. surtout E.M. Chatziotou, G. STRATOuli et E. KOTZAMPOPOUlOu, «H $\Sigma \pi \eta \lambda \iota \dot{\alpha} \tau \eta \varsigma$

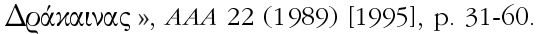

J. WhitLEY, AR 2003-2004 (2004), p. 38.

\section{[06. Phthiotide, Thessalie]}

\section{Macédoine (Emmanuel VOuTIRAs et Kalliopi CHATZINIKOLAOU)}

\subsection{0 - Généralités}

- Présentation du projet «la religion romaine en Macédoine ». En novembre 2000 la Deutsche Forschungsgemeinschaft (DFG) a approuvé un projet de recherche intitulé «La religion romaine dans l'Empire et dans ses provinces », dont le but est d'étudier le phénomène de la diffusion et de l'assimilation de la religion romaine dans les provinces de l'Empire. La section concernant la province de Macédoine a été confiée à une équipe de chercheurs de l'Université d'Erfurt et comprend deux parties : a) la Macédoine avec une mention spécale pour lî̀le de Samothrace et b) Thessalonique. Par une étude combinée des textes, des inscriptions, des monnaies et des données archéologiques les collaborateurs du projet se proposent d'atteindre les objectifs suivants : 1. Étudier l'histoire religieuse de la région en fonction des relations entre centre et périphérie, c'est-à-dire entre capitale et province, afin de déterminer l'acceptation ou le rejet éventuel de nouvelles idées ainsi que les influences mutuelles. 2. Développer une théorie sur le processus de formation et les moyens de transmission des faits religieux. 3. Comprendre la Macédoine en tant qu'unité politique et culturelle par rapport aux régions avoisinantes, en faisant ressortir son caractère de zone de transition.

La Macédoine se prête à ce genre d'étude, car elle a connu un essor presque ininterrompu (sauf dans les deux premiers tiers du $\mathrm{I}^{\mathrm{er}}$ s. av. J.-C.) grâce à la construction de la via Egnatia, important axe routier qui assurait la liaison entre la partie occidentale et la partie orientale de l'Empire romain. La présence de soldats, de vétérans et de trafiquants romains a contribué à un brassage des cultes et des idées religieuses. Bien sûr, cette évolution s'est produite de manière différente dans les centres urbains, plus ouverts aux influences extérieures, et dans les campagnes. Les pratiques cultuelles peuvent également varier en fonction du statut social des fidèles. La langue et l'éducation sont aussi des facteurs importants dans la propagation des cultes. Les périodes étudiées en particulier sont : 1 . Des premiers contacts entre la Macédoine et Rome jusqu'à la création de la province (221 à 148 [ou plutôt 146] av. J.-C.). 2. La période qui va des guerres civiles romaines et de la création de colonies en Macédoine à la venue de l'apôtre Paul ( 42 av. J.C. à 50 ap. J.-C.). 3. L'époque des Sévères. 4. L'époque de la Tétrarchie, quand Thessalonique devient pendant quelque temps siège impérial.

Samothrace, bien qu'appartenant à la Thrace sous les Romains comme auparavant, est examinée dans le contexte de cette étude parce que son sort était étroitement lié à celui de la Macédoine. En effet, plusieurs Macédoniens, y compris des souverains, s'étaient fait initier aux fameux mystères pratiqués dans le grand sanctuaire de lî̀le. Ces mystères étaient associés au culte dominant, celui des Grands Dieux (Megaloi Theoi) ou Kabires, mentionnés par plusieurs auteurs 
anciens. Il faut pourtant noter que le nom de «Kabires » n'apparaît jamais dans les documents provenant de lî̀le elle-même : les Dieux de Samothrace ne sont appelés ainsi qu'en dehors de leur sanctuaire, par exemple à Philippes ou à Thessalonique. Nous possédons très peu de renseignements sur le culte et les mystères ( $c$ f. infra, 09.03). Au début, les Dieux de Samothrace ne semblent pas avoir beaucoup intéressé les Romains. Cependant Varron a essayé de les associer aux Pénates, amenés, selon la tradition, en Italie par Énée après la chute de Troie. Vers la fin de la période républicaine, certains dignitaires romains se font initier aux mystères des Dieux de Samothrace. À partir du I ${ }^{\text {er }}$ s. ap. J.-C. le nombre des initiés romains augmente sensiblement d'après le témoignage des inscriptions. Toutefois, il ne semble pas que des Romains se soient installés dans l'île. On ne constate aucune influence romaine sur le culte des Grands Dieux.

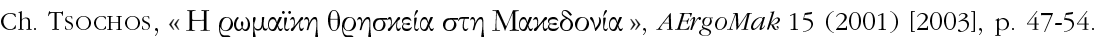

- Dans le cadre d'un volume dédié aux cultes dans les zones "périphériques» du monde hellénique, l'A. revient sur un sujet qu'il avait déjà étudié (M.B. Hatzopoulos, Cultes et rites de passage en Macédoine, Athènes 1994 [Meletemata, 19]). Contrairement à ce qu'on a pu croire dans le passé, la religion des anciens Macédoniens était fondée sur un panthéon entièrement hellénique; Zeus, Héraclès et Asclépios y occupaient une place importante. Les recherches archéologiques ont révélé en outre l'existence du culte d'une importante divinité féminine (la Mère des Dieux), à laquelle on pourrait associer un "parèdre » masculin qu'il est tentant d'identifier avec Dionysos. Ce culte paraît avoir comporté des rites à caractère intiatique et plus spécialement des rites de passage à l'âge adulte pour des jeunes filles et des garçons. Un ensemble d'inscriptions et de sculptures provenant d'un sanctuaire situé dans le territoire de Létè offre la possibilité d'étudier certaines pratiques cultuelles concernant les jeunes filles. L'A. évoque des parallèles surtout thessaliens. D’autre part, l'épigraphie de Beroia a révélé la présence (du mois à l'époque impériale) du culte de Dionysos Pseudanôr, déjà connu par des témoignages littéraires, associé à des travestissements rituels et à la pratique de la krypteia. Ce dieu présidait probablement à des rites de passage à l'âge adulte. Un autre aspect de Dionysos, associé cette fois à Perséphone, serait le rôle important qu'il aurait joué lors du passage des morts dans l'audelà. L'A. examine les croyances des anciens Macédoniens sur le sort des âmes dans le règne d'Hadès et insiste sur l'importance des croyances et des rites bacchiques et orphiques, que nous révèlent en partie quelques inscriptions funéraires et les lamelles orphiques.

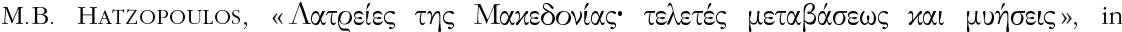

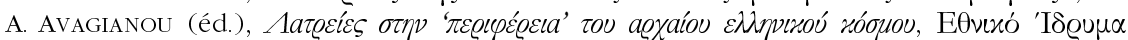

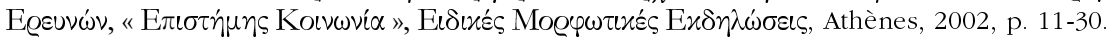

- L'A. publie une monnaie en bronze appartenant à un petit trésor de sept monnaies dont six sont des émissions de cités macédoniennes (3 de Pella, 1 d'Amphipolis, 2 de Thessalonique). Ce trésor, trouvé au sud de Serrès dans un pot en terre, est passé dans une collection privée en Allemagne. Les six monnaies macédoniennes sont des émissions des années 187-168 av. J.-C. et elles sont assez usées, ce qui indique qu'elles sont restées longtemps en circulation. Le trésor a dû être caché après la défaite de Persée à Pydna. La septième monnaie est une pièce unique; elle porte la tête de Zeus couronné de laurier, un foudre et l'inscription $\Delta \mathrm{IO} \Sigma$ E $\Lambda$ EY $\Theta E P I O Y$. Il n'y a ni indication de l'autorité d'émission ni de monogramme. L'A. attribue cette monnaie à la Macédoine à cause de l'alliage et de l'étalon, et considère Pella comme le lieu d'émission le plus probable. Quand au type monétaire, il peut être daté au $2^{e}$ quart du $\mathrm{II}^{\mathrm{e}} \mathrm{s}$. av. J.-C., ce qui en fait le plus ancien témoignage du culte de Zeus Eleuthérios en Macédoine. Une recherche sur cette épiclèse de Zeus montre qu'elle apparaît souvent en association avec le culte de Dea Roma et des empereurs romains, notamment dans des inscriptions d'époque impériale provenant de Macédoine et de Thrace (Thessalonique, Kalindoia, Abdères, Maronée, Ainos). Après une discussion détaillée des diverses opinions qui ont été exprimées au sujet de l'introduction du culte de Zeus Eleutherios en Macédoine, l'A. parvient à la conclusion qu'elle doit être placée après la bataille de Pydna. Ce culte, qui allait de pair avec celui de Dea Roma, servait sans doute la propagande romaine. 
K. LIAMPI, «Die Einführung des Kultes des Zeus Eleutherios in Makedonien. Die numismatischen Zeugnisse aus dem Hortfund von Serres », MDAI(A) 117 (2002) [2003], p. 203-220, pl. 40 .

07.01 - Kastoria - site de Psalida ou Vigla - XVII Éphorie des antiquités prébistoriques et classiques - Un sanctuaire datant des périodes hellénistique et romaine a été localisé et fouillé en partie sur le sommet appelé Psalida dans la préfecture de Kastoria. Des fragments de reliefs votifs, aussi bien en marbre qu'en calcaire, à Zeus Hypsistos, à Héra et à Hermès y ont été découverts. (cf. ChronARG [2001], 07.02 p. 260).

Ch. Tsougaris, ADelt 52 (1997) [2003], Chron. B2, p. 744, 750.

07.02 - Polyneri, site de Kastri (préfecture de Grevena) - Université Aristote de Thessalonique La poursuite de la fouille sur le site de Kastri près de Polynéri, où l'acropole et un sanctuaire d'une ville inconnue ont été découverts (ChronARG [2004], 07.02), a dégagé une plus grande partie du temple dorique déjà connu, ce qui a permis d'en calculer les dimensions avec exactitude $(18,80 \mathrm{~m} \times 11,40 \mathrm{~m})$ et de préciser un certain nombre de traits structurels et morphologiques. À l'angle NE, il existe une construction en forme de tour directement liée au temple. On a aussi poursuivi le dégagement du portique dorique monumental dans la partie $\mathrm{S}$ de la terrasse du sanctuaire. Des tronçons de l'enceinte fortifiée de la ville ont été repérés en bordure de cette terrasse. Les trouvailles comprennent, outre de nombreux membres architecturaux, un grand nombre d'objets variés (vases, bijoux, monnaies). La date de construction du sanctuaire à la fin du IV ${ }^{e}$ s. av. J.-C. a pu être confirmée, de même que sa destruction vers le milieu du II ${ }^{e}$ s. av. J.-C. Les A. proposent, comme hypothèse de travail, l'identification du site avec la cité antique d'Aiginion en Tymphée.

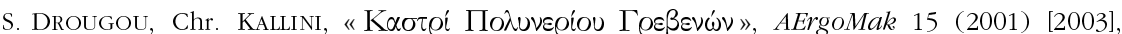
p. $587-592$.

07.03 - Kozani - XVII Éphorie des antiquités prébistoriques et classiques - Mention d'une stèle votive inscrite à Zeus Hypsistos (II - III $^{\mathrm{e}}$ s. ap. J.-C.) provenant des environs de Agios Dimitrios

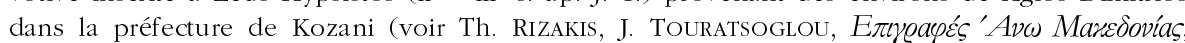
Athènes, 1985 , p. 37, n 22 )

Ch. ZIOTA, ADelt 52 ( 1997 ) [ 2003 ], Chron. B2, p. 749 et n. 111.

07.04 - Eordée, site de Agia Paraskevi (municipalité de Agia Paraskevi) (préfecture de Kozani) - XVII Éphorie des antiquités prébistoriques et classiques - L'A. énumère les découvertes archéologiques faites dans la passé dans la région de la municipalié de Agia Paraskevi, dont certaines ont un intérêt religieux :

- Lieu-dit Ekklissaki près de Spilia : clé en fer de type laconien et partie basse d'un relief votif avec la figure d'un aigle, associé sans doute au culte de Zeus Hypsistos.

- Lieu-dit Kioupi près de Karyochori : sanctuaire d'Artémis d'époque romaine identifié déjà en 1922. D'ici proviennent des membres architecturaux (une colonne, des parpaings, des tuiles de toiture) ainsi qu'une stèle votive inscrite à Artémis Lochia avec des oreilles en relief. L'A. pense que la stèle votive à Artémis Agrotera (II ${ }^{e}$ - III ${ }^{\text {s }}$ s. ap. J.-C.) publiée comme provenant de Spilia (RIZAKIS - TOURATSOGLOU, supra $\mathbf{0 7 . 0 3}, n^{\circ} 101$ ) pourrait être associée à ce sanctuaire.

- Lieu-dit Zounolo près de Agios Christophoros : stèle votive inscrite à Zeus Hypsistos.

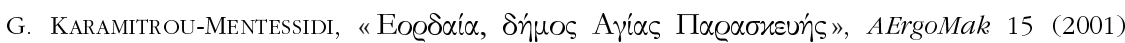
[2003], p. 620-624.

07.05 - Aiani (préfecture de Kozani ) - XI Éphorie des antiquités byzantines - Du matériel provenant d'un sanctuaire antique a été remployé lors de la construction de l'église du monastère de Saint Athanase à Aiané (voir K. E. Siampanopoulos, Atavŕ, Thessalonique, 1974, p.122-127). Il est probable que le monastère fut construit sur le site même du sanctuaire en question.

A.TsilipaKOU, ADelt 52 (1997) [2003], Chron. B2, p. 789-790. 
07.06 - Menèis en Bottiée (préfecture de Pella) - XVII Éphorie des antiquités prébistoriques et classiques - Nouvelle présentation du sanctuaire funéraire des mystes de Dionysos à Menèis en Bottiée (ChronARG [2004], 07.05).

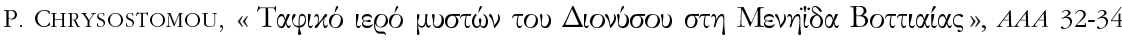

(1999-2001) [2003], p. 195-220.

07.07 - Beroia - XVIT Éphorie des antiquités préhistoriques et classiques - Deux figurines en terre cuite proviennent d'une tombe à chambre d'époque hellénistique taillée dans le rocher tendre, découverte dans une ruelle latérale de la rue Stadiou dans la ville moderne de Beroia. L'une d'elles représente une femme vêtue d'un chiton ceint haut et portant une hydrie qui pourrait être liée au culte de Déméter et à la fête des Thesmophories (ChronARG [2004], 07.06); l'autre est une femme vêtue d'un peplos dont le drapé, de style archaïsant, rappelle les hekataia en marbre de l'époque hellénistique tardive.

V. Allamani, ADelt 52 (1997) [2003], Chron. B2, p. 730-731.

- Une base inscrite en marbre (Musée de Béroia, $\mathrm{n}^{\circ} \Lambda$ 919), datant du début du II s. av. J.-C., a été découverte sous le dallage d'une rue de la période romaine tardive au cours de travaux pour la pose d'un conduit d'eau potable. Ce document fournit des renseignements relatifs à la topographie de la ville de Beroia et mentionne le sanctuaire d'Asclépios.

$$
\text { E. STEFANI, ADelt } 52 \text { (1997) [2003], Chron. B2, p. } 729 .
$$

- Les travaux pour le percement d'une rue conduisant au cimetière moderne de Beroia ont mis au jour une stèle funéraire du III $^{e}$ s. ap. J.-C. à couronnement arché. Sur le champ principal sont représentées une femme assise et une Artémis vêtue d'un chiton court et avançant vers la droite. Dans le champ du couronnement, on voit deux figures de taille plus petite dont la première représente un petit Éros et la deuxième une Aphrodite. Il s'agit sans doute de représentations de défunts sous les traits de divinités, phénomène bien attesté en Macédoine à l'époque romaine.

V. Allamani, ADelt 52 (1997) [2003], Chron. B 2, p. 746.

07.08 - Leukopetra, site de Kallipetra (préfecture d'Imathia) - XVII Éphorie des antiquités prébistoriques et classiques - Les travaux pour la construction de la nouvelle autoroute "via Egnatia » au lieu-dit Kallipetra, à $700 \mathrm{~m}$ au SO du sanctuaire de la "Mère des Dieux Autochthone» de Leukopetra, ont conduit à la découverte et à la fouille partielle d'un complexe d'habitations de l'époque hellénistique. Deux espaces de ce complexe (pièces 2 et 3) abritaient probablement des sanctuaires domestiques. La découverte dans l'angle NO de la pièce 2 de deux thymiateria (brûle-parfums) ainsi que de figurines en terre cuite d'Éros et d'Aphrodite font penser qu'on y adorait Aphrodite. Par ailleurs, la pièce 3, destinée sans doute en premier lieu aux activités domestiques puisqu'elle contenait une construction en pierre interprétée comme un moulin, des jarres et de nombreux vases, fonctionnait probablement elle aussi, du moins en partie, comme lieu de culte. En effet, on y a trouvé, près du mur $\mathrm{N}$, deux figurines en terre cuite représentant des femmes drapées, une protomé de Pan (faussement identifié comme satyre) portant la syrinx à ses lèvres, un thymiaterion et un petit autel. Ces objets étaient apparemment posés sur un gradin en terre, car ils ont été trouvés dans une masse de terre glaise. Il faut également noter la présence d'une construction isolée dans la nécropole de l'agglomération hellénistique. Il s'agit d'une petite salle rectangulaire, ouverte d'un long côté, qui contenait une quantité de vases en terre cuite et des objets en métal. L'A. pense que ce bâtiment, qu'elle date du $2^{\mathrm{e}}$ quart du $\mathrm{III}^{\mathrm{e}}$ s. av. J.-C., pourrait avoir eu une fonction cultuelle.

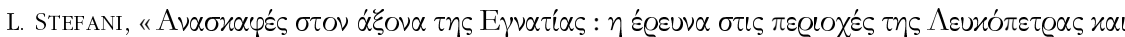

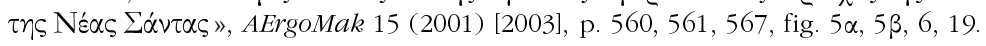

07.09 - Vergina-Aigai - Université Aristote de Thessalonique - L'A. résume les résultats des recherches menées dans la ville antique d'Aigai pendant la dernière décennie. Référence est faite entre autre au sanctuaire d'Eukleia, situé dans l'axe du palais et du théâtre, et dont la construction remonte au $\mathrm{IV}^{e} \mathrm{~s}$. av. J.-C. Le caractère politique de ce culte est relevé et comparé à celui d'Héraclès dans le palais (sans doute très important pour la monarchie macédonienne) et de Zeus sur l'agora. Le sanctuaire hellénistique de la Mère des Dieux est également mentionné. 
S. Drougou, «Begyíva 2001 - Minimalia », AErgoMak 15 (2001) [2003], p. 549-557.

07.10 - Pella, ville antique - XVII Éphorie des antiquités prébistoriques et classiques - Mention du sanctuaire du héros guérisseur Darron récemment fouillé, qui contenait entre autres une baignoire en terre cuite (p. 714; ChronARG [2004], 07.07). Les excroissances en maçonnerie au bas des murs intérieurs d'une cour à ciel ouvert dans le sanctuaire étaient probablement des supports de banquettes (p. 715).

M. LilimpaKi-AKamati, ADelt 52 (1997) [2003], Chron. B2, p. 714 et n. 9, 715 et n. 19.

07.11 - Pella, palais - Une base quadrangulaire en calcaire ayant probablement porté une offrande a été découverte dans la partie sud de la cour du complexe identifié comme la palestre du palais. Parmi les trouvailles provenant des puits de la palestre se trouve un autre fragment de base qui pourrait aussi avoir porté une offrande.

P. Chrysostomou, ADelt 52 (1997) [2003], Chron. B2, p. 718, 719

- Mention des exedres et des bases découvertes dans les cours des bâtiments I, II et V (identifié par l'A. comme palestre) au cours des récentes campagnes de fouilles. Il est permis de supposer qu'au moins certaines de ces bases portaient des statues en bronze de dieux et de héros liés à la famille royale de Macédoine (cf. P. Chrysostomou, « Luveı

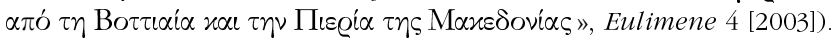

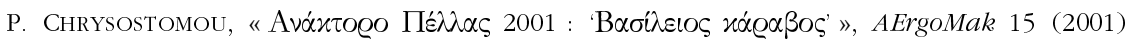
[2003], p. 442, 444.

07.12 - Archontiko (préfecture de Pella) - XVII Éphorie des antiquités prébistoriques et classiques - Mention d'une figurine en terre cuite représentant Dionysos au banquet trouvée dans une tombe archaïque de la nécropole $\mathrm{O}$ d'Archontiko.

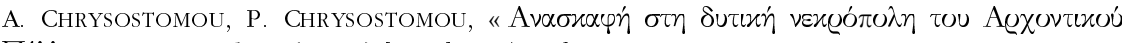

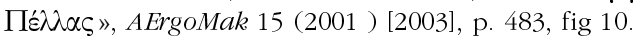

07.13 - Dion - XVI Éphorie des antiquités préhistoriques et classiques - Brève présentation de l'histoire de la recherche et mention des principaux témoignages mythologiques et historiques concernant le sanctuaire de Zeus à Dion de Piérie.

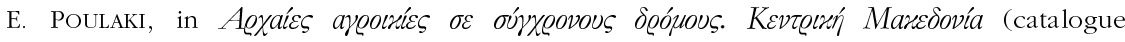
d'exposition), Athènes, 2003, p. 32.

- Université Aristote de Thessalonique - Au cours des campagnes de fouilles de 1998-2001 dans le sanctuaire de Déméter un portique d'époque hellénistique a été dégagé au sud des édifices cultuels. Le portique est ouvert vers le $\mathrm{N}$ et son mur de fond est conservé sur une longueur de $30 \mathrm{~m}$; ses extrémités n'ont pas été repérées. En façade, des poteaux de bois en série posés sur des bases quadrangulaires en pierre, dont six sont conservées, supportaient la toiture. L'aspect du portique a été modifié lors d'une réfection survenue probablement peu de temps après sa construction : la façade a été fermée par un mur entrecoupé d'ouvertures et l'intérieur a été divisé en chambres. Ce réaménagement témoigne sans doute d'un changement d'usage de l'édifice. À l'époque romaine, le portique fut détruit et sa partie $\mathrm{E}$ fut occupée par un four de pottier.

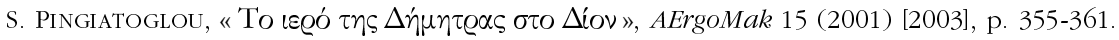

- Des travaux effectués pour dévier les eaux qui innondent régulièrement une partie du site archéologique de Dion en Piérie ont mis au jour un sanctuaire de Zeus Hypsistos en très bon état de conservation avec des trouvailles datant principalement de l'époque impériale. Le sanctuaire est situé à côté de celui d'Isis. La statue de culte (malheureusement acéphale) du dieu assis sur son trône a été trouvée au fond de la cella. On a aussi découvert l'autel du sanctuaire ainsi que 14 aigles votifs et des inscriptions grecques et latines.

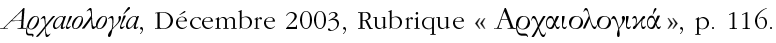

07.14 - Mont Olympe - XVI Éphorie des antiquités prébistoriques et classiques - (a) Bref aperçu des principaux témoignages littéraires relatifs au culte de Zeus sur le Mont Olympe, mention du sanctuaire du dieu sur le sommet de Agios Antonios et réference à une statuette en argent 
provenant de Kallipeuké dans le Bas Olympe à l'Ashmolean Museum d'Oxford. (b) Référence à Orphée et à ses liens avec la région de Leibethra rapportés par la tradition écrite : sa naissance dans une grotte de la région; son rôle dans la création des mystères dionysiaques; sa mise à mort violente par les femmes de la Piérie. La tombe d'Orphée à Leibethra aurait été à l'origine un berôon, graduellement transformé en sanctuaire contenant son xoanon.

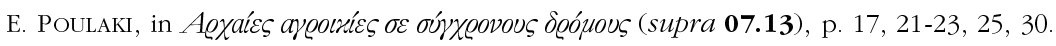

- Municipalité de l'Olympe oriental. Sur la hauteur appelée Pappous, près d'un site encore inexploré au lieu-dit Paliokastro, entre Leibethra et Platamôn, a été localisée depuis quelque temps une grotte, aujourd'hui fermée; selon certains reneignements, on y aurait trouvé «des tessons de vases offerts à Poseidon ».

E. Poulaki-Pantermali, ADelt 52 (1997) [2003], Chron. B2, p.661.

07.15 - Mont Olympe, site de Krania (Heraklion) - XVI Éphorie des antiquités prébistoriques et classiques - Une statuette en bronze d'Artémis a été découverte sur le site de Krania, qui a été indentifié avec l'ancien Hérakleion, dans une couche de destruction d'époque hellénistique parmi plusieurs autres trouvailles, principalement des figurines en terre cuite représentant des femmes et des animaux.

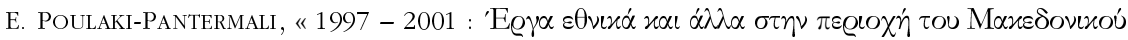

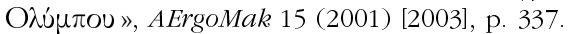

07.16 - Thessalonique - Aperçu des cultes religieux attestés à Thessalonique et dans sa région depuis la fondation de la cité par Cassandre. L'A. tient compte de la présence de cultes similaires ou apparentés ailleurs en Macédoine, ce qui rend son exposé particulièrement détaillé et intéressant. Les premières données archéologiques relatives à des cultes divins et hérö̈ques à Thessalonique remontent à la fin $\mathrm{du}_{\mathrm{IV}}^{\mathrm{e}} \mathrm{s}$. av. J.-C. et concernent les divinités grecques traditionnelles. À partir du $\mathrm{III}^{\mathrm{e}}$ s. av. J.-C., on observe l'introduction de cultes orientaux (surtout égyptiens), due sans doute à l'importance de la cité comme centre commercial. La conquête romaine a pour conséquence l'introduction de nouveaux cultes, en particulier celui de la Dea Roma et plus tard de divinités populaires parmi les troupes romaines, comme Mithra et Epona. Certaines divinités importantes apparaissent sur le monnayage de la cité. Dans la partie O de la ville, on a proposé d'identifier une "aire sacrée », où étaient situés les pricipaux sanctuaires, notamment le «Sarapieion » et un temple ionien reconstruit en ce lieu avec des membres apportés d'ailleurs. Il faut noter le grand nombre de sculptures votives découvertes dans la ville et dans sa région. Les cultes examinés sont les suivants : I. Cultes de divinités : Athéna, Artémis, Aphrodite, Déméter, Zeus et Theos Hypsistos, Hermès, Poseidon, Dionysos. II. Cultes hérö̈ques : Le héros cavalier vénéré sous les noms Héros ou Hérôn [mais il faut noter qu'il est parfois appelé theos], Héros Aulônitès, Énée (à Aineia et à Thessalonique), Héros Hippalkmos, Asclépios, Héraclès. III. Cultes de personnifications divinisées : Némésis et Tychè. L'A. traite aussi du culte de Kabeiros, divinité tutélaire de la cité à l'époque impériale, et du culte des Korybantes, associés de la Grande Mère, attesté au IV ${ }^{e}$ s. av. J.-C., avant la fondation de Thessalonique. IV. Cultes orientaux : Isis, Sarapis et les autres dieux d'origine égyptienne, Cybèle, Mithra. V. Cultes d'origine occidentale : Epona (déesse d'origine celtique attestée à l'époque de Galère).

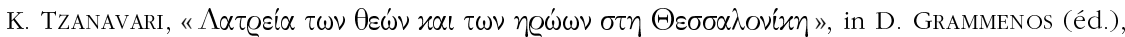

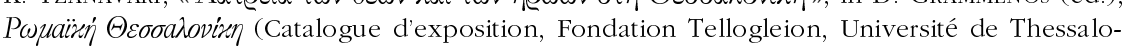
nique, Juin 2003 - Janvier 2004. Éditions du Musée Archéologique de Thessalonique, 1), Thessalonique, 2003, p. 177- 262.

- Aperçu du culte des empereurs romains et de celui de la Dea Roma à Thessalonique. Déjà Jules César était vénéré à Thessalonique comme Divus Julius selon le témoignage des monnaies; une inscription aujourd'hui perdue atteste la construction d'un temple en son honneur. Le culte de Jules César était, semble-t-il, associé à celui de son ancêtre mythique Aphrodite dont le temple fut transféré à Thessalonique, dans l'aire sacrée à l'O de la ville, probablement d'Aineia, à l'époque d'Auguste. Ce temple, fouillé déjà avant la dernière guerre, a été récemment remis au jour et des statues d'empereurs romains y ont été découvertes (ChronARG [2004], 07.10). Un temple dédié au culte impérial devait exister dans la même zone, puisque les statues d'Auguste et d'un autre 
empereur ont été trouvées non loin de là, bien qu'il n'ait pas encore été découvert. Les cultes de Dea Roma et des Romains bienfaiteurs ainsi que celui de Zeus Eleutherios (cf. supra, 07.00) sont sans doute antérieurs à l'époque impériale; ils sont attestés par des inscriptions à Thessalonique et à Kalindoia. Une statue de culte de Dea Roma dans le type d'une Amazone provient du temple de la zone $\mathrm{O}$ de la ville déjà mentionné. Le culte des empereurs était également présent dans les deux édifices monumentaux de la terrasse $\mathrm{N}$ de l'agora romaine de Thessalonique, conjointement avec le culte de la famille d'Alexandre le Grand ( $c f$. les études de Th. Stefanidou-Tiveriou présentées ci-dessous). Nous savons en effet que le culte d'Alexandre connaît une grande faveur au III $^{e}$ s. ap. J.-C., particulièrement sous les Sévères. Dans le voisinage de l'église de Saint Démètre devait se trouver un sanctuaire dédié au dieu Fulvus, le fils de Marc Aurèle (ou d'Antonin le Pieux selon Edson) divinisé après sa mort prématurée. Le culte du dieu Fulvus est attesté par des inscriptions du $\mathrm{III}^{\mathrm{e}}$ s. ap. J.-C.

V. Allamani-SOURI, «H $\alpha u \tau O \varkappa \varrho \alpha \tau O \varrho\llcorner x \dot{~} \lambda \alpha \tau \varrho \varepsilon i \alpha »$, ibid., p. 98-119.

07.17 - Thessalonique, agora - L'A. soumet à un nouvel examen les résultats des recherches effectuées sur la terrasse $\mathrm{N}$ de l'agora romaine de Thessalonique, où Stratis Pélékidis avait fouillé, en 1924, un édifice rectangulaire d'époque impériale avec une grande abside sur son côté N (édifice B). Cet édifice a livré des fragments d'inscriptions et des sculptures remarquables (incorporées pour la plupart dans des murs tardifs, ajoutés probablement au $\mathrm{IV}^{\mathrm{e}}$ ou au $\mathrm{V}^{\mathrm{e}} \mathrm{s}$. ap. J.C.) dont les parties en marbre d'une statue acrolithe colossale d'Athéna « Medici » transformée ultérieurement, sans doute au début du III $^{\mathrm{e}}$ s., en portrait de l'impératrice Julia Domna. Une nouvelle fouille, effectuée sur le même terrain en 1973, a permis d'étudier l'édifice B avec plus d'attention. Les résultats de cette fouille furent publiés par E. Kambouri, qui interpréta le somptueux édifice comme une bibliothèque, suivant une opinion émise par Ch. Bouras, et le data du milieu du $\mathrm{II}^{\mathrm{e}}$ s. ap. J.-C., date proposée par G. Despinis pour la statue colossale d'Athéna, qui se dressait vraisemblablement dans l'abside. Cependant la fouille de Pélékidis avait aussi mis au jour un édifice triconque de plus petites dimensions (édifice A), qui jouxtait le mur O de l'édifice B. L'édifice A apparâ̂t sur un dessin non publié de la fouille de 1924 que l'A. a retrouvé et publie dans son étude. L'emplacement exact des sculptures et les inscriptions découvertes dans le complexe est noté sur le plan. Les plus importantes parmi les sculptures, outre la statue d'Athéna déjà mentionnée, sont : (a) une tête colossale de l'empereur Titus ( $n^{\circ} 882$; voir le $n^{\circ}$ suivant), (b) un buste cuirassé de Septime Sévère, (c et d) deux têtes de facture similaire, une barbue et une imberbe ( $n^{\text {os }} 886+6130,878$ ), associées probablement, comme l'a vu G. Despinis, à une base portant les noms de certains membres de la famille d'Alexandre le Grand et (e) une partie nue (comprenant la tête et la poitrine) d'une statue de divinité féminine, peut-être acrolithe $\left(\mathrm{n}^{\circ} 887\right)$. Près du complexe fut trouvée une tête de Sarapis ( $n^{\circ}$ 897) portant des traces de dorure et provenant sans doute d'une statue de culte. Les dimensions et la qualité de ces œuvres soulignent l'importance des deux édifices, sans aucun doute publics. L'interprétation de l'édifice B comme bibliothèque peut être mise en doute à partir d'une série d'observations sur l'architecture. En outre, ses liens avec l'édifice A, qui, comme le montrent de nombreux indices, relève du même programme architectural, amènent l'A. à supposer que nous avons affaire à des constructions à caractère cultuel alignées sur une terrasse à part, comme c'est le cas sur le forum de Philippes.

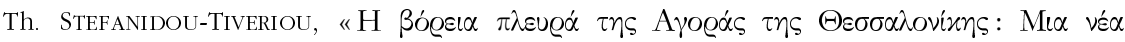

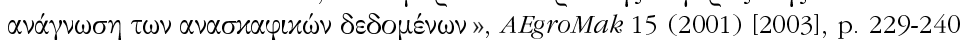

- La tête en marbre $n^{\circ} 882$ du Musée de Thessalonique provient de la terrasse $\mathrm{N}$ de l'agora romaine de la ville (supra) où l'on a fouillé, en 1924 et 1973, un somptueux édifice d'époque impériale (édifice B) associé à un plus petit édifice triconque (édifice A). Cette tête devait appartenir à une statue acrolithe colossale au type du personnage en toge, comme le prouvent ses caractéristiques techniques. Le personnage représenté est identifié avec l'empereur Titus, puisque les traits typologiques de la tête et surtout de la chevelure renvoient à des portraits connus de cet empereur. Certaines particularités de cette ouvre grecque, dans le rendu des joues et des yeux, nous amènent à la comparer avec la tête de la statue de Titus d'Olympie qui est attribuée à un atelier attique. Il est permis de penser que la statue acrolithe colossale de l'empereur dont nous avons la tête avait été dressée dans un temple consacré au culte des 
Flaviens, peut-être fondé lorsque Vespasien fut divinisé par son fils Titus (79 ap. J.-C.). Ce raisonnement conforte l'interprétation des deux édifices de la terrasse $\mathrm{N}$ de l'agora comme des constructions à caractère cultuel.

Th. Stefanidou-Tiveriou, " Une tête colossale de Titus au forum de Thessalonique ", $B C H$

125 (2001) 1 Études, p. 389-411.

07.18 - Thessalonique - XVI Éphorie des antiquités prébistoriques et classiques - Les tombes de la nécropole orientale de Thessalonique fouillées dans le terrain de Foire internationale et datant de l'époque hellénistique et du début de l'époque romaine contenaient, entre autre, un grand nombre de figurines en terre cuite représentant des divinités ou des êtres mythiques: Éros et Psychè, Aphrodite (Cnidienne et type « de Fréjus »), Télesphore. Il y avait également des figurines d'animaux : chiens et bovins.

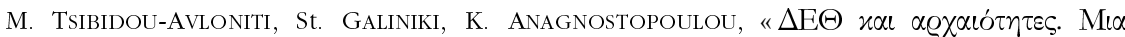

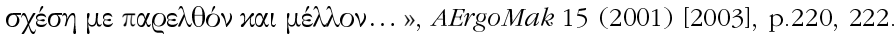

- Les travaux de creusement pour la mise en place d'un réseau de distribution de gaz naturel dans le centre ville de Thessalonique ont mis au jour, entre autre, une stèle portant une inscription à caractère religieux et un fragment d'un des piliers décorés de reliefs du portique de «las Incantadas». La stèle inscrite a été trouvée à l'angle des rues Palaion Patron Germanou et Alexandrou Svolou; son texte concerne les membres d'une association religieuse de Dionysos et date de la deuxième moitié du II ${ }^{e}$ ou du III $^{e}$ s. ap. J.-C. Le fragment de pilier a été trouvé dans la rue Rogoti (près de la place Elefthérias); il conserve en partie la représentation en relief d'une figure féminine rappelant la Victoire sur un pilier du même monument au Musée du Louvre. ( $c f$. ChronARG [2001], 07.13 p. 263).

A. LiOUTAS, ADelt 52 (1997) [2003], Chron B2, p. 635-637.

07.19 - Thessalonique, Oraiokastron - XVI Éphorie des antiquités prébistoriques et classiques Une protomé féminine en terre cuite représentant Aphrodite ou Perséphone provient du voisinage d'une tombe du $\mathrm{IV}^{e} \mathrm{~s}$. av. J.-C. (tombe 1) de la nécropole associée à l'agglomération antique de la toumba Daoutbali (toumba A) à Oraiokastro (terrain agricole $\mathrm{n}^{\circ}$ 528). Dans l'aire de la nécropole on a trouvé une tablette de défixion avec une malédiction contre les fils d'Ospéros.

K. SOUEREF, ADelt 52 (1997) [2003], Chron. B2, p.644.

07.20 - Létè (préfecture de Thessalonique ) - XVI Éphorie des antiquités prébistoriques et classiques - La fondation du sanctuaire de Déméter et de Korè à Létè, découvert en 1936 au S de la colline Assar, dont proviennent entre autre des représentations statuaires des deux divinités, peut être située vers la fin de la période classique. Par ailleurs, les trouvailles de statuettes en marbre et de figurines en terre cuite datant des époques classique, hellénistique et romaine révèlent la présence de plusieurs cultes dans la région de Létè, plus particulièrement ceux de la Mère des Dieux, de Sarapis et d'Isis, d'Artémis, de Dionysos et peut-être d'Enodia. Il faut noter que des figurines de la Mère des Dieux ont été trouvées dans des maisons rurales (ChronARG [2004], 07.09). L'épigraphie atteste l'existence, à l'époque romaine, d'une association d'Asianoi pratiquant le culte de Dionysos.

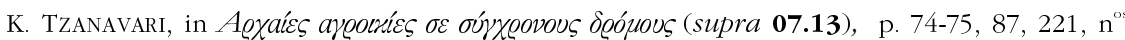
239-241.

07.21 - Profitis (préfecture de Thessalonique) - XVI Éphorie des antiquités préhistoriques et classiques - Les travaux pour la construction de la nouvelle autoroute «via Egnatia» dans la région entre les lacs de Koroneia et de Volvi, près du village moderne de Profitis, ont mis au jour des restes de constructions antiques appartenant à deux phases, dont la première remonte à la fin du $\mathrm{VI}^{e}$ et la deuxième au $\mathrm{IV}^{e}$ s. av. J.-C. Les vestiges des fondations d'une structure rectangulaire et d'un espace auxiliaire ainsi qu'une fosse remblayée appartiennent à la première phase; un mur en pierre long de $6 \mathrm{~m}$ conservé en partie date de la deuxième phase, qui a recouvert la précédente. On a aussi dégagé une section d'un enclos circulaire. Les phases successives ont été largement détruites par la culture des champs. Toutefois, les trouvailles monétaires montrent que le complexe était en usage jusqu'à l'époque impériale. Deux monnaies trouvées en surface 
appartiennent au $\mathrm{IV}^{\mathrm{e}}$ s. ap. J.-C. La céramique ainsi que les nombreuses figures féminines en terre cuite provenant du remblai de la fosse permettraient, de l'avis des A., d'identifier le lieu comme le sanctuaire d'une divinité féminine inconnue.

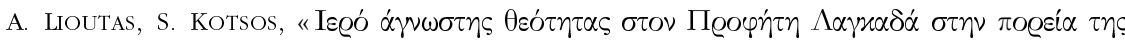

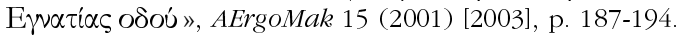

07.22 - Mygdonie, site de «Poli Rachi» (préfecture de Thessalonique) - XVI Éphorie des antiquités prébistoriques et classiques - L'A. propose de situer la cité de Bormiskos, connue par Thucydide, IV, 103, 1, au lieu-dit «Poli Rachi » près du lac de Bolbè. Il y aurait là un culte de Dionysos associé à l'eau.

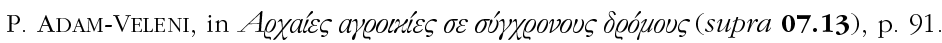

07.23 - Stagire (préfecture de Chalcidique) - XVT Éphorie des antiquités prébistoriques et classiques - Sur la colline N du site de la ville antique de Stagire, trois édifices à caractère sacré ont été repérés; certaines constructions plus modestes leur étaient probablement associées. L'édifice le plus important était un temple hécatompède du $\mathrm{VI}^{\mathrm{e}} \mathrm{s}$. av. J.-C., fouillé en partie, dont proviennent de nombreux fragments de membres archtecturaux. Il y avait aussi un petit sanctuaire du $\mathrm{VI}^{\mathrm{e}}$ s. av. J.-C. disposant d'un autel et d'une fosse sacrificielle, dédié à une divinité inconnue, sans doute féminine, qui a livré plusieurs objets, surtout des statuettes en terre cuite de figures féminines et de Dionysos ainsi que des lampes. Le troisième édifice était circulaire; il appartient à la même période et peut être identifié comme un Thesmophorion. Il y a lieu de mentionner aussi le linteau de la porte pricipale du rempart de la ville, orné d'un relief représentant un lion et un sanglier. Le sanglier est en effet l'emblème de la cité de Stagire et il apparaît sur son monnayage.

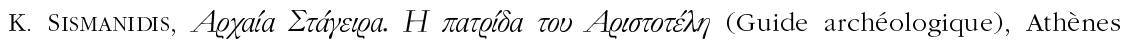
2003, p. 63, 66 fig. 63, 67 fig. 65, 68, 70-73, 75-81, 89-93.

07.24 - Asprovalta, site de Liotopi Routscheli (préfecture de Thessalonique) - XVI Éphorie des antiquités prébistoriques et classiques - Mention de deux figurines représentant Aphrodite Ourania et Cybèle provenant d'une maison agricole d'époque classique et hellénistique à Asprovalta (lieu-dit « Liotopi Routscheli »).

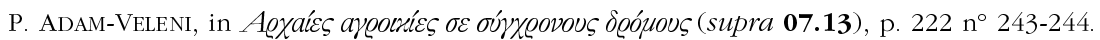

07.25 - Nea Kerdyllia, site de Strovolos (préfecture de Serres) - XVIII Éphorie des antiquités prébistoriques et classiques - Des figurines en terre cuite représentant Aphrodite dans le type «de l'Anadyomène » avec l'himation étendu derrière les épaules, fabriqués peut-être dans la voisine Amphipolis, ont été trouvées dans des tombes d'époque romaine au lieu-dit Strovolos près de Néa Kerdyllia (sur le site cf. ChronARG [2004], 07.14). Des figurines de bovins ont également été trouvées.

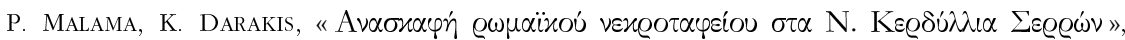
AErgoMak 15 (2001) [2003], p. 142-143, fig. 20

07.26 - Amphipolis - XVIII Éphorie des antiquités prébistoriques et classiques - Une lamelle en or inscrite (transcription en majuscules), trouvée pliée sur la poitrine de la défunte dans un sarcophage en calcaire d'époque classique de la nécropole orientale d'Amphipolis, montre que cette femme était une dévote du culte bacchique et probablement orphique.

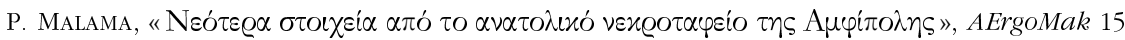
(2001) [2003], p. 118.

07.27 - Serres - XVIII Éphorie des antiquités prébistoriques et classiques - L'A. émet l'hypothèse qu'un sanctuaire antique pourrait être situé sur la pente SE de l'acropole de Serres, dans le voisinage du premier lycée pour jeunes filles de la ville. Une stèle votive du II $^{\mathrm{e}} \mathrm{s}$. ap. J.-C. avec un catalogue de 36 membres d'une association religieuse a été trouvée dans le voisinage de cette école en 1891.

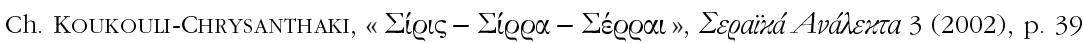


07.28 - Région de Serres (?) - Une nouvelle inscription votive aux Theoi Megaloi de provenance inconnue a été donnée au Musée de Serres par un habitant du village de Mavrothalassa de la préfecture de Serres en 1998 ( $n^{\circ}$ L 276). L'A. date l'inscription à la deuxième moitié du I ${ }^{\text {er }} \mathrm{s}$. ap. J.-C. et suppose que le culte des « Grands Dieux » de Samothrace avait été importé dans une cité inconnue de la Macédoine orientale.

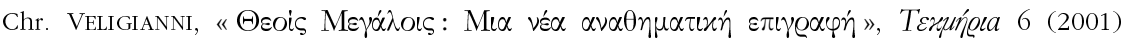
[2002], p. 14-21.

07.29 - Philippes - XVIII Éphorie des antiquités prébistoriques et classiques, Université Aristote de Thessalonique - Les A. supposent la présence d'un sanctuaire de Dionysos à proximité du théâtre de Philippes, à l'O de la parodos occidentale et du mur de soutènement $\mathrm{O}$ de la cavea. Cet espace n'a pas encore été fouillé.

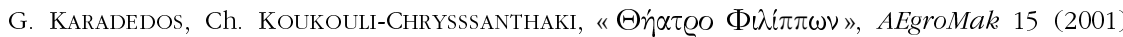
[2003], p. 106

\section{Thrace (partim) (K. Chatzinikolaou et E. Voutiras)}

\subsection{0 - Généralités}

L'A. traite d'une catégorie de monuments funéraires d'époque classique en forme de naïskos associés à des tumulus. De tels monuments ont été découverts à Strelcha, Sveshtari, Ravnogor, Starosel, Aleksadrovo, Ostrusha et surtout dans la région de Kazanlak, que l'A. appelle la vallée des princes thraces; il propose de distinguer les monuments de ce type des tombes à chambre et de les considérer en quelque sorte comme des temples dédiés au culte des princes thraces qui y étaient probablement ensevelis.

G. KiTOV, «Dolinata na Trakiskite Vladeteli (I)», Archeologia (Sofia) 44 (2003), 1, p. 13-28, idem, «Dolinata na Trakiskite Vladeteli (II) », Archeologia (Sofia) 44 (2003), 2, p. 28-42.

08.01 - Mont Haemus, site de Turlata à côté de Troyan - Un sanctuaire de sommet du début le l'âge du Fer a été mis au jour sur la hauteur de Turlata, près de la ville de Troyan, au pied N de la partie centrale de la chaîne de l'Haemus. On y a découvert les traces d'une enceinte circulaire ainsi que des tessons de céramique et des restes d'incinérations, probablement à caractère cultuel.

I. Hristov, A. Gotsev, «Proutcavane na Trakiskoto svetilise v. m. Turlata krai Troian », Arbeologia (Sofia) 44 (2003), 3, p.21-30.

08.02 - Sofia, site de Lozenets - Un ensemble de cinq fosses et de deux constructions en partie souterraines a été découvert à proximité d'un monument funéraire du IV ${ }^{e}$ s. av. J.-C., sur la pente basse d'une colline de la région de Lozenets, près de Sofia. L'A. pense qu'il pourrait s'agir de «sanctuaires creusés dans le sol».

M. Ivanov, «Komplex ot iami i sorzenia ot IV v. pr. Hr. v. kv. Lozenec, Sofia », Archeologia (Sofia) 44 (2003), 2, p.43-51.

08.03 - Polystylon-Abdères (préfecture de Xanthi) - XII Éphorie des antiquités byzantines Pendant les fouilles de l'enceinte fortifiée de Polystylon, un fragment de triglyphe a été trouvé hors contexte. L'A. suppose que cette pièce pourrait provenir d'un temple dont l'emplacement reste inconnu. Il est possible que deux autres membres architecturaux jadis repérés dans la zone appartiennent au même temple.

S. DOUKATA, ADelt 52 (1997) [2003], Chron. B3, p.894

08.04 - Plotinopolis (préfecture d'Evros) - XIX Éphorie des antiquités prébistoriques et classiques - Mention d'un torse d'Éros portant un baudrier d'épée en bandoulière, datant probablement de l'époque impériale et provenant d'un site archéologique près de Didymoteichon, sur la rive droite de l'Hèbre, identifié avec Plotinopolis

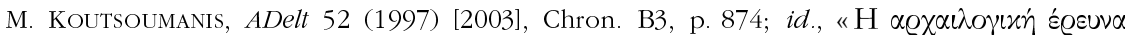

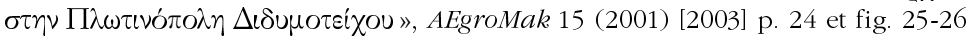




\section{9. Îles de l'Égée (Kalliopi ChatziniKolaou, Alexis D'HautcourT, Natacha MASSAR, Zozie PAPADOPOUlOU, Emmanuel VouTIRAS)}

09.01 - Thasos - XVIII Éphorie des antiquités prébistoriques et classiques - La fouille dans la zone du Poseidonion a mis au jour une série de chambres datant de la fin de l'époque classique, qui s'ouvrent sur l'ancien temenos. Le mur de façade a été dégagé sur toute sa longueur, de même qu'une partie des chambres. L'A. pense qu'il s'agit d'espaces auxiliaires du sanctuaire. [E.V.; K.Ch.]

Z. BONIAS, ADelt 52 (1997) [2003], Chron. B3, p. 828.

09.02 - Thasos - École française d'Athènes - La découverte, dans une tranchée stratigraphique ouverte dans l'angle NE de l'agora de Thasos, près du monument de Glaukos, d'un ensemble d'ossements appartenant à un porcelet, à un jeune bovin et à un bélier mis en morceaux et déposés ensemble dans une fosse a fait l'objet d'une étude approfondie. Cf. supra, p. 476-479. [E.V.; K.Ch.]

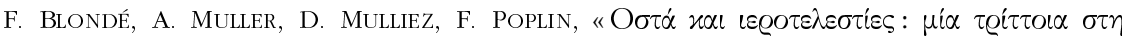

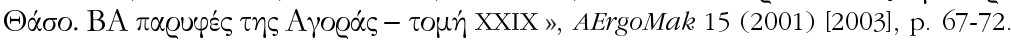

09.03 - Samothrace - Excellente mise au point sur les célèbres mystères de Samothrace et le non moins fameux sanctuaire des Megaloi Theo $i$ ou Kabires. L'A. examine de manière judicieuse tous les témoignages, littéraires et archéologiques, relatifs à ce culte fort intéressant mais parfois mal compris. Il remarque tout d'abord que, d'une manière générale, les mystères de la Grèce ancienne ne sont pas des religions au sens moderne du terme, car ils ne comportent ni dogme ni code de conduite morale. L'adhésion à ces mystères était avant tout un choix personnel. À propos des mystères de Samothrace l'A. évoque l'analogie du pèlerinage de Saint Jacques de Compostelle : les adeptes (mystai) se rendaient au sanctuaire de l'île afin de vivre une expérience unique et gagner l'espoir d'un meilleur sort dans l'au-delà. Suit un aperçu des recherches archéologiques dans l'île depuis la découverte de la Victoire (aujourd'hui au Louvre) par Champoiseau en 1863 jusqu'aux fouilles américaines de Karl et Phyllis Lehmann et de James McCredie. Samothrace était importante déjà à l'âge du Bronze. Mais les plus anciennes trouvailles faites dans le sanctuaire remontent au début du VII $^{e}$ s. av. J.-C.; c'est à peu près l'époque de la fondation d'une colonie samienne, à laquelle l'île doit son nom. Le plus ancien texte mentionnant Samothrace comme centre cultuel est un fragment des Catalogues hésiodiques (POxy. 1329), qui établit un rapport avec la Troie homérique et la lignée d'Énée en particulier. Cette tradition mythologique recoupe ce que rapportent les auteurs postérieurs, d'Hellanicos à Apollodore. La contribution de l'archéologie à la connaissance du sanctuaire aux $\mathrm{vI}^{e}$ et $\mathrm{v}^{\mathrm{e}} \mathrm{s}$. av. J.-C. est modeste et se limite aux trouvailles de céramique et d'objets mineurs. La plus ancienne construction est une aire théâtrale circulaire à fonction sans doute cultuelle datant de la fin $\mathrm{du} \mathrm{V}^{\mathrm{e}} \mathrm{s}$. Le culte nous est connu par des témoignages littéraires (Hérodote surtout, mais aussi Stésimbrote de Thasos, Callimaque, Cicéron, Varron). Karl Lehmann a identifié un des édifices fouillés avec l'Anaktoron du sanctuaire, où étaient érigées, selon l'évêque chrétien Hippolyte, deux statues ithyphalliques. Les IV et III $^{\text {e }}$ siècles marquent l'apparition de l'architecture monumentale dans le sanctuaire de Samothrace, à l'initiative d'abord de Philippe II et ensuite de Philippe Arrhidée, de Ptolémée II et d'Arsinoé. L'édifice circulaire construit par cette dernière a été souvent interprété comme lieu de cérémonies mystiques, mais sa fonction reste incertaine. L'A. examine en détail les étymologies proposées pour les noms des divinités de Samothrace. Il faut aussi noter l'intérêt des Romains pour les dieux de Samothrace, qui se manifeste à partir de leur arrivée dans la région après la bataille de Pydna en 168 av. J.-C. Cet intérêt est dû sans doute, du moins en partie, aux liens de l'île avec Énée dans la tradition mythologique. La traduction grecque laisse à désirer. [E.V.; K.Ch.]

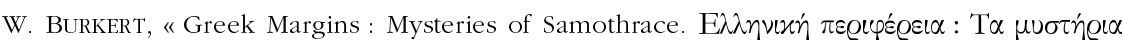

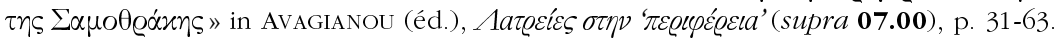


09.04 - Samothrace, site de Kerasouda - XIX Éphorie des antiquités prébistoriques et classiques - Découverte dans la partie S de l'île, à $530 \mathrm{~m}$ de hauteur, d'un sanctuaire à ciel ouvert où la Grande Mère était adorée comme divinité de montagne. Les trouvailles provenant de ce site, ressemblent à celles du site de Mandal' Panagia ( $c f$. ChronARG [2004], 09.02; tessons de céramique portant des inscriptions votives et fragments de figurines représentant une déesse assise) et témoignent de la coexistence de Thraces et de Grecs. [E.V.; K.Ch.]

Chr. Karadina, ADelt 52 (1997) [2003], Chron. B3, p. 878.

09.05 - Samothrace, site de Mandal' Panagia - XIX Éphorie des antiquités prébistoriques et classiques - Mention de trouvailles du début de la période archaïque provenant du sanctuaire à ciel ouvert de la Grande Mère ( $c f$. ChronARG [2004], $\mathbf{0 9 . 0 2}$ et ci-dessus, site de Kerasouda). [E.V.; K.Ch.]

D. Triantaphyllos, ADelt 52 (1997) [2003], Chron. B3, p. 881

09.06 - Astypalaia (Tallara) - Sur le site des bains de Tallara ( $\mathrm{v}^{\mathrm{e}} \mathrm{s}$. ap. J.-C.), on trouve une mosaïque (photos) représentant les douze signes du zodiaque entourant la figure d'Hélios. Ce motif circulaire est inscrit dans un carré dont les angles sont occupés par la représentation des quatre saisons. Le tapis de motifs géométriques dans lequel est inséré ce panneau inclut des carrés dans lesquels sont inscrits douze bustes ( 9 hommes et 3 femmes) qui figurent les douze mois. Alors que la représentation du cycle de l'année est un motif courant sur les mosaïques de l'antiquité tardive, la combinaison de motifs du panneau central était considérée jusqu'ici comme une iconographie spécifique aux anciennes synagogues d'Israël. Cet exemple montre qu'il n'en est rien. [N.M.; A.DH.]

R. JACOBY, «The Four Seasons in Zodiac Mosaics: The Tallaras Baths in Astypalaea », Greece, IEJ 51 (2001), p. 225-230.

- Thesi Katsalos - XXIr Éphorie des antiquités prébistoriques et classiques - Mise au jour de 17 sépultures (plan Fig. 13 p. 1118) : 12 en fosses rectangulaires, deux incinérations (dont l'une placée dans un fosse ovale; $2^{\text {e }}$ quart du III $^{\mathrm{e}}$ s. av. J.-C.) et trois vases incomplets qui ont pu servir pour des sépultures à enchytrismos. Trois tombes à fosse contenaient encore du matériel (en céramique et en métal) et des ossements; l'une appartenait à un jeune homme (T19) et les deux autres à des jeunes filles (T14, T27). Ces deux dernières datent du IV s. av. J.-C. [N.M.; A.DH.]

E. Pharmakidou, $A D 52$ B 3 (1997) [2003], p. 1117-1118; J. WhitLey, AR 50 (2004), p. 72.

- Thesi Kylindra - XXII Éphorie des antiquités prébistoriques et classiques - Découverte de tombes à enchytrismos des époques classique et hellénistique. [N.M.; A.DH.]

E. Pharmakidou, $A D 52$ B 3 (1997) [2003], p. 1118-1119; J. Whitley, AR 50 (2004), p. 72.

09.07 - Kos - Suite à l'étude de D. Berges (Rundaltäre aus Kos und Rhodos, Berlin, 1996), H. reprend la question de la chronologie des autels cylindriques de Kos. Elle date de manière précise quelques pièces (photos) sur base des inscriptions qu'elles portent, en combinant études prosopographique et paléographique. Partant de ce nouveau cadre chronologique, elle propose de revoir la datation des trois groupes de décor identifiés (combinaison de divers motifs avec des bucranes) par Berges et de ne pas les considérer comme les trois phases d'un développement linéaire, du plus simple au plus élaboré, mais davantage comme trois types coexistants s'adressant à des clientèles différentes. Un appendice signale l'aire de diffusion des autels cylindriques de Kos (exportés vers Iasos, Halicarnasse, Cnide et Nisyros). [N.M.; A.DH.]

K. HÖGHAmmer, «The Inscribed, Cylindrical, Funerary Altars: Questions of Date and Stylistic Development », in K. Höghammer (éd.), The Hellenistic Polis of Kos. State, Economy and Culture, Uppsala, 2004 (Boreas, 28), p. 69-81.

09.08 - Kos (ville) - XXIT Éphorie des antiquités prébistoriques et classiques - Odos Argurokastrou et Korutsas. Découverte d'une tombe mycénienne à tholos (chambre funéraire de 4,50 m environ; dromos de 7,50 × 1,70 m), violée sans doute dès l'antiquité. Dans la chambre, on a fouillé deux tranchées à incinération contenant des restes d'ossements humains, de la céramique, la dent d'un animal (cheval ?) et des bijoux en or (pl. 417 (). [N.M.; A.DH.] 
E. SKerlou, $A D 52$ B 3 (1997) [2003], p. 1111; J. Whitley, $A R 50$ (2004), p. 73.

09.09 - Kos (ville, nécropoles) - XXII Éphorie des antiquités prébistoriques et classiques Fouilles de nombreuses sépultures, dont quatre (3 incinérations d'adultes; une tombe d'enfant à ciste) de l'époque géométrique (Odos Ethnikis Antistateos et Aparchiaki Odos; p. 1113) et des dizaines de tombes de types variés d'époque hellénistique et romaine. On notera la présence de nombreuses sépultures d'enfants à enchytrismos (en particulier dans le secteur Odos Asklepiou et Australias, p. 1113-1114). [N.M.; A.DH.]

D. Grigoriadou, E. Skerlou, $A D 52$ B 3 (1997) [2003], p. 1112-1115; J. Whitley, AR 50 (2004), p. 73.

09.10 - Kos (Halassama) - En complément à sa publication (sous presse) des inscriptions découvertes lors des fouilles menées au sanctuaire d'Apollon à Halassarna, K.-A. présente un commentaire de deux inscriptions (avec photos) d'époque hellénistique. La première, datant du milieu du III $^{e}$ s., est un décret interdisant d'emprunter de l'argent en utilisant comme garantie les coupes et autres vases du sanctuaire d'Apollon. Le second est un calendrier qui définit les sacrifices que doit offrir le prêtre d'Apollon au cours de l'année. Les discussions relatives aux divinités concernées (notamment les différentes épithètes sous lesquelles elles sont honorées) mènent à des considérations sur la topographie religieuse du dème d'Halassarna. K.-A. évoque en particulier le culte d'Hestia Phamia au Timacheion, le siège des timachoi, des magistrats du dème, et d'Hekatè Stratia, mentionnée dans plusieurs inscriptions trouvées près du sanctuaire d'Apollon ce qui suggère que son lieu de culte se trouvait à proximité. L'inscription mentionne également un culte de Zeus Polieus «sur l'Acropole »; l'acropole du dème est également mentionnée dans d'autres inscriptions et surplombait le sanctuaire d'Apollon (p. 124-5). K.-A. pense que le nombre de cultes mentionnés suggère qu'il y avait plusieurs temples à Halassarna, ce que confirmeraient des notes prises par R. Herzog lors de visites qu'il a faites au dème d'Halassarna. Cependant, seules les fouilles en cours pourront fournir la preuve de cette hypothèse. [N.M.; A.DH.]

K. KoKKOROU-Alevras, "New Epigraphical Evidence on the Cults of Ancient Halasarna in Cos », in HÖGHAMMER (supra 09.04), p. 119-127.

09.11 - Kos (Alexandreion et Ptolemaieion) - À l'occasion de la publication d'une inscription fragmentaire mentionnant un Alexandreion et un Ptolémaieion (on ne sait pas s'il s'agissait d'un seul sanctuaire ou de deux structures différentes), B. et $\mathrm{H}$. donnent un bref résumé de la documentation épigraphique et archéologique des cultes d'Alexandre et des Ptolémées à Rhodes et à Kos. [N.M.; A.DH.]

D. Bosnakis, K. Hallof, "Alte und neue Inschriften aus Kos. I », Chiron 33 (2003), p. 203 $262, n^{\circ} 13$, p. $226-228$.

09.12 - Rhodes - M. présente brièvement quelques statues découvertes depuis 1947, «trouvées en principe à l'E de l'acropole sur le versant de Monte Smith ", une zone d'occupation mixte (privée et publique, parfois religieuse). Nous signalons une Aphrodite nue (les dimensions ne sont pas données; non reproduite ici, mais voir $A D 23$ [1968], B 2, pl. $403 \gamma$ ), une Tychè de 54 cm (brève analyse iconographique et stylistique; fig. 1), une Artémis (dimensions non données; fig. 3). [N.M.; A.DH.]

V. MACHAIRA, «Sculptures hellénistiques de Rhodes en contexte public ou privé », RA (2003), p. 205-210.

09.13 - Rhodes (ville) - XXII Éphorie des antiquités préhistoriques et classiques - Secteur N et O de la ville: Odos Ammochostou et Lochagou Phanouraki (O.T. 38). Poursuite des fouilles du secteur. On signalera en particulier la découverte, au S des secteurs A, A1 et G, d'une citerne scellée par des murs postérieurs. Le dégagement de la conduite, d'une longueur d'environ 3,60 m, a révélé des débris de céramique des $\mathrm{III}^{\mathrm{e}}-\mathrm{I}^{\mathrm{er}} \mathrm{s}$. av. J.-C. Dans la citerne, on a retrouvé des fragments de statuettes, dont le torse d'une Aphrodite à moitié dénudée et l'arrière-train d'un animal assis. [N.M.; A.DH.]

K. BAÏrAMI, $A D 52$ B 3 (1997) [2003], p. 1079-1080 
09.14 - Rbodes (ville) - F.-T. retrace dans ses grandes lignes le développement urbanistique (plan général) de Rhodes depuis sa fondation, suite au synécisme de 408/7, jusqu'à l'époque médiévale, en se concentrant sur l'époque hellénistique (photos). La position des grands centres cultuels et leurs principales constructions sont évoquées. [N.M.; A.DH.]

M. Filimonos-Tsopotou, «Rhodos: Städtebau und Stadtbild im Wandel », in Die Stadt als Grossbaustelle. Von der Antike bis zur Neuzeit. Internationaler Kongress vom 7. bis 11. November 2001 in Auswärtigen Amt, Berlin, Berlin, 2003, p. 32-39.

09.15 - Rhodes (ville) - Dans ce livre, qui par son format et sa présentation s'adresse plutôt au grand public, l'éditeur et ses collaborateurs abordent de nombreuses questions liées tant aux colosses dans l'antiquité qu'à celui de Rhodes plus précisément. L'ouvrage est constitué d'une multitude de petits chapitres (entre 2 et 5 p.) abondamment illustrés, consacrés à des considérations variées sur le culte d'Hélios, des problèmes topographiques, techniques et artistiques concernant le Colosse de Rhodes, mais également des aspects de l'histoire plus récente, réelle et imaginaire du Colosse. Leur ordre n'apparaît pas clairement. Nous nous concentrerons ici sur les questions concernant la religion à proprement parler, en signalant seulement les autres thèmes abordés. Plusieurs chapitres du début et de la fin de l'ouvrage sont consacrés à des problèmes techniques spécifiques aux statues colossales: déformations optiques dues à la position des membres supérieurs et comment les compenser; techniques du coulage du bronze propres à la fabrication d'une statue d'une telle taille; son équilibrage (contrepoids, etc.); nombre de ces considérations techniques ont d'ailleurs été émises par un ingénieur. Des réflexions sur les dimensions, les proportions et le poids du résultat final font l'objet de plusieurs chapitres (dont l'un par K. Vogl et H. Sachse, et l'autre par G. Zimmer). La destruction du colosse lors du tremblement de terre de $226 / 5$, et son hypothétique reconstruction par Hadrien sont également évoquées, ainsi que la représentation erronée que l'on s'est faite à partir du XIV s. d'un colosse debout enjambant l'entrée du port de la ville. Cette vision, qui domine les représentations figurées jusqu'au XIX 's., est impossible pour des raisons de stabilité. Quelques chapitres évoquent l'art de la sculpture rhodienne (N. Königs), l'identité de l'auteur du colosse (Charès de Lindos) ou les diverses listes des Sept merveilles du monde, au nombre desquelles figure le colosse de Rhodes (J. Berndt). Ces considérations encadrent le cour du propos qui concerne le Colosse, son emplacement et son type iconographique. Partant d'un exposé général sur la topographie de Rhodes, H. situe le colosse à l'entrée du port de guerre de la ville. Viennent ensuite des considérations sur le culte d'Hélios. H. insiste sur la relative rareté du culte dans le monde grec, pourtant choisi comme culte civique par Rhodes après le synécisme de 408/7. Il mentionne brièvement (p. 32) les manifestations du culte du dieu dans la cité (procession, concours, etc.). Le lieu d'implantation du sanctuaire d'Hélios dans la ville reste incertain et, après avoir évoqué les différentes solutions évoquées dans l'historiographie, H. propose de situer ce sanctuaire près du temple d'Apollon pythien. Il suggère qu'un grand bassin $(38,50 \times 34 \mathrm{~m})$ situé à proximité a pu constituer un décor dans lequel s'inscrivait la célèbre statue d'Hélios par Lysippe. Il restitue à cet effet un socle au centre du bassin avec une sorte de rocaille en arrière-fond (côté N) : le quadrige du dieu aurait paru émerger de l'eau. Cependant, S. Ridgway, dans son compte rendu, souligne à raison que, dans cette reconstitution, la statue d'Hélios est orientée N-S ce qui paraît difficile à défendre. Le chapitre suivant concerne le lieu de réunion des Haliastai. Une maison, dans laquelle ont été retrouvées de nombreuses dédicaces à Hélios, est identifiée par H. comme le lieu de réunion des fidèles de ce dieu. Si cette interprétation est plausible au vu du matériel épigraphique, les restitutions proposées à la fig. 67, notamment celle des pièces situées à l'O du bâtiment, reposent sur peu d'indices. Un long chapitre est consacré à l'analyse des vestiges archéologiques qui se trouvent sous la tour d'Agios Nikolaos à l'entrée du "port de guerre » et que $\mathrm{H}$. identifie comme les restes d'une base décorative sur laquelle se dressait le colosse; ces vues ont déjà été développées dans un précédent article. Les raisonnements sont souvent rapides (ainsi écarter en quelques lignes, p. 60, l'idée que le colosse est une dédicace semble d'autant plus hardi que l'épigramme citée p. 57 émet clairement cette idée) et ne reposent pas sur une analyse détaillée des sources. Plusieurs chapitres sont consacrés à des discussions concernant les multiples petits bronzes d'époque impériale (fin $\mathrm{II}^{\mathrm{e}} \mathrm{s}$. au plus tôt) représentant Hélios nu, portant une chlamyde sur une épaule, le dos ou le bras gauche, et ce qu'elles peuvent apporter à une 
hypothétique reconstitution du colosse, dont nous ne possédons pas de description antique. Les restitutions proposées reposent sur des bases fort incertaines (voir les deux compte rendus mentionnés ci-dessous). [N.M.; A.DH.]

W. HOEPFNER, Der Koloss von Rhodos und die Bauten des Helios. Neue Forschungen zu einem der Sieben Weltwunder. Sonderband der Antiken Welt, Zaberns Bildbände zur Archäologie, Mainz, 2003. On trouvera sur internet deux compte rendus développés de cet ouvrage: B.S. RiDGWAY, Bryn Mawr Classical Review 2004.01.25 (http://ccat.sas.upenn.edu/bmcr/2004/ 2004-01-25.html) et U. VEDDER, Göttinger Forum für Altertumswissenschaft 7 (2004), p. 11031113 (http://webdoc.sub.gwdg.de/edoc/p/gfa/7-04/vedder.pdf).

09.16 - Rhodes (ville, secteurs S et E) - XXIf Éphorie des antiquités prébistoriques et classiques - Odos Romanou tou Melodou et Agion Anargiron. Découverte de deux fragments de grandes bases et d'une base cylindrique portant des inscriptions votives; deux d'entre elles se réfèrent à Asklépios. Cette découverte combinée à d'autres suggère qu'on se trouve ici dans le sanctuaire du dieu ou dans son voisinage. Dans le même secteur, dans les fondations de la rue R17, ont été découvertes trois bases votives inscrites; l'une porte également le nom d'Asklépios; on peut lire sur les deux autres des épigrammes avec une dédicace aux dieux. Cette zone pourrait faire partie de l'aire ouverte du sanctuaire d'Asklépios. [N.M.; A.DH.]

C. Phantaoutsaki et al., AD 52 B 3 (1997) [2003], p. 1083-1085; J. Whitley, AR 50 (2004), p. 74 .

09.17 - Rhodes (Afandou) - XXIT Éphorie des antiquités prébistoriques et classiques - Fouilles lors de l'aménagement d'un terrain de golf. Découverte de trois tombes appartenant à la nécropole de l'ancien dème des Brygandarioi. La structure située le plus au nord contenait une couronne en or qui date de peu avant le milieu du III $^{\mathrm{e}}$ s. av. J.-C. [N.M.; A.DH.]

E. Kaninia, $A D 52$ B 3 (1997) [2003], p. 1108; J. Whitley, $A R 50$ (2004), p. 76.

09.18 - Rhodes (Ialysos) - P.C. publie succinctement, avec d'excellentes photographies, deux inscriptions d'une ligne, sur deux objets de bronze provenant d'un dépôt votif du sanctuaire d'Athéna à Ialysos (décrit brièvement par M. MARTELLI, dans Archaeology in the Dodecanesos [1988], p. 104-120) : 1. un manche de racloir (?), long d'une quinzaine de centimètres, terminé en bec de canard et dédié à Athéna (pas de datation); 2. un vase de bronze (paléographie : $\mathrm{VI}^{\mathrm{e}} \mathrm{s}$. av. J.-C.), écrasé, écrit sur le col, prix d'un concours (athlon). Le nom du dédicant amène l'A. à émettre l'hypothèse qu'il est originaire d'Eubée. [N.M.; A.DH.]

G. Pugliese Carratelli, « Dalla stipe dell'Athenaion di Ialysos. I », PP 328 (2003), p. 71-73; id., « Due epigrafi dalla stipe dell'Athenaion di Ialysos. II », PP 331 (2003), p. 309-311 (p. 71 : la publication du dépôt votif a été confiée à M. Martinelli, M.A. Rizzo et E. Zervondakis).

09.19 - Rhodes (Lindos, région de Koskinou) - XXII Éphorie des antiquités prébistoriques et classiques - On a trouvé un ensemble funéraire de 8 tombes. Trois d'entre elles sont des sarcophages et trois autres sont des caveaux avec antichambre. L'un des sarcophages contenait une osthéothèque inscrite. Du matériel fut retrouvé dans les caveaux. On peut dater le site du III s. av. J.-C. [N.M.; A.DH.]

St. Palaiologou, $A D 52$ B 3 (1997) [2003], p. 1107-1108; J. Whitley, AR 50 (2004), p. 76.

09.20 - Rbodes (Lindos) - Parution de L.W. SORENSEN, Lindos IV, 2. Excavations and Surveys in Southern Rhodes (Copenhague, 2004). Nous présenterons cette publication l'année prochaine. [N.M.; A.DH.]

- H. a écrit un livre important sur un document épigraphique qui présente une archéologie imaginaire de ce que pouvaient être les offrandes d'un sanctuaire grec, ou plutôt d'une certaine manière grecque de concevoir le mobilier sacré d'un sanctuaire en un lieu et un temps donnés. À ce titre, l'ouvrage devrait être lu par tous les archéologues qui fouillent un temple grec. Rappelons que l'appellation traditionnelle de "Chronique de Lindos » est malheureuse puisque cette inscription du début du $\mathrm{I}^{\text {er }} \mathrm{s}$. av. J.-C., dont on ne connaît pas avec précision l'emplacement original, est en fait un décret suivi de deux catalogues, d'une part d'offrandes mythiques et réelles déposées au sanctuaire de Lindos ( 42 entrées) et d'autre part d'apparitions de la déesse Athéna (à 
3 occasions différentes; la pierre est brisée). Faute de place, on ne peut ici qu'offrir une brève idée du contenu de cette étude, essentiellement épigraphique: une courte présentation topographique et archéologique de l'Acropole (p. 1-15), le texte grec de l'inscription et une traduction anglaise juxtaposée (p. 18-48), un commentaire fouillé (p. 51-151), épigraphique, historique et religieux. Les informations fournies font du livre un objet de travail dorénavant indispensable pour l'étude de l'histoire et de la religion de Rhodes. Malgré les efforts méritoires de H., le commentaire archéologique de la Chronique, quant à lui, reste à faire. Par contre, les parallèles littéraires ou épigraphiques de tous les objets mentionnés ont été très bien établis par H., qui a, notamment, exploité plusieurs inventaires de sanctuaires gravés sur pierre. Sera aussi précieuse la liste de témoignages à propos d'offrandes ignorées par la Chronique (p. 166-167). Une dernière partie, intitulée "Essays on the Greek Past» (p. 155-288), analyse la façon dont cette liste de dons, réels ou inventés, crée une histoire de Rhodes, en utilisant et citant documents écrits (historiens et autres auteurs anciens de recherches locales, et archives) et objets, visibles, disparus ou inexistants. La plupart de ces offrandes n'existaient plus au moment de la rédaction du document : seules six d'entre elles (entre Alexandre le Grand et Philippe de Macédoine) semblent avoir été vues par les auteurs du document (hypothèse fondée sur l'emploi d'un temps grammatical pour ces 6 notices). Le traitement des objets dans l'inscription ne diffère guère de celui des apparitions de la déesse : une entrée de catalogue, plus ou moins descriptive, suivie d'une liste de références à des sources plus anciennes. Nous voudrions apporter quelques remarques. D'abord, il est dommage que l'A. n'ait pas mieux utilisé l'archéologie dans la dernière partie de son étude : l'architecture et la décoration figurée des bâtiments du sanctuaire racontent aussi une histoire, qui était bien plus visible à un public en majorité analphabète qu'une stèle monumentale à l'écriture difficilement déchiffrable. L'histoire de Lindos n'avait pas besoin de l'inscription pour être exprimée et diffusée. Ensuite, H. donne l'impression que l'inscription visait d'abord les visiteurs étrangers du sanctuaire, mais on ne comprend pas pourquoi elle ne se serait pas d'abord adressée à un public local. En cela, à notre avis, H. a été trop influencée par la lecture de Pausanias, et elle a projeté de façon anachronique les préoccupations du monde grec impérial et de la seconde sophistique (il est malheureux que la pierre soit brisée au moment où elle aurait pu témoigner de la visite de Romains à Lindos). Vu l'importance du rôle d'une famille particulière pour cette inscription, il faut aussi se demander comment les différents membres de l'élite d'une cité hellénistique pouvaient rivaliser pour en contrôler et manipuler l'histoire, peutêtre à travers son historiographie. Ne finissons pas sur cette note négative et répétons encore une fois combien ce livre sera précieux pour de nouvelles études sur Rhodes et ses cultes. [N.M.; A.DH.]

C. Higbie, The Lindian Chronicle and the Greek Creation of their Past, Oxford, 2003.

09.21 - Rhodes (Nécropoles) - XXII Éphorie des antiquités prébistoriques et classiques - Les fouilles se sont poursuivies dans plusieurs secteurs. La plupart des tombes datent de la haute époque hellénistique; seules quelques-unes (du secteur de l'Odos Parthenopis) sont du début de l'époque impériale (p. 1089). Les vestiges retrouvés témoignent de la pratique contemporaine d'inhumations et d'incinérations. Les structures sont variées : tombes creusées dans le rocher, tombes à couvercle coulissant, caveaux, souvent précédés d'une antichambre et contenant de multiples sépultures, inhumations et incinérations (vases placés dans des niches dans les parois, etc.). Les incinérations se font dans des hydries ou des ostéothèques, souvent en pierre, qui portent parfois une inscription. Aux sépultures sont souvent associées des stèles funéraires inscrites, parfois ornées d'une scène de dexiosis (Prolongation de l'Odos Peiraios; p. 1091 K. Baïrami), ainsi que des autels portant fréquemment un décor de bucranes et de guirlandes. À côté de la tombe 73 de l'Odos Parthenopis (p. 1089), on a retrouvé un autel cyclindrique inscrit avec la représentation d'un homme tenant dans la main gauche deux papyrus. Dans quelques secteurs de la nécropole, les tombes sont groupées en un ensemble structuré. On notera ainsi que, dans le secteur de l'Odos Parthenopis, les 12 tombes de l'angle S-O (Plan fig. 4, p. 1088) de la parcelle semblent appartenir à un seul groupe. Les tombes sont toutes orientées de la même manière, perpendiculairement au sens du rocher, et elles sont d'une taille supérieure à la plupart des autres sépultures du secteur. Le tout semble être organisé autour d'un couloir central commun. Lorsque les tombes sont suffisamment bien conservées, les notices du AD fournissent 
une liste du matériel retrouvé (céramique, bijoux, objets en verre et en métal). Quelques objets exceptionnels ont été mis au jour, dont, Odos Parthenopis, tombe 33, une phiale à omphalos de type dit achéménide en verre (p. 1087; pl. $411 \alpha$ ) [tombe du $3^{\mathrm{e}}$ quart du IV ${ }^{\mathrm{e}} \mathrm{s}$.] et, dans la zone archéologique Korakonerou, une phiale en or et un alabastre en argent portant un décor végétal incisé (Date: vers 300 av. J.-C.; p. 1099) ont été retrouvés dans une tranchée funéraire. Notons aussi, à proximité, une boîte ronde et une hydrie d'Hadra qui servait d'urne cinéraire (p. 10991100), ainsi que de grandes stèles funéraires avec base, Odos Ataburou (P1. 413 \&), p. 1097. [N.M.; A.DH.]

Nécropole occidentale : M. Chalkiti, E. Kaninia, Ch. Giakoumaki, AD 52 B 3 (1997) [2003], p. 1085-1089; Nécropole centrale : E. Kaninia, K. Bä̈rami, P. Triantaphyllidis, Ph. Zervaki, ibid. p. 1089-1093; Nécropole orientale : E. KAninia, K. BaÏrami, Ph. Zervaki, Ch. PhanTAOUTSAKI, ibid. p. 1093-1100; J. WHITLEY, AR 50 (2004), p. 72-76.

09.22 - Rhodes (Theologos - sanctuaire d'Apollon Erethimios) - XXII Éphorie des antiquités préhistoriques et classiques - "Bâtiment à stoa » A. La structure fouillée, orientée N-S, se divise en deux parties comportant chacune cinq pièces, les plus grandes se situant à l'E et les plus petites à l'O. [N.M.; A.DH.]

L. Marangou, I. Papachristodoulou, $A D 52$ B 3 (1997) [2003], p. 1108-1109; J. Whitley, $A R$ 50 (2004), p. 76.

09.23 - Rbodes (Vroulia) - Dans le cadre d'une réflexion générale sur la présence phénicienne dans le monde égéen, K. discute des traces de présences phénicienne et chypriote sur l'île de Rhodes de l'époque mycénienne à la fin du vi ${ }^{\mathrm{e}} \mathrm{s}$. Au VIII ${ }^{\mathrm{e}}$ s., les contacts avec Chypre et le Levant se sont intensifiés, comme le montre le matériel trouvé dans les trois grands sanctuaires d'Athéna de l'île : des coquillages tridacna de la mer Rouge, des ivoires phéniciens et de Syrie du nord, des objets en métal. La céramique produite à Rhodes à cette période témoigne également d'une forte influence de modes orientales. Aux siècles suivants, les objets votifs importés les plus marquants trouvés dans les sanctuaires rhodiens sont des statuettes en terre cuite ou en calcaire. Quel que soit leur matériau, il est vraisemblable que toutes aient été fabriquées à Chypre (même si le style et la typologie des statuettes en pierre trouvées en Égée, notamment la représentation de jeunes hommes nus, diffèrent de celles découvertes à Chypre et dans le Levant). En conséquence, lorsque ces statuettes sont inscrites, la langue de la dédicace dépend du dédicant et non du fabricant. K. étudie de manière plus approfondie deux statuettes provenant de Rhodes et portant des inscriptions qui ne sont pas en grec (photos). Sur un lion aujourd'hui à Copenhague, mais trouvé sans doute à Vroulia ou dans le N-O de l'île, sont gravés deux signes en syllabaire chypriote. L'objet aurait donc été dédié par un Chypriote. Un sphinx de facture chypriote en calcaire, provenant du site de «la chapelle» à Vroulia, porte une inscription en phénicien. Il correspond à un type de sphinx assis, très rare à Chypre mais bien connu en Égée et en particulier à Rhodes. L'inscription phénicienne indiquerait une dédicace par quelqu'un d'origine levantine. La fin de l'article est consacrée à une rapide discussion du site de Vroulia (S de l'île), fondé sans doute vers 700 , même si la date est disputée. Le sanctuaire principal de l'endroit a fourni du matériel datant de la fin du vIII à la fin du vI ${ }^{e}$ s. Un petit sanctuaire extra urbain, le lieu-dit «la chapelle », présentait lui du matériel de la seconde moitié du vII au début du vi ${ }^{e} \mathrm{~s}$., de même qu'un cimetière voisin. La nature générale du site est disputée : poste militaire ou port commercial? La présence d'une statuette de facture chypriote, de même que de la poterie levantine de type noir sur rouge révèlent des contacts avec le Proche-Orient, mais la majorité de la poterie trouvée à " la chapelle» était rhodienne. La discussion qui a suivi la communication porte surtout sur le lieu de production des statuettes, qui sont de très petite taille : a-t-on pu exporter le calcaire et le tailler à divers endroits (artisans itinérants ou artisans étrangers installés sur des sites grecs)? Ou bien, comme le suggère Niemeyer dans le même volume, les statuettes étaient-elles sculptées toutes au même endroit mais selon des types différents en fonction de la clientèle? K. admet aussi que la région de Cnide n'a pas été envisagée dans son étude du calcaire, et l'on ne peut donc exclure que le matériau provienne de là plutôt que de Chypre. [N.M.; A.DH.] 
N. Kourou, "Rhodes: The Phoenician Issue Revisited. Phoenicians at Vroulia? », in N. STAMPOLIDIS, V. KARAGEORGHIS (éds), Sea Routes... Interconnections in the Mediterranean 16th Gth c. B.C. - Proceedings of the International Symposium held at Rethymnon, Crete, Sept. 29th-Oct. 2nd 2002, Athènes, 2003, p. 249-262

\section{Cyclades (Zozie PAPADOPOULOU) 09.24 - Généralités}

Dans un article de synthèse, l'A. (Université-Lumière Lyon 2) offre une mise au point sur la vie religieuse des Cyclades à l'époque impériale (à l'exception de Délos, dont l'histoire cultuelle est retracée par Ph. BRUNEAU dans les Recherches sur les cultes de Délos à l'époque hellénistique et à l'époque impériale, Paris, 1970). Malgré les difficultés (manque de documentation épigraphique et archéologique pour certaines îles, fouilles anciennes, etc.), l'A. fait le point sur l'évolution des cultes traditionnels à cette époque. Elle observe que certains cultes locaux sont abandonnés (comme par exemple celui de Zeus Damatrios à Théra, d'Archiloque à Paros, de Poséidon à Ténos) tandis que d'autres ont continué d'être pratiqués (par ex. Apollon Karneios, Asclépios et Aphrodite à Théra, Ilithye à Paros, Athéna à Mélos, etc.). Les cultes les plus importants sont ceux qui étaient considérés comme panhélleniques pendant cette période, à savoir le culte de Dionysos et celui d'Asclépios. Le culte des Kabires, répandu dans les Cyclades à l'époque hellénistique, prend encore plus d'importance à cette époque, spécialement à Syros. Le matériel, surtout épigraphique, concernant le rituel est très intéressant dans certaines îles (par ex., une série des décrets à Syros, qui nous renseignent sur le déroulement des banquets rituels) et révèle l'étroite relation entre la vie religieuse et la cité, ainsi que la place de Rome dans certaines fêtes.

Les cultes des divinités étrangères, existant déjà à l'époque hellénistique (comme ceux d'Isis et de Sérapis) ainsi que de nouveaux cultes introduits (comme ceux de Mithra et des anges à Théra), sont aussi attestés à l'époque impériale (Isis à Syros, Andros, Ios, Paros, Amorgos, Sérapis à Paros, Amorgos, Mykonos) et prennent maintenant plus d'ampleur en se mêlant à ceux des divinités grecques. Le culte de Mithra n'était pas populaire dans les îles et est seulement attesté à Andros. Un culte sans parallèle dans le monde grec est celui des anges, mentionnés sur des inscriptions funéraires provenant de Théra. Ces épitaphes semblent provenir des courants en marge du judaïsme et du christianisme. Des communautés juives sont attestées à Délos et à Paros. En ce qui concerne la religion chrétienne, les premières églises datent $\mathrm{du}_{\mathrm{IV}}^{\mathrm{e}} \mathrm{s}$. de notre ère.

M.-Th. LE DiNAHET, «Cultes étrangers et cultes locaux dans les Cyclades à l'époque impériale », in G. LABARRE (éd.) Les cultes locaux dans les mondes grec et romain, Lyon, 2004, p. $129-142$.

09.25 - Délos - École française d'Athènes - De nouveaux sondages effectués dans le sanctuaire d'Apollon modifient les opinions antérieures de R. Vallois et G. Gruben sur la forme et la date des deux états des Propylées.

R. Étienne, M. Wurch-KozelJ, "Propylées et sondages dans le sanctuaire d'Apollon », $B C H$ 126 (2002), p. 529-535.

- Des sondages ont été faits sur la terrasse méridionale du Sarapieion : Sondage I, dans une des boutiques à l'O du Sarapieion C, pour préciser la date du contrebas de la terrasse méridionale, ainsi que l'histoire de cet endroit. Les données montrent que l'abandon de la boutique, utilisée pour une période très brève, intervient avant même son achèvement et n'est pas lié à la construction du portique de Sarapieion comme Roussel le supposait. Sondage II : un sondage derrière le temple $\mathrm{C}$ place, sous toutes réserves comme l'A. le souligne, la construction du temple à une date postérieure à 150 av. J.-C. Sondage III : le nettoyage d'une construction à l'E du temple C a montré qu'il s'agissait d'un autel daté de la phase d'aménagement de la terrasse S du sanctuaire.

H. SIARD, « Le Sarapieion C », BCH 126 (2002), p. 537-545.

- L'A. (American School of Classical Studies) propose une nouvelle lecture d'une tablette de malédiction, en essayant d'éclaircir certains passages difficiles interprétés de façon incomplète 
dans la première publication de la tablette. La prière, qui s'adresse aux Dieux Syriens, habitants d'un lieu inconnu dit Sykôn, est dirigée contre un voleur. Le texte est daté par l'A. au début de l'ère chrétienne.

D. JORDAN, «Une prière de vengeance sur une tablette de plomb à Délos », RA (2002), p. 5560

- L'A. (École française d'Athènes) réexamine le riche corpus des peintures liturgiques, des monuments architecturaux et des témoignages épigraphiques de Délos, ainsi que les sources littéraires et les parallèles iconographiques d'Italie, pour définir les modalités de la fête des Compitalia attestée à Délos aux II $^{e}$ et $\mathrm{I}^{\text {er }} \mathrm{S}$. av. J.-C. La fête était célébrée dans un cadre familial, aux portes des habitations, et contribuait à la perpétuation des traditions fondamentales romaines et au renforcement des liens familiaux; mais, comme les sources épigraphiques le montrent, c'était aussi une fête officielle de la communauté italienne, organisée par le collège des Compitaliastes, célébrée sur l'Agora dite des Compitaliastes, où un sanctuaire consacrée aux Lares était construit. Le réexamen des peintures montre qu'auprès des Lares Compitales - divinités principalement vénérées dans cette fête -, Hercule et d'autres divinités appartenaient aussi au panthéon des Compitalia. En plus, les peintures liturgiques sont précieuses pour l'étude des rites de Compitalia, à savoir le sacrifice et les $l u d i$, les jeux athlétiques. Comme l'A. le remarque, il devient clair que la fête était influencée par certains élements locaux en ce qui concerne les rites des dieux, l'emplacement de la célébration ainsi que l'origine des fidèles.

Cl. HASENHOR, «Les Compitalia à Délos », BCH 127 (2003), p. 167-249.

- Dans cet article, l'A. (École française d'Athènes), s'appuyant surtout sur les sources épigraphiques, reprend la question des magistri italiens à Délos, c'est-à-dire des collèges de dignitaires portant le titre d'Hermaïstes, Apolloniastes, Poséidoniastes en grec, dépendants de la communauté des Italicei de Délos. Parmi leurs activités officielles intervenaient la consécration des monuments (petits temples, autels, statues, etc.) à diverses divinités, l'ornementation des édifices et très probablement l'organisation des jeux.

Cl. HaSENHOR, "Les collèges de magistri et la communauté italienne de Délos », in Chr Müller, Cl. Hasenhor (éds), Les Italiens dans le monde grec. II s. av. J.-C. - ir s. ap. J.-C. Ciriculation, activités, intégration, Paris, 2002 (BCH, Supplément 41), p. 67-76. Cf. aussi Cl. HaSENHOR, "Les monuments des collèges italiens sur l"Agora des Compitaliastes' à Délos (II - Ir s. av. J.-C.) ", in J.-Y. MARC, J.-Ch. MORETTI (éds), Constructions publiques et programme édilitaires en Grèce entre le II s. av. J.-C. et le Ir s. ap. J.-C., Paris, 2001 (BCH, Supplément 39), p. 329-348.

09.26 - Despotiko - XXI Éphorie des antiquités prébistoriques et classiques - Présentation de la fouille (avec des photographies, des plans et des rélevés récents) menée sur le terrain Mandra à Despotiko, à l'O d'Antiparos, où un sanctuaire a été mis au jour. En 2003, cinq nouveaux ensembles de constructions ont été localisés et partiellement fouillés (bâtiments $\mathrm{B} \Gamma \Delta \mathrm{EZ}$; pour le bâtiment A, voir ChronARG [2003], 09.27). 520 membres architecturaux ont été trouvés dans des constructions modernes, appartenant au temple qui n'est pas encore localisé avec certitude (probablement le bâtiment A). À l'E des pièces A1 et A2 du bâtiment A, un autel rectangulaire construit de quatre plaques de marbre similaires a été fouillé. Un de ces plaques porte l'inscription E ETIA $\Sigma \Sigma \Theta M I A \Sigma$, datée de l'époque tardo-classique (I $\Sigma \Theta M O \Sigma$ désigne un isthme qui existait probablement à l'époque entre Despotiko et Antiparos). Un tesson portant l'inscription APTHME ou APEHME, daté de la fin du $\mathrm{VI}^{e}$ - début $\mathrm{V}^{\mathrm{e}} \mathrm{s}$. av. J.-C., a été trouvé à l'angle S-E de la pièce Est du bâtiment $\Gamma$. Ce tesson, ainsi que cinq autres portant l'inscription $\mathrm{A} \Pi \mathrm{O} \Lambda \Lambda$, datés du $\mathrm{VI}^{e}$ au $\mathrm{III}^{\mathrm{e}}$ s. av. J.-C, permettent de faire du site un sanctuaire d'Apollon et d'Artémis. La similitude des objets et des restes architecturaux trouvés à Despotiko avec ceux trouvés au Délion de Paros, ainsi que la situation du site en face de Délos, permettent de supposer qu'il s'agit d'un Délion.

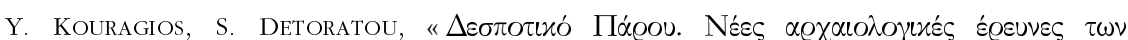

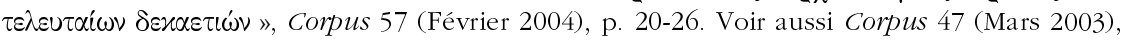
p. 32-47. 
09.27 - Kythnos - Université de Thessalie - Présentation des résultats de la campagne de fouille de 2003, menée dans un sanctuaire de l'ancienne ville de Kythnos. Les secteurs suivants ont été investigués: Secteur B : achèvement de la fouille de l'adyton et de la cella du temple; le soubassement a été mis au jour; au niveau inférieur du sol de l'adyton ca 30 objets votifs ont été trouvés (fragments de lames en or, bague, pendentif, rosettes, fibules, sceaux, etc). Secteurs $\Gamma$ (entre le mur est de l'adyton et le péribole du temple) et $\Delta$ (entre le mur s et le péribole du temple) : dans les remblais, des tuiles ont été trouvées ainsi que des objets votifs s'étalant de l'époque archaïque à l'époque hellénistique. Secteur $\Delta$, entre l'angle SE de l'adyton et le péribole du temple : une pyra contenant des cendres, des os et des fragments de vases est interprétée en relation avec l'inauguration du temple pendant sa restauration au $\mathrm{III}^{\mathrm{e}} \mathrm{s}$. av. J.-C. Secteur au $S d u$ temple : une construction a été trouvée, probablement un autel monumental. Secteur de l'analema au nord du temple: la fouille a montré que la partie centrale de l'analema a été fortement endommagée, probablement lors d'un tremblement de terre. Dans ce secteur, plusieurs trouvailles ont été mises au jour, datées des époques archaïque et classique, parmi lesquelles un fragment de triglyphe qui permet de supposer que le temple était d'ordre dorique. En résumant les résultats actuels de la recherche, l'A. conclut que le sanctuaire était en usage jusqu'à l'époque héllenistique et était consacré à une divinité féminine dont l'identité ne peut pas encore être déterminée.

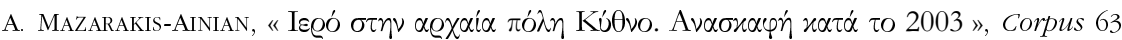

(Août-Septembre 2004), p. 16-19.

\section{[10. Crète]}

\section{Chypre (Thierry PETIT)}

\subsection{0 - Généralités}

- L'ouvrage est essentiellement consacré à la typologie et à la chronologie des fibules cypriotes découvertes dans un contexte funéraire. Mais l'auteur envisage aussi certaines trouvailles en contexte cultuel. Ainsi dans les sanctuaires d'Apollon Hylatès à Kourion, par exemple (p. 292 et 360).

K. GIESEN, Zyprische Fibeln. Typologie und Chronologie, Jonsered, 2001 (Studies in Mediterranean Archaeology and Literature, Pocket book 161).

- Il s'agit là d'une thèse soutenue devant l'Université de Pennsylvanie en 1980 qui reflète, bien sûr, l'état de la question du moment. L'ouvrage constitue sans aucun doute une synthèse utile des sources littéraires, épigraphiques et archéologiques sur la religion cypriote. On peut toutefois déplorer l'absence d'une discussion sur le concept de «Greek Cypriotes » et celle d'une mise en perspective et d'une problématique : ainsi on n'y trouve aucune discussion sur les personnalités qui se cachent sous les diverses appellations souvent tardives (les divinités y sont simplement classées par ordre alphabétique).

C.G. BENNETT, The Cults of Ancient Greek Cypriotes, Londres/Ann Arbor (UMI), 2003

- La provenance des objets de cette collection privée cypriote est inconnue, mais elle compte notamment plusieurs figurines dont certaines pourraient être des ex-voto ( $\left.n^{\circ} 520-571\right)$.

St. Lubsen-AdmiraAl, Ancient Cypriote Art in the T.N. Zintilis Collection, Säveladen, 2003 (SIMA, XX:25).

- Ces collections proviennent de sources très différentes, au point qu'il serait nécessaire, pour établir le contexte de trouvaille de chaque objet, de suivre individuellement son parcours. Quoi qu'il en soit, certains objets figurés (statues, statuettes ou figurines) du catalogue ( $\left.n^{\circ} 306-329\right)$ sont très vraisemblablement des offrandes votives découvertes en contexte cultuel (en particulier certains prêts du Fitzwilliam Museum de Cambridge, provenant du petit sanctuaire de Mersineri, près de Lefka : voir p. 12; ou du sanctuaire de Salamine Toumba tou Michali : $\mathrm{n}^{\circ} 308$ sq.). 
J.M. WeBB, Cypriote Antiquities in the Nicholson Museum at the University of Sydney, Jonsered, 2001 (SIMA, XX:20).

- La presque totalité des objets de la collection du Musée de Stockholm provient des fouilles de la célèbre Swedish Cyprus Expedition, qui, en quatre années (1927-1931), posa les bases de l'archéologie cypriote. En vertu des dispositions légales de l'époque, la totalité des trouvailles mobilières fut divisée entre Chypre et la Suède en 1931. C'est un peu plus de la moitié de ces nombreux objets qui parvint ainsi à Stockholm. L'intérêt de cette collection réside dans le contexte sûr de provenance, qui fait souvent défaut aux ouvres conservées dans les musées d'Occident. Pour ce qui nous concerne, on relèvera l'importance les trouvailles des sanctuaires d'Agia Irini, de Mersinaki, de Vouni et de Kition, qui permirent à Einar Gjerstad de poser les fondements d'une chronotypologie de la statuaire cypriote et de caractériser ses styles successifs et les influences qu'elle subit. Ces sanctuaires d'époque archaïque et classique abondaient, en effet, en oeuvres en terre cuite et en calcaire; outre des séries relativement bien attestées (Héraclès en Smiting God à la léontè de Kition : n 274-275), elles présentent aussi des types rares ou inconnus ailleurs dans lî̀le: des taureaux au cou enlacé de serpents ( $n^{\circ} 181$ sqq.), des figures anthropoïdes avec masque de taureau ( $\left.{ }^{\circ} 187\right)$, des «centaures» ou «minotaures » ( ${ }^{\circ} 188$ sq.), Athéna et son quadrige $\left(n^{\circ} 257\right)$, une très belle tête de déesse à la couronne (alternance de «Bès » et de rosettes), etc. Tous ces objets ont déjà fait l'objet d'une publication dans la série $S C E$ (en particulier SCE II, III, IV2) et d'autres études (voir notamment Sjöqvist dans ARW 30 [1933], p. 308-359, pour Agia Irini); mais les notices des objets ici présentés réactualisent les références bibliographiques et offrent des illustrations d'excellente qualité, aux normes récentes. Le volume contient en outre quelques études thématiques, notamment sur les fouilles suédoises à Chypre (p. 24 sqq.) et sur le sanctuaire d'Agia Irini (p. 151 sq. : voir notamment l'impressionnant cliché p. 154, qui montrent les ex-voto figurés d'Agia Irini autour de l'idole aniconique, sphérique, du sanctuaire).

V. Karageorghis et al., The Cyprus Collections in the Medelhavsmuseet, Nicosie, 2003.

- La collection cypriote du musée d'Odessa se limite à une trentaine de pièces ( $\left.n^{\circ} 148-175\right)$. Elle est constituée essentiellement de statues ou fragments de statues en calcaire. Leur provenance est inconnue. On relèvera cependant quelques types iconographiques proches des ex-voto connus dans les sanctuaires de lîle: des porteuses d'offrande du type de la "Dame de Mersinaki » $\left(n^{\circ} 155-156\right)$ un jeune homme au bandeau orné de rosettes $\left(n^{\circ} 157\right)$, un Héraclès à la leontè $\left(n^{\circ} 162\right)$, des temple boys, un personnage à la syrinx $\left(n^{\circ} 175\right)$.

V. Karageorghis et al., Greek and Cypriote Antiquities in the Archaeological Museum of Odessa, Nicosie, 2001.

- De la même manière, la provenance des objets conservés dans les collections hongroises est inconnue, à peu d'exceptions près. On relèvera simplement une figurine féminine modelée $\left(n^{\circ} 112\right)$, deux têtes de figurines masculines modelées ( $n^{\circ} 108$ et 109$)$ et une " applique murale » avec décor de tête de taureau ( $n^{\circ} 103$ ), qui peuvent provenir d'un contexte cultuel.

B. Csornay-Caprez, Cypriote Antiquities, Rome, 2000 (Monumenta Antiquitatis extra Fines Hungariae Reperta, 6).

- La plupart des objets cypriotes du Musée de Berlin proviennent des fouilles de Max OhnefalschRichter qui, dans les années 1880, fouilla un grand nombre de sites insulaires. Parmi eux, un certains nombre de sanctuaires, notamment dans la région d'Idalion, et à Tamassos. Les trouvailles figurées en terre cuite $\left(n^{\circ} 82-137\right)$ et en calcaire ( ${ }^{\circ}$ 138-183) ont déjà été étudiées et reproduites ailleurs. La bibliographie récente sur chaque pièce est, à cet égard, fort utile. L'iconographie de ces ouvres est souvent exceptionnelle : ainsi, pour la terre cuite, un "Bès" aux serpents $\left(\mathrm{n}^{\circ} 104\right)$, une tête féminine casquée $\left(\mathrm{n}^{\circ} 107\right)$, une très belle tête féminine avec couvre-oreilles $\left(n^{\circ} 110\right)$; pour le calcaire, une tête coiffée du pschent $\left(n^{\circ} 144\right)$, une tête masculine avec un curieux couvre-chef non encore identifié $\left(n^{\circ} 145\right.$; peut-être, selon moi, une tiare perse dont les rabats sont noués sur le front, à la manière caractéristique de certains dignitaires perses : cf. $B C H 112$ [1988], p. 322 et n. 95), une statue fragmentaire d'un type égyptisant, avec devanteau décoré ( ${ }^{\circ}$ 177), l'intéressant chapiteau hathorique d'Amathonte avec un «Maître des 'Pégases' » 
en lieu et place du naïskos ( $\left.n^{\circ} 181\right)$. Notons enfin, parmi les sceaux, l'image d'un « Bès » affrontant un lion ( $\left.n^{\circ} 207\right)$.

S. Brehme, M. BrÖnner, V. Karageorghis, et al., Ancient Cypriot Art in Berlin, Nicosie, 2001.

- Quoique, par nature, issus d'un contexte funéraire, ces reliefs fournissent des indications précieuses sur les croyances des Cypriotes : on y distingue nombre de lions ( $\mathrm{n}^{\circ} 1-11,17-19$, etc.), de sphinx ( $n^{\circ} 12-16$, etc.), hybrides associés à l'arbre de la (sur)vie; des banquets funéraires ( $\left.n^{\circ} 17-35\right)$, des scènes de départ, etc. Ce n'est cependant pas le propos de l'auteur qui traite essentiellement du developpement stylistique et thématique des 124 ouvres étudiées.

El. PogiatZi, Die Grabreliefs auf Zypern. Von der archaischen bis zur römischen Zeit, Mannheim/Möhnesee, 2003.

- Outre ses innombrables travaux spécialisés, Vassos Karageorghis livre, à intervalles réguliers, une synthèse sur l'archéologie cypriote; cette dernière se renouvelle rapidement du fait des nombreuses fouilles dont l'île est le théâtre. Cet ouvrage était attendu et tient toutes ses promesses, tant par la richesse du texte, qui n'élude aucune des discussions récentes, que par la remarquable qualité des illustrations. On y trouvera donc une synthèse des connaissances nouvellement acquises, entre autres, en matière de religion cypriote. Les chapitres concernant l'époque qui va de l'âge du Fer à la fin de l'époque archaïque couvrent les pages 115 à 217.

V. KARAGEORGHIS, Early Cyprus. Crossroads of the Mediterranean, Los Angeles, 2002.

- Dans le premier tophet de Carthage (VIII s.) des figurines en terre cuite et des askoi de type cypriote (p. 91-92; 96-98).

N. Kourou, «Phéniciens, Chypriotes, Eubéens et la fondation de Carthage », CCEC 32 (2002), p. 89-114 (Hommages à Marguerite Yon).

- Étude de plaquettes en or ou en argent, travaillées à l'estampage (p. 199), datant des époques géométrique et archaïque, et trouvées dans les nécropoles d'Amathonte, de Lapéthos et de Palaepaphos. Elles sont la plupart du temps décorées d'un personnage féminin de type oriental, qui se tient les seins. L'auteur admet une hypothèse de R. Laffineur, selon laquelle il s'agirait d'une "parure funéraire liée à une croyance de vie après la mort » (p. 196), qui décorait une couronne ou tiare.

M. Kontomichali, «Les plaquettes métalliques à décor figuré. Origines, iconographie et destination », CCEC 32 (2002), p. 191-208 (Hommages à Marguerite Yon).

- La monographie naguère consacrée à ces cruches à embouchures plastiques (figurines féminines), propres à l'ouest de l'île, est ici complétée par l'évocation d'une quinzaine d'autres exemplaires. La plupart ont été découverts dans des contextes funéraires; mais il est fait mention spéciale de trois fragments découverts dans les remblais du palais d'Amathonte, qui, selon l'A., pourraient être liés «à un culte palatial, car la plupart de ces récipients sont des rbyta et pouvaient servir à des libations » (p. 331-332).

Fr. VANDENABEELE, «Les royaumes de Chypre et les cruches à Cruches à Choéphores », CCEC 32 (2002), p. 327-337 (Hommages à Marguerite Yon).

- Utile énumération de publications récentes, et de monnaies apparues en ventes publiques ou publiées dans des collections publiques ou privées.

M. AMANDRY, «Chronique de numismatique chypriote (II)», CCEC 32 (2002), p. 403-414

(Hommages à Marguerite Yon).

- Étude d'une catégorie particulière de kouroi cypriotes du $\mathrm{vI}^{\mathrm{e}} \mathrm{s}$. av. J.-C., vêtus d'une sorte de caleçon et portant un diadème à rosettes. Ils ont été découverts à Chypre, dans des sanctuaires de divinités masculines, et parfois en dehors de l'île. L'A. propose d'y voir, non des " princes" comme d'aucuns l'avaient suggéré, mais des sacrificateurs.

R. Hurschmann, « Archaisch-kyprische Kouroi mit Hosen », CCEC 33 (2003), p. 169-209. 
11.01 - Athiénou-Malloura - Parmi les trouvailles du sanctuaire en activité de l"époque archaïque à l'époque romaine, une tête féminine avec sakkos, du v $\mathrm{v}^{\mathrm{s}} \mathrm{s}$. av. J.-C., est très similaire aux représentations de la déesse Artémis connues à Chypre, notamment deux œuvres du Louvre provenant précisément de Malloura. Quoique la déesse de Chypre ne soit connue sous son nom qu'à partir de l'époque hellénistique, les sculpteurs insulaires ont adopté l'iconographie d'Artémis dès le début de l'époque classique. Elle présente alors les attributs de la déesse de la fertilité ou ceux de la potnia therôn. Son culte perdurera pendant toute l'époque hellénistique.

D.B. CounTs et M.K. Toumazou, «Artemis at Athienou-Malloura », CCEC 33 (2003), p. 237 251.

11.02 - Golgoi - Voir 11.06 [Amathonte] : HERMARY, «Les ascendances légendaires des rois chypriotes... », CCEC, 32 (2002), p. 275-288 (Hommages à Marguerite Yon).

11.03 - Idalion - Rappel des fouilles britanniques (et autres) sur le site de la ville antique. Evocation de ses sanctuaires et des études récentes qui leur ont été consacrées (p. 244-245); et évocation de plusieurs pièces de sculptures, déjà discutées dans la publication de R. Senff (1993), d'une vaisselle en verre, de quelques bronzes, vases et d'une lampe, aujourd'hui au British Museum. Parmi les œuvres figurées, la plupart d'époques archaïque et classique, on notera un Héraclès (fig. 7), une dame au calathos (fig. 8), une tête d'Apollon du III $^{\mathrm{e}}$ s. (fig. 9).

V. TAtTon-Brown, "The Kingdom of Idalion. Lang's Excavations in the British Museum », CCEC 32 (2002), p. 243-256 (Hommages à Marguerite Yon).

- Étude d'une tête de déesse en marbre coiffée d'un polos en forme de couronne tourelée, conservée au musée de Graz. Sa coiffure présente des analogies avec celles de statuettes anatoliennes de l'âge du Fer, ainsi qu'avec des couronnes tourelées de type achéménide. L'A. conclut qu'il s'agit d'une image de Tyché, datée du deuxième quart du IV ${ }^{e}$ s. av. J.-C. C'est là un type rare à Chypre, sans aucun doute un avatar de la Grande Déesse en tant que souveraine des États-cités et, en particulier, patronne d'Idalion.

C. BEER, «A Head Marble Tyche from Idalion », CCEC 32 (2002), p. 369-385 (Hommages à Marguerite Yon).

11.04 - Achna - Analyse du vêtement représenté sur une figurine d'époque archaïque trouvée dans le sanctuaire d'Achna (est de l'île), et composé de sept éléments. La figurine était dédiée à la déesse d'Achna au cours de rites qui associaient dans leur invocation le mariage, la fertilité, la naissance, et qui étaient pratiqués par des jeunes filles. Se fondant sur certains textes grecs, l'A. voit un aspect chthonien à cette déesse. Discussion aussi des pendentifs et amulettes qu'elle porte sur sa poitrine.

St. Lubsen-AdmiraAl, "The Goddess of Achna: Heptastolos », CCEC 32 (2002), p. 257-274 (Hommages à Marguerite Yon).

11.05 - Kition - Comparaison entre les figurines de terre cuite de Tyr, Sidon et Kition, qui reflèteraient «les préoccupations idéologiques, politiques et territoriales des royaumes de Phénicie et de Chypre» (p. 151).

A. CAubet, « Royaumes de Chypre et royaumes de Phénicie. Le cas des figurines de terre cuite à Sidon, Tyr et Kition », CCEC 32 (2002), p. 147-154 (Hommages à Marguerite Yon).

- L'auteur rappelle que les sanctuaires phéniciens qui se succédèrent du Cypro-Géométrique III à l'époque classique et dont les vestiges ont été découverts lors de fouilles de la colline de Bamboula à Larnaca ne se trouvaient qu'à une altitude allant de deux à cinq mètres au-dessus du niveau de la mer (p. 134). Sur le site de Kathari, les Phéniciens installèrent leurs grands sanctuaires à Astarté/Aphrodite et Melqart/Héraclès sur d'anciens lieux de culte de l'âge du Bronze; tandis qu'à Bamboula ils fondèrent un sanctuaire plus modeste sur un lieu jusqu'alors inoccupé

M. YON, «The Acropolis that never was. A myth to be destroyed », RDAC (2002), p. 127-138.

- Rappel des résultats des deux missions françaises. La découverte des sanctuaires phéniciens de Kition-Bamboula est évoquée (p. 72-73; 77-78). 
M. YON, «Salamine et Kition. Mission française 1964-2004 », CCEC 33 (2003), p. 67-87.

11.06 - Amatbonte - Utilisation vraisemblable de poids dans l'administration des sanctuaires cypriotes, en particulier au sanctuaire d'Aphrodite à Amathonte (spéc. p. 242).

A. Hermary, « Poids d'Amathonte », RDAC (2002), p. 235-244.

- L'A. évoque un fragment de groupe sculpté découvert près du palais d'Amathonte et représentant Phryxos sur le bélier. Celui-ci illustrerait les luttes idéologiques, portant sur leurs ascendances respectives, auxquelles se livraient les rois de l'île à la fin de l'époque archaïque et à l'époque classique. Des conclusions analogues sont tirées d'autres scènes: le décor figuré des trois boucliers d'un Géryon en calcaire de Golgoi, qui montrerait Persée décapitant la Gorgone, Ajax portant le corps d'Achille et un personnage (Héraclès ?) combattant un centaure; une série monétaire de Marion avec Phryxos sur le bélier, motif qui sera remplacé par Europe sur le taureau.

A. HERMARY, «Les ascendances légendaires des rois chypriotes. Quelques messages idéologiques », CCEC 32 (2002), p. 275-288 (Hommages à Marguerite Yon).

- Évocation de plusieurs sanctuaires découverts dans les fouilles du Palais d'Amathonte. L'un d'eux a livré un certain nombre de trouvailles qui permettent de l'attribuer à une divinité féminine, dont une statuette d'un homme portant un masque de taureau, une tête en calcaire coiffée de la mitra, des sphinx-thymiateria, et surtout un cippe/bétyle en forme de Tau renversé. Mise au point également sur l'importance relative des divers lieux de culte connus sur l'acropole de la cité et sur les rapports statistiques des offrandes qui en proviennent; les sanctuaires palatiaux s'y taillent la part du lion.

Th. PETIT, «Sanctuaires palatiaux d'Amathonte (dont un sanctuaire à bétyles) », CCEC 32

(2002), p. 289-326 (Hommages à Marguerite Yon).

- Voir aussi 11.00 [Généralités] : VAndenABEele, "Les royaumes de Chypre et les cruches à Cruches à Choéphores ».

11.07 - Kouklia-Palaepaphos - L'A. propose une synthèse historique sur ce que l'on sait du sanctuaire d'Aphrodite à Palaepaphos. Elle traite notamment des vestiges du grand sanctuaire de l'âge du Bronze, du titre de Wanassa donné à la déesse, du statut sacerdotal du roi, de l'adoption d'une iconographie occidentale sous la forme de la déesse aux bras levés.

J. KARAgEORGHIS, «Royaume et sanctuaire à Palaepaphos », CCEC 32 (2002), p. 155-171 (Hommages à Marguerite Yon).

- Peut-être des indices du sacrifice d'une femme (épouse ?) dans la tombe d'un guerrier de la nécropole de Palaepaphos-Plakes (T. 144), et des signes de l'adoption d'usages égéens.

E. RAPTOU, « Nouveaux témoignages sur Palaepaphos à l'époque géométrique d'après les fouilles de Kouklia-Plakes », CCEC 32 (2002), p. 115-133 (Hommages à Marguerite Yon).

- Discussion des vestiges archéologiques et des trouvailles mobilières du sanctuaire du CyproGéométrique III, sur la colline de Bamboula, près du port de Kition. Deux phases sont distinguées. La première a livré deux autels, dont un monolithe, des idoles aux bras levés. Dans cette première phase, " il s'agissait probablement d'un sanctuaire de la Grande Déesse, en relation avec un culte d'Astarté, venu avec les Phéniciens » (p. 176). La seconde phase voit des agrandissements et la grande pièce est divisée en deux. Elle a livré les mêmes types de figurines féminines, mais le cloisonnement de la pièce principale pourrait indiquer que le culte de Melqart/Héraclès a été adjoint à celui de la Déesse.

Y. CALVET, «La fondation d'un sanctuaire phénicien à Kition-Bamboula », CCEC 32 (2002),

p. 172-183 (Hommages à Marguerite Yon).

- Le Grand temple de Kition-Kathari, reconstruit au $\mathrm{IX}^{e}$ s. sur les ruines du temple de l'âge du Bronze, comporte un curieux aménagement intérieur: dans l'axe longitudinal de la travée centrale subsistent les bases de deux épais piliers peu espacés, entourés d'aménagements secondaires. L'auteur suggère qu'ils constituaient une sorte de naïskos et qu'ils encadraient l'objet 
de culte, peut-être une de ces fameuses «Dames à la fenêtre » bien connues, notamment par des ivoires.

O. CALLOT, « Une 'Dame à la fenêtre' à Kition ? », CCEC 32 (2002), p. 185-190 (Hommages à Marguerite Yon).

11.08 - Pegeia (Paphos) - Des ossements animaux (moutons, chèvres et poulets) découverts à l'intérieur d'une tombe hellénistique (fin $\mathrm{III}^{\mathrm{e}}$ - fin $\mathrm{II}^{\mathrm{e}}$ s. av. J.-C.) de Pegeia attestent l'existence de rites funéraires et illustrent ces pratiques : des groupes d'animaux sacrifiés sont clairement en rapport avec plusieurs loculi. Un squelette d'agneau avait même été déposé sur le sarcophage du loculus 4 (p. 224).

P. CROFT, «Appendix II. Animal Bones from the Hellenistic Tomb at Pegeia », RDAC (2002),

p. $228-233$.

11.09 - Geronisos - Bilan de huit années de fouilles sur l'île, dont le nom indique qu'elle était sacrée. Elle abritait, à l'époque ptolémaïque et romaine, le sanctuaire d'une divinité masculine, sans doute Apollon (p. 249). De nombreux vestiges architecturaux ont été mis au jour : peut-être des propylées (p. 263) et sans doute un temple de même ampleur que le temple d'Aphrodite à Neapaphos (p. 266). Ce temple d'époque romaine incluait une structure d'autel antérieure, d'époque hellénistique (p. 264). Pour le mobilier, on trouve notamment des petits plateaux à offrandes en pierre; de grandes quantités de vaisselle fine témoignent de repas communs pris au sein du sanctuaire; on trouve aussi du matériel pour écorcher les victimes et de nombreux ossements animaux (moutons, chèvres, porcs, vaches et poissons), avec traces de combustion.

J.B. Connelly, «Excavations at Geronisos (1990-1997): First Report », RDAC (2002), p. 245 268.

11.10 - Marion-Arsinoè - Une structure en portique d'époque romaine (II s. ap. J.-C.) évoque un édifice similaire à celui découvert dans le sanctuaire d'Apollon Hylatès à Kourion (p. 144). La suite de la fouille permettra peut-être de déterminer s'il s'agit bien d'un sanctuaire.

T. NajBerjerg, Ch. Nicklies et A. PaPalexandrou, «Princeton University Excavations at Polis/Arsinoe: Preliminary report on the Roman and Medieval Levels », RDAC (2002), p. 139154.

- Voir aussi 11.06 [Amathonte] : HERMARY, « Les ascendances légendaires des rois chypriotes...».

\section{Asie Mineure (partim) (Isabelle TASSIGNON)}

\section{Lycie}

12.01 - Tyberissos - Université de Tübingen - Dans un article tout récent ["Hafen und Hinterland; Wege der Akkulturation an der lykischen Küste: Vorbericht über die Feldforschungen in den zentrallykischen Orten Tyberissos und Timiussa in den Jahren 1999-2001 », MDAI(I) 53 (2003), p. 265-312], M. Zimmermann a exposé les différentes étapes chronologiques de la formation de Tyberissos. En 2002, les travaux de relevés architecturaux se sont poursuivis au temple d'Apollon. Orienté au S, le temple suivait l'orientation habituelle des temples lyciens. Par ailleurs, une approche d'ensemble des sanctuaires locaux de Tyberissos semble montrer que les plus anciens d'entre eux, disposant de séries de niches cultuelles, semblent se rattacher aux temples en bois de la plus ancienne tradition lycienne, les autres s'inspirant des formes architecturales d'époque hellénistique et impériale. Dans la chôra, un grand complexe cultuel comprenant des cavités, de nombreuses niches et des salles rupestres qui communiquaient avec les cavités par des petits puits a été mis au jour. Les fouilleurs proposent d'interpréter ces constructions soit comme un dispositif oraculaire, soit comme le petit sanctuaire d'un culte à mystères. Une présentation générale de cette aire cultuelle à niches rupestres a également été faite par O. Hülden dans l'article cité plus haut. 
M. ZimmermanN, «Feldforschungen auf dem Gebiet der antiken Polis Kyaneai und in Tyberissos sowie Teimiusa ", 20. Araştırma sonuçları toplantısı, 2. cilt, 27-31 Mayıs 2002, Ankara, 2003, p. 23-28 et spéc. p. 27-28.

12.02 - Tlos - Université d'Antalya - Les archéologues ont relevé un ensemble de pierres parmi lesquelles des fragments d'éléments architecturaux appartenant à l'ordre corinthien; il pourrait s'agir d'un temple. Ils proposent un plan des structures visibles, encore difficile à interpréter en l'état.

H. IŞKAN, "Tlos 2001", 20. Araştırma sonuçları toplantısı (supra 12.01), p. 99-112 et spéc. p. 102 , fig. 8 .

\section{Pamphylie}

12.03 - Kaunos - Université d'Antalya - Les fouilles entreprises ces dernières années sur la vaste terrasse qui se trouve au $\mathrm{N}$ de la stoa du Port ont mis au jour un temple dédié à Basileus Kaunios, fondateur et grand dieu de la ville, identifié à l'époque hellénistique avec Apollon. Mais une autre divinité semble aussi avoir été honorée dans un sanctuaire situé entre "l'édifice à banquettes » et l'espace sacré d'Aphrodite Euploia. Au centre d'un grand temenos de 8,70 × 12,35 $\mathrm{m}$, une zone rectangulaire où le rocher a été laissé à l'état brut se démarque du reste de la construction. La pente naturelle du rocher a été approfondie et une niche centrale a été aménagée dans la paroi $O$. Le type d'accès et sa situation sont encore incertains. Tous ces éléments suggèrent que la pièce devait être l'adyton d'un lieu de culte souterrain. Les A. rapprochent cet édifice de ceux du culte de la Grande Mère anatolienne. Il leur paraît cependant douteux que cette divinité puisse être ici la Grande Mère, mais plutôt une Artémis locale, plus précisément une forme de Cybèle.

Dans l'aire anatolienne, de semblables cellae rupestres sont connues dès le XIv $\mathrm{s}$. Deux éléments archéologiques provenant du temenos invitent les auteurs à formuler l'hypothèse que Kaunos était un centre important du culte de Cybèle. Il y a tout d'abord une grande base de statue dont le lit d'attente montre des traces d'encastrement d'un trône et d'un animal couché ou assis. Les A. pensent à une Cybèle accompagnée d'un lion; il y a ensuite une statuette de calcaire trouvée dans la salle de culte. Il s'agit en réalité d'un petit pilier dont seul l'arrière est sculpté et qui comporte comme élément anthropomorphique unique une tête ornée d'une couronne tourelée et d'un collier, alors que la partie inférieure, raccourcie, comporte des traces en haut-relief d'un scorpion, d'un cerf (?), d'une grenouille (?), de Nikè, d'un buste d'Hélios. Le type évoque celui d'Artémis, telle qu'elle est connue à Éphèse et à Perge, et qui pourrait être ici l'Artémis Kaunienne; cette statuette devait prendre place dans la niche de la salle de culte souterraine. Cet article, qui présente du matériel archéologique intéressant, se déforce cependant par son défaut d'étude sérieuse des syncrétismes possibles entre Cybèle et Artémis.

C. IȘIK, «Kaunos’ta (Kbid) bir kült mahzen -fakat kimin için ?-, Anadolu/Anatolia 25 (2003), p. 53-69; C. IŞıK, « Kaunos 2001 yıllı çalışmaları », 24. Kazı sonuçları toplantısı, 2. cilt, 27-31 Mayls 2002, Ankara, 2003, p. 219-225.

\section{Cilicie}

12.04 - Olba/Diokaisareia - Université de Mersin - Des prospections archéologiques se sont déroulées autour de la zone sacrée du sanctuaire de Zeus Olbios à Diokaisareia. De nouvelles tombes rupestres dont l'entrée affecte la forme d'une façade de temple ont été repérées; une tombe monumentale construite (et non rupestre), imitant un temple prostyle, décoré de colonnes corinthiennes, a également fait l'objet d'un relevé.

E. ERTEN, «Olba (Uğuralani) 2001 Yüzey araştırması », 20. Araștırma sonuçları toplantısı (supra 12.01), p. 185-196 et spéc. p. 188 et fig. 10-12. 


\section{Pisidie}

12.05 - Pednelissos - Université de Cologne - Les premiers travaux accomplis à Pednelissos ont permis de repérer les vestiges du temenos d'un temple situé en partie sous la tour S de la localité. Un relief votif, orné d'un dieu tenant un bâton surmonté d'un rameau d'olivier, a été identifié par les archéologues comme une représentation d'Apollon et daté de la seconde moitié du I ${ }^{\text {er }}$ siècle av. J.-C.

L. VAndePute, V. KÖSE, "Pisidien Survey Project: erste Kampagne in Pednelissos », 20. Araştırma sonuçları toplantısı (supra 12.01), p. 315-319 et spéc. p. 319 et fig. 11.

12.06 - Sagalassos - Université de Louvain (KUL) - On signale la découverte, au cours d'une campagne de prospection dans la zone suburbaine de Sagalassos, d'un petit autel en pierre de plan circulaire.

M. WAELKENS et al., "The 2001 survey season at Sagalassos and in its territory », 20 . Araştırma sonuçları toplantısı (supra 12.01), p. 329-343 et spéc. p. 338 et fig. 13.

\section{Carie}

12.07 - Iasos (Golfe de Mandalya, Çirkince Tepe) - Université de Naples - Un sanctuaire de type indigène, situé dans la chôra de Iasos, sur le versant S-E de Çirkince Tepe, a été repéré au cours d'une vaste campagne de prospection. La situation de ce sanctuaire, sur une point stratégique qui domine toute la vallée, est frappante et présente des similitudes avec celui de Çanagik Tepe, dans la même région. De nombreux fragments de statuettes de terre cuite ont été ramassés; une statuette de femme au polos, datée du VI siècle, et un fragment de bol mégarien plaideraient pour une occupation longue, allant de l'époque archaïque jusqu'à la période hellénistique. Le plan de ce sanctuaire, étranger à la tradition classique, suggère un culte rendu à une divinité indigène.

R. Pierobon Benoit, «Survey of the Mandalya Gulf Report on the 2000 and 2001 Cam-

paigns », 20. Araştırma sonuçları toplantısı (supra 12.01), p. 335-348, et spéc. 339-340.

12.08 - Cnide - Université de Konya - Les vérifications entreprises dans le "sanctuaire des Muses ", déjà repéré et décrit par C. Newton au milieu du XIX siècle, avaient pour objectif de mieux cerner le contexte archéologique des trouvailles faites par l'archéologue anglais (aujourd'hui conservées au British Museum). La mise au jour de couches intactes contenant beaucoup de céramique a permis à I. Jenkins de dater la fondation du sanctuaire de la fin du IV siècle av. J.-C. ou du début du III'; cette date est confortée par la comparaison de l'appareil de maçonnerie avec ceux d'autres bâtiments de Cnide. Par ailleurs, de nouvelles investigations au sanctuaire de Déméter rendront bientôt possible d'en proposer un plan définitif.

R. ÖZgan et al., « 2001 Knidos Kazıları », 24. Kazı sonuçları toplantısı (supra 12.03), p. 359371, et spéc. 362-364 et fig. 1-2.

12.09 - Pedasa (Halicarnasse) - Université de Muğla - Un grand temple a été repéré au cours d'une vaste prospection à Pedasa et sur son territoire. Des terres cuites fragmentaires de la fin de l'époque archaïque (notamment de femmes au polos) et du début de l'époque classique, venant probablement d'un bothros, ont été répertoriées.

A. DİLER, «Damlıboğaz/Hydai ve Leleg Yarımadası araştırmaları 2001 », 20. Araştırma sonuçlar toplantısı (supra 12.01), p. 11-22, et spéc. 14-15 et fig. 7-8.

\section{Ionie}

12.10 - Claros - Université d'Izmir - Dans le secteur de l'autel d'Artémis, les fouilles de 2001, reprenant la plupart du temps des zones ouvertes en 1995-1997, ont mis au jour plusieurs statuettes en terre cuite datées du début de l'époque hellénistique : Aphrodite, Éros, Apollon à la lyre, ainsi que des vestiges d'hécatombes. Les fouilleurs signalent aussi l'étude des quelque 800 fragments d'œenochoés et de temple-boys trouvés dans une couche archaïque en 1995.

N. ŞAHIN et al., «Klaros 2001 », 24. Kazı sonuçları toplantısı (supra 12.03), p. 81-90. 
12.11 - Phocée - Université d'Izmir - On signalera la parution d'une étude sur les sanctuaires de Phocée, suite à la reprise par Ö. Özyigit des fouilles jadis menées par E. Akurgal. Ainsi l'orientation et les dimensions du temple archä̈que d'Athéna ont pu être déterminées. Près du Port Sud de la ville antique, à proximité d'une nécropole, deux autels archaïques ont été mis au jour. Situés en dehors des murs de la ville, ils semblent indépendants de tout temple. Leurs gros blocs rectangulaires en calcaire rappellent ceux des fortifications datées de 590-580 av. J.-C. ainsi que l'appareil du temple d'Athéna. Enfin on trouve dans cet article une présentation des cinq sanctuaires dédiés à Cybèle à Phocée et aux alentours : il semble que son culte se soit pratiqué non dans un temple, mais conformément à la tradition phrygienne, autour de niches rupestres.

Ö. ÖZyígit, A. ERDOgan, «Les sanctuaires de Phocée à la lumière des dernières fouilles », Études massaliètes 6 (2000), p. 11-23; Ö. ÖzYIGiT, « 2000-2001 yılları Phokaia kazı çalışmalar1 », 24. Kazı sonuçları toplantısı (supra 12.03), p. 333-349

\section{Grande Grèce (Massimo OSANNA et Ilaria BATTILORO)}

13.01 - Caulonia - Soprintendenza archeologica della Calabria et Scuola Normale Superiore di Pisa - Un volume récent consacré à l'antique Caulonia trace le bilan des investigations menées par la surintendance de Calabre sur le territoire, comprenant une confrontation avec le résultat des fouilles antérieures. Les recherches sur le site du temple dorique découvert par P. Orsi ont été effectuées en 1998 en collaboration avec la Scuola Normale Superiore di Pisa. La contribution de M.T. Iannelli, centrée sur les campagnes de fouilles de 1912-1913, propose une relecture de quelques passages des carnets 86 et 88 de P. Orsi (déjà publiés dans le volume XXIII [1914] des Monumenti antichi de l'Accademia dei Lincei), relatifs aux investigations menées à l'entour du temple et dans le "predio Delfino", afin de récupérer des données sur la provenance d'un matériel archéologique pour lequel on manque d'une documentation adéquate. [I.B.]

M.T. IANNELL, "Le campagne di scavo al tempio dorico di Caulonia attraverso i taccuini nn. 86 e 88 di Paolo Orsi e gli atti d'archivio della Soprintendenza ai Beni Archeologici della Calabria », in M.C. PARRA (éd.), Kaulonía, Caulonia, Stilida (e oltre). Nuovi contributi storici, archeologici e topografici, Pisa, 2003 (Quaderni ASNP, 11), p. 163-218.

- Dans le même volume, M.C. Parra présente les principaux résultats des investigations menées dans le sanctuaire de Punta Stilo depuis 1999, qui ont confirmé le caractère sacré de l'endroit à l'époque archaïque (comme l'atteste, entre autre, un deinos orientalisant considéré comme offrande votive : $c f$. dans le même volume, I. CAVAzzuTI, «Ceramica arcaica fine dal santuario di Punta Stilo», p. 249-278). Les investigations se sont concentrées autour du stéréobate du temple dorique mis au jour par P. Orsi ( $c f$. F. BARRELlo, Architettura greca a Caulonia. Edilizia monumentale e decorazione architettonica in una città della Magna Grecia, Firenze, 1995), dans un secteur où sont encore visibles quelques structures à insérer - selon l'A. - dans une vaste réorganisation de l'endroit en rapport avec la construction du temple dorique. Afin de comprendre la dynamique cultuelle du sanctuaire, les données émanant du site fouillé au S-E du temple sont intéressantes: une caisse de tuiles plantées en terre (pour des pratiques rituelles de type chthonien ?) en relation avec lesquelles ont été déposées de petites lames en bronze décorées en saillie (probablement des décorations de boucliers) et des armes. De nombreux éléments d'architecture et de sculpture ont été récupérés dans le niveau de destruction du temple. Dans le secteur au $\mathrm{N}$ du temple, à proximité des trois puits déjà mis au jour par P. Orsi, a été dégagée une vasque quadrangulaire recouverte de tuiles avec, au centre, le fond d'une amphore, évidemment destinée à des rituels en relation avec l'eau (sur la céramique mise au jour sur le site, $c f$. dans le même volume, V. GaGLiardi, "Ceramica a vernice nera dal santuario di Punta Stilo: contributi all'analisi delle produzioni », p. 279-318). Il est difficile de préciser l'identité de la divinité vénérée dans le sanctuaire. À Héra, peut-être en sa qualité d'Hoplosmia, on pourrait attribuer la dédicace d'armes; à Apollon Pythien, présent aussi sur les incuses cauloniates, pourraient faire référence des fragments de sculpture avec des anneaux de serpents. À Artémis, enfin, pourrait correspondre l'usage rituel des eaux (rites de passage ?). Aucune hypothèse 
explicite n'est donnée pour expliquer la fonction de l'espace défini par l'escalier monumental, qui a été interprété comme un espace destiné aux assemblées de la Ligue achéenne, dans le cadre du culte de Zeus Homarios [cf. M. Osanna, «Sull'ubicazione del tempio di Zeus Homarios in Magna Grecia », DArch (1989), p. 55-63]. [I.B.]

M.C. PARRA, «Con Paolo Orsi, ed altri, nel santuario di Punta Stilo. Campagne di scavo 19992001 », in M.C. PARRA, Kaulonia (supra), p. 219-248.

13.02 - Herakleia - Università degli studi di Perugia et Soprintendenza per i Beni archeologici della Basilicata - Présentation des investigations menées dans le sanctuaire héracléote de Déméter, coordonnées par Brinna Otto de l'Université d'Innsburck. En 2002, elles se sont concentrées sur les secteurs $\mathrm{N}$ et $\mathrm{O}$ de la zone. À l'O, on a identifié des restes de murs délimitant les espaces appartenant au sanctuaire, tandis qu'au $\mathrm{N}$, il faut souligner la découverte d'une vasque à associer à une activité rituelle. [I.B.]

M.L. NAVA, «Attività archeologica in Basilicata », Atti del XLII Convegno di studi della Magna Grecia (Taranto settembre-ottobre 2002), Taranto, 2003, p. 663-664.

- Institut archéologique de l'Université d'Innsbruck - Présentation d'une synthèse des résultats des dernières campagnes de fouilles menées au sanctuaire de Siris-Herakleia, dont surgit une meilleure vision de la nature du culte pratiqué, que ce soit dans la phase siriote ou héracléote du lieu sacré. Les rituels attestés dans le sanctuaire siriote (sacrifices avec feu sur eschara, repas rituels consommés sur place, libations réalisées directement sur le sol avec des entonnoirs), autant que l'iconographie récurrente sur la coroplastie votive (figures féminines trônant et enfants debout), renvoient à une culte de type chthonien, comme le confirme, d'autre part, l'évocation explicite à Gè griffonnée sur une kylix archaïque. Les mêmes rituels se retrouvent dans le sanctuaire à la phase liée à Herakleia, lorsque le lieu sacré est incontestablement dédié à Déméter. L'A. souligne que les libations pratiquées directement sur le sol et surtout, dans l'iconographie des ex-voto en terre cuite, l'attribut de la torche en croix - variante de la torche éleusinienne - autorisent à identifier Déméter en tant que divinité des mystères éleusiniens, liée au monde l'au-delà et protectrice des défunts en tant que mère de Perséphone (avec laquelle elle est souvent représentée aussi à Herakleia). Cette divinité revêt un important rôle politique pour la cité, alors qu'Herakleia est devenue capitale de la Ligue italiote en 374 av. J.-C., comme l'attestent - entre autres - quelques dédicaces de citoyens politiquement influents inscrites sur des vases, ainsi que la présence du symbole de la torche en croix sur les monnaies en bronze d'Herakleia. On ne peut exclure l'hypothèse que ce sanctuaire ait été utilisé comme siège des réunions de la Ligue, comme l'avait déjà affirmé, mais sans éléments probants, K. LOMAS, Rome and the Western Greeks. 350 BC ad 200, London, 1993. [I.B.]

B. Отто, «Il santuario sorgivo di Siris-Herakleia nell'odierno Comune di Policoro », in LO spazio del rito. Santuari e culti in Italia meridionale tra Indigeni e Greci. Atti del Convegno di Studi, Matera 28 e 29 giugno 2002, Bari, 2005, p. 5-18.

13.03 - Métaponte - - Soprintendenza per i Beni archeologici della Basilicata - Dans une brève synthèse des résultats d'une étude sur les terres cuites votives et les cultes du sanctuaire urbain de Métaponte à l'époque archä̈que, on peut relever l'iconographie la plus significative : figures féminines avec oiseaux, avec stephanè et les mains placées sur le ventre, avec animal, avec bouton de rose. Bien que l'on puisse isoler des emplacements caractérisés par une grande quantité de matériel votif (la zone du petit sanctuaire, construction qui a précédé celle du temple C), il n'est pas possible d'associer des exemplaires typologiquement liés à des lieux de culte spécifique. Derrière les iconographies attestées, qui pourraient renvoyer à toutes les divinités présentes dans le sanctuaire - Héra, Artémis et Athéna - semble se profiler une divinité conçue comme Potnia Therôn, qui se rapporte à la sphère féminine et en particulier au domaine du mariage et de la naissance. Les statuettes mises au jour dans la zone du temple B, interprété comme temple d'Apollon, renvoient aussi à une divinité féminine [A. DE SIENA, «Metaponto: problemi urbanistici e scoperte recenti ", in Siritide e Metapontino. Storie di due territori coloniali. Atti dell'incontro di studio (Policoro 1991), Napoli/Paestum, 1998, p. 163 sq.] : l'A. fait l'hypothèse que la divinité féminine pourrait avoir été honorée en qualité de «divinité hôte » du sanctuaire 
(peut-être Artémis, sœur d'Apollon), un phénomène attesté dans d'autres lieux sacrés du monde grec et de Grande Grèce. (I.B.)

V. BARBERIS, «Terrecotte votive e culti nel santuario urbano di Metaponto: l'età arcaica e severa ", in Lo spazio del rito (supra 13.02), p. 55-67.

- Synthèse du matériel votif des périodes classique et hellénistique provenant du même espace sacré de Métaponte. Les terres cuites mises au jour renvoient d'une part à la sphère de Déméter, de l'autre à celle d'Artémis Bendis. Ces deux groupes d'ex-voto proviennent des mêmes contextes de trouvailles, tout particulièrement concentrés dans la partie voisine des temples $\mathrm{C}$ et $\mathrm{D}$, une donnée spatiale qui confirme l'hypothèse récemment avancée par A. De Siena que le temple ionique D serait un Artémision ("Metaponto: problemi urbanistici e scoperte recenti », in Siritide e Metapontino - Storie di due territori coloniali, Napoli, 1998 [Cabiers CJB, 20], p. 141-170; id., "La colonizzazione achea del metapontino», in G. DE RosA, A. CESTARO, Storia della BasilicataL'antichità, Bari, 1999, p. 211-246). Il s'agit de l'association de deux divinités bien attestée dans le monde grec et en Grande Grèce, que l'A. explique par la fonction commune d'Artémis et de Déméter comme divinités de la fertilité et de la végétation, héritée de l'antique Potnia de tradition archaïque. [I.B.]

E. CAlabria, «Coroplastica votiva dal Santuario urbano di Metaponto: nuove attestazioni di

culto di età classica ed ellenistica ", in Lo spazio del rito (supra 13.02), p. 69-82.

- Mise en perspective de l'iconographie de quelques antéfixes de Métaponte, afin d'en tirer des informations sur les cultes et les mythes de la colonie achéenne. Il faut souligner tout particulièrement la présence de deux types d'antéfixes, un avec protomé d'Io, une typologie largement attestée en Grande Grèce, l'autre à l'image de Dionysos, un type seulement connu à Métaponte. L'iconographie d'Io - dont le mythe qui en faisait la prêtresse d'Héra et l'ancêtre de Danaos était certainement connu des colons achéens de Métaponte -, répondait à un programme idéologique qui voyait la reprise des cultes de la plus antique tradition achéenne de la colonie (et des mythes afférents), réinterprétés en termes de propagande de la part des élites aristocratiques. Les antéfixes à protomé de Dionysos, encadrées de deux griffons ailés, font référence au culte de Sabazios, le Dionysos thraco-phrygien, fils de Zeus et de Perséphone, des divinités fortement liées à l'orphisme. Cette iconographie insolite pourrait refléter la nouvelle religiosité de type eschatologique diffusée en Grande-Grèce aux $\mathrm{IV}^{\mathrm{e}}$ et $\mathrm{III}^{\mathrm{e}} \mathrm{s}$. av. J.-C., en réponse à un climat d'instabilité politique et sociale généralisé. [I.B.]

A.L. Tempesta, «Attestazioni del mito di Io e del culto di Dioniso a Metaponto: alcune considerazioni », in Lo spazio del rito (supra 13.02), p. 83-90.

13.04 - Sybaris - Institut d'archéologie de l'Université de Groningen - Cette brève monographie livre une synthèse des données relatives aux investigations de l'espace sacré de Francavilla Marittima, sur le territoire de Sybaris, conduites par l'Université de Groningen. La présentation des nouvelles données est précédée d’une discussion des recherches antérieures, tant dans l'établissement énotrien que dans le sanctuaire grec (sur lequel M. KLEIBRINK MaASKANT, "Cenni nuovi sull'aristocrazia enotria a Francavilla Marittima: evidenze dalle Tombe di Macchiabate e dagli edifici di Timpone della Motta », in Emergenze ambientali di carattere culturale (Francavilla Marittima, 9-10 settembre 2000), Trebisacce, 2000, p. 11-25). Concernant les investigations au sommet du Timpone della Motta, dans l'espace du sanctuaire, les recherches entreprises en 1991 et toujours en cours ont permis de récupérer un matériel très riche, renvoyant autant au culte pratiqué et à la structure à laquelle il s'articulait, qu'à la présence indigène antérieure. Sur la base de la lecture parallèle des données anciennes ( $c f$. S. LuPpino et alii, "Il santuario del Timpone della Motta di Francavilla Marittima: nuove prospettive di ricerca dall'analisi dei vecchi scavi ", in Depositi votivi e culti dell'Italia antica dal periodo arcaico a quello tardo-repubblicano (Atti del Convegno di Perugia, giugno 2000, in c.d.s.) et nouvelles, on analyse l'organisation du sanctuaire entre les VIII $^{e}$ et $\mathrm{VII}^{\mathrm{e}}$ s. av. J.-C., lorsque l'acropole naturelle devait compter trois structures de temple en bois qui ont succédé à trois maisons en bois d'un segment relevant de la société énotrienne pré-coloniale (dans l'une d'entre elle, appelée «casa delle tessitrici », l'A. fait l'hypothèse - sans argument probant - de rites célébrés autour d'un foyer et destinés à une 
déesse du tissage enotrienne, à laquelle aurait succédé l'Athéna grecque). Les dynamiques rituelles qui mettent en scène Athéna dans le sanctuaire grec doivent donc renvoyer à une déesse Erganè, liée à la laine et au tissage, et, à en juger par la grande quantité d'hydries mises au jour, à l'offrande d'eau, qui devait être au centre du culte. L'accomplissement d'actes rituels à l'intérieur de cet espace est documenté par le dépôt d'une grande quantité d'objets manufacturés en des lieux particulièrement significatifs (à l'intérieur du périmètre des temples et du mur d'enceinte du sanctuaire) qui associent de nombreuses bydriskai à des coupes et des coupes miniatures qui renvoient à l'offrande d'eau à la déesse. La troisième partie, moins convaincante, discute les sources littéraires et les mythes qui permettraient d'identifier cette implantation avec l'antique Lagaria, attestée par Strabon au nord de Thourioi. C'est dans l'Athénaion du lieu qu'Épeios aurait déposé les instruments utilisé pour la construction du cheval de Troie. Les sources relatives à ce lieu et au mythe d'Épeios [ $c f$. M. OsanNA, "Strabone VI, 263 e l'ubicazione di Lagaria », AnnPerugia 39 n.s. 10 (1986/87), p. 171-184] ne permettent pas une telle identification. [M.O.]

M. KLEIBRINK MAASKANT, Dalla Lana all'acqua. Culto e identità nell'Athenaion di Lagaria, Francavilla Marittima, Rossano, 2003.

- L'étude de l'A. sur les objets votifs en métal du sanctuaire de Francavilla Marittima s'inscrit dans un projet d'étude et de publication de l'importante quantité de matériel archéologique provenant de fouilles clandestines effectuées dans le cadre du sanctuaire sybarite, recueilli dans les collections de l'Institut d'archéologie classique de l'Université de Berne et du Département des antiquités du J.Paul Getty Museum de Malibu, et ensuite restitué par les autorités suisses et américaines au Museo Nazionale Archeologico della Sibaritide. L'étude comprend deux parties. La première partie s'ouvre sur une présentation du site de Timpone della Motta et rappelle, sous forme de synthèse, les campagnes de fouille qui ont été conduites, depuis les investigations commencées en 1963 par la Soprintendenza Archeologica della Calabria et reprises en 1982 avec la collaboration de l'Istituto Archeologico Germanico di Roma, jusqu'aux campagnes entreprises en 1991 par Marianne Kleibrink de l'Université de Groningen. Au matériel provenant de ces explorations sont systématiquement confrontés les objets examinés par l'A., afin d'en reconstituer le contexte de provenance et la fonction originelle. Ensuite vient le catalogue détaillé du matériel examiné - 517 objets en or, argent, bronze, plomb et fer - avec une introduction pour chaque catégorie distinguée. Les objets en bronze sont majoritaires, constitués surtout d'une grande quantité de récipients, armes, fragments ou parties d'armement, objets ornementaux, instruments de musique, rameaux votifs. L'arc chronologique des objets manufacturés va de la fin du vII à la totalité du $\mathrm{vI}^{\mathrm{e}}$ s. av. J.-C., à l'exception de quelques objets qui datent de l'âge du Fer ou d'une période postérieure à la destruction de Sybaris. Une partie du matériel appartient à une tradition indigène, d'autres objets sont assurément grecs, d'autres encore semblent importés. Dans la plupart des cas, une attribution sur base stylistique est difficile et il pourrait s'agir d'objets spécifiquement locaux. La difficulté tient aux multiples influences culturelles auxquelles fut soumis le territoire de Sybaris, tant grecques (achéennes, corinthiennes, laconiennes, argiennes, gréco-orientales, etc.) que phéniciennes. À la lumière de ces constats, l'A. définit comme «hybrides » tant la nature du site de Francavilla que le culte qui y était pratiqué, renvoyant à la notion d'hybridation définie par H. BнавHA ("The Other Question: Stereotype, Discrimination and the Discourse of Colonialism », in H. BHABHA, The location of Culture, London, 1992 [1994], p. 66-184). Cette notion définit le matériel que l'on ne peut qualifier ni de grec, ni de proprement indigène en le qualifiant de "South Italian». La seconde partie du volume est consacrée aux analyses métallographiques effectuées sur les trouvailles, coordonnées par David Scott des Museum Services Laboratory de la Getty Conservation Institution. [I.B.]

J.K. PAPADOPOUlos, La dea di Sibari e il santuario ritrovato. Studi sui rinvenimenti dal Timpone Motta di Francavilla Marittima. II.1, The archaic votive metal objects, Rome, 2003 (BdA, vol. special).

13.05 - Poseidonia - Università degli Studi di Perugia, University of Michigan - Presque dix ans après la parution du premier volume consacré au sanctuaire hors-les-murs de S. Venera à Paestum (J.G. PeDley, M. TORELli, The Sanctuary of Santa Venera at Paestum I, Roma 1993) parait le deuxième volume, qui traite des terres cuites votives mises au jour dans le sanctuaire à partir 
des fouilles des années 1950, jusqu'aux investigations reprises par les Universités de Pérouse et de Michigan en 1980. L'A. introduit son étude en passant systématiquement en revue les phases d'existence du sanctuaire, depuis les maigres vestiges d'architecture dorique du vi $\mathrm{s}$. av. J.-C. en passant par la première articulation des espaces sacrés un peu mieux documentée (oikos, salle rectangulaire, édifice méridional), jusqu'aux modifications substantielles apportées au sanctuaire lors de la fondation de la colonie latine de Paestum en 273 av. J.-C. S'ensuivit la grande extension du sanctuaire datée de l'époque républicaine et des débuts de l'empire, qui ne connut pas de solution de continuité jusqu'au III $^{\mathrm{e}}$ s. ap. J.-C., en dépit des dommages dus à l'éruption du Vésuve de 79. Pour le culte pratiqué dans le sanctuaire à la période romaine, lorsqu'est attesté le culte de Vénus, les témoignages épigraphiques sont nombreux. Par contre, aucune source écrite ne permet l'identification de la divinité patronne du sanctuaire à la période grecque. Les seuls instruments permettant de renouer le fil de l'histoire cultuelle et rituelle du sanctuaire sont les 4800 terres cuites votives mises au jour par les fouilles. Ce richissime corpus d'objets votifs est soigneusement analysé et les mould series sont identifiées afin de fixer la chronologie relative des exemplaires : des statuettes archaïques de figures féminines nues aux statuettes de déesse trônant majoritaires à la période classique; des figures féminines habillées de la période hellénistique aux statuettes contemporaines qui reproduisent des divinités spécifiques, et en particulier Éros et Aphrodite, et aux ex-voto anatomiques d'époque romaine, lorsque la dédicace d'ex-voto en terre cuite commença à devenir obsolète à $\mathrm{S}$. Venera, bien que le sanctuaire ait été actif jusqu'à la fin du III $^{e}$ s. ap. J.-C. Sur la base des données tirées de l'analyse des terres cuites de S. Venera, il est possible de parcourir les lignes fondamentales de l'industrie coroplastique pestane ( $c f$. M. CIPRIANI, «Le produzioni artistiche e artigianali », in F. ZEVI (ed.), Paestum, Napoli, 1990, p. 105125; ead., "Poseidonia tra VI e IV secolo a.C.: La coroplastica votiva », in E. LIPPOLIs (ed.), Arte e artigianato in magna Grecia. I Greci in Occidente, Napoli, 1996, p. 206-215), depuis les premières influences achéenes et ioniennes de la période archaïque, en passant par le développement d'un style particulier et original vers la fin du vi s. av. J.-C. jusqu'à la période classique où émergent les productions plus originales de la coroplastie pestane, et au floruit à la période lucanienne. La période suivante va jusqu'à l'époque hellénistique (qui voit l'introduction dans les ateliers pestans d'une série de sujets appartenant à la koinè hellénistique), puis c'est la «décadence » de la période tardo-républicaine et du début de la période impériale. À la lumière des données établies par l'étude typologique et stylistique des statuettes, l'A. s'interroge enfin sur les informations qu'il est possible d'en tirer pour le culte pratiqué dans le sanctuaire de S. Venera. En prenant seulement en compte les iconographies qui, bien que numériquement non pertinentes, présentent des aspects particuliers qu'il est possible d'associer à une divinité précise et à des cultes, l'A. conclut que les plus anciens colons de Poseidonia doivent avoir dédié le sanctuaire extra-urbain de S. Venera au culte d'Aphrodite, qui ne semble pas avoir connu de solution de continuité jusqu'à la fin de la période romaine. [I.B.]

R. Miller Ammermann, The Sanctuary of Santa Venera at Paestum II, Ann Arbor, 2002.

- Présentation des résultats préliminaires de la révision des données de fouille et de l'analyse quantitative des trouvailles mises au jour dans l'aire sacrée de Capodifiume. Il s'agit de tirer des conclusions nouvelles sur le culte et le rituel qui y étaient pratiqués. Le matériel s'inscrit dans un

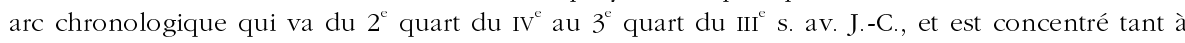
l'extérieur de l'édifice qu'à l'intérieur de l'une des pièces identifiées. Il ressort de l'examen des formes céramiques et de leur distribution que les vases majoritairement représentés (petits récipients, vases à onguents et pyxides) étaient destinés à être offerts à la divinité, mais la grande quantité de vaisselle retrouvée devait être fonctionnelle pour des rituels bien connus qui impliquaient la préparation et la consommation de repas. Bien que moins bien représentés, les ex-voto en terre cuite contribuent à définir le culte pratiqué dans le sanctuaire : il s'agit surtout de représentations féminines qui comptent, dans une première phase (IV ${ }^{e}-$ début III $\mathrm{e}$. av. J.-C.), des bustes, des têtes, des statuettes; dans une deuxième phase (à partir du début III $^{e}$ s.), des têtes de facture hellénistique et des erotes. À la lumière de ces données, on peut conclure que le culte pratiqué à Capodifiume était destiné à une déesse. Quant à la détermination de son identité, il semble que le début du $\mathrm{III}^{\mathrm{e}} \mathrm{s}$. constitue une césure qui reflète des transformations cultuelles : dans la première phase prévalent des bustes féminins qui rappellent ceux de tradition siciliote en face 
de dynamiques cultuelles qui renvoient au culte de Korè; dans la deuxième phase, lorsque, avec la disparition des bustes, deviennent prépondérantes les figures habillées et les erotes, on perçoit des modèles propres à la communauté italique. Vient appuyer cette hypothèse la découverte d'un trépied datable de la fin du IV ${ }^{e}$ s. av. J.-C., dont la décoration associe les images d'Athéna avec le casque phrygien, Héraclès, des hermaphrodites et une scène d'anodos qui renvoie au culte de Korè. Dans cette décoration, l'A. voit un véritable programme idéologique : l'association des images «manifesta la rifunzionalizzazione di un culto di tradizione greca nel quadro di rinnovate esigenze cultuali rispondenti a modelli propri delle comunità italiche ». [I.B.]

A. Serritella, «Poseidonia: l'area sacra di Capodifiume », in Lo spazio del rito (supra 13.02), p. $19-26$.

13.06 - Tarente - Dans sa communication, E. Lippolis propose une série d'observations sur la pratique rituelle attestée à Tarante, dans le cadre d'une étude plus large réservée à l'analyse des contextes archéologiques du matériel votif. L'A. s'attache tout particulièrement aux dépôts de matériel votif dispersé après la fragmentation rituelle dans la région extra-urbaine de Tarante, en mettant ce type de dépôt en relation avec des cérémonies liées à des rites de passage vers la condition de défunt. Il énonce une série de principes méthodologiques, parmi lesquels il souligne combien l'association de différents sujets à l'intérieur d'une même fosse reflète la logique interne de l'action rituelle et constitue une donnée très importante pour sa reconstitution. À ces observations générales s'ajoute, à titre d'exemple, l'analyse d'un sujet coroplastique bien connu dans la région tarentine, l'Artémis Bendis, dont l'A. propose une révision complète de la bibliographie existante. Les terres cuites italiotes d'Artémis Bendis témoigneraient, d'un côté, de la participation des fidèles aux rites de passages, mais pourraient, de l'autre, revêtir également un rôle dans des rituels funéraires (en association avec les typologies des personnages couchés et des personnages faisant le geste de l'offrande, où la statuette deviendrait l'image du défunt luimême). [I.B.]

E. LipPolis, «Pratica rituale e coroplastica votiva a Taranto », in Lo spazio del rito (supra 13.02), p. $91-102$

\section{Sicile (Nicola CUCUZZA)}

\subsection{0 - Généralités}

Présentation d'une étude d'ensemble sur le type coroplastique dit « de l'Athéna Lindia » ou de la «statuettes aux parures » (selon M. Dewailly). Les exemplaires connus sont catalogués par type et l'iconographie, la chronologie et le contexte de mise au jour en sont discutés. L'A. identifie avec l'Agrigente du $\mathrm{VI}^{\mathrm{e}}$ s. av. J.-C. le centre dont émane le type coroplastique qui se retrouve quasi exclusivement en Sicile jusqu'à la fin du v vo av. J.-C. Elle exclut l'identification traditionnelle du type avec Athéna Lindia, proposée par Blinkenberg : elle souligne plutôt le caractère générique de la statuette, ce qui en explique la diffusion en contexte funéraire, en plus des sanctuaires qui semblent voués à des divinités chthoniennes. La faible circulation du type à l'extérieur de la Sicile et la diffusion dans les colonies et centres indigènes, surtout dans la région centrale du $\mathrm{S}$ de la Sicile (en particulier Agrigente, Géla, Sélinonte, Heloros) sont expliquées selon l'hypothèse que les statuettes auraient reproduit la statue de culte d'une divinité protectrice de la fertilité agraire et humaine.

M. ALBERTOCCHI, Athana Lindia. Le statuette siceliote con pettorali di età arcaica e classica, Roma, 2004 (Suppl. Rivista di Archeologia, 28)

- Proposition d'une typologie des autels puniques retrouvés sur les sites de Sélinonte, Solonte et le mont Adranone : des autels en forme de parallélépipède, en forme de parallélépipède avec des bords verticaux et autels à trois bétyles.

F. SPAGNOLI, "Altari punici dei santuari della Sicilia occidentale», Sicilia Archeologica 36 (2003), p. 169-190. 
14.01 - Lentini (Santuario di Scala Portazza) - Soprintendenza ai Beni Culturali e Ambientali di Siracusa - Présentation préliminaire de la découverte d'un espace sacré, entre 1999 et 2001, à l'O de l'habitat antique, non loin du sanctuaire des Dioscures de Contrada Alaimo (ChronARG [2002], 14.07). Le sanctuaire, structuré en deux terrasses, était limité par un mur de temenos (retrouvé le long des côtés $\mathrm{N}$ et $\mathrm{O}$ ), dans lequel ont été identifiées deux ouvertures : une, avec un large escalier, à l'O, et une, étroite, au N. Cette dernière, à brève distance des fondations d'un autel rectiligne avec frise à métopes et triglyphes, orienté N-S, est interprétée comme l'entrée destinée aux victimes du sacrifice sur l'autel voisin. Devant cette structure (en particulier à l'E de celle-ci), une couche de cendres a été retrouvée, contenant de petits fragments d'ossements consumés avec de minuscules fragments de céramique, en relation avec une phase d'utilisation du sanctuaire antérieure à la construction de l'autel. Des incertitudes demeurent sur la planimétrie et la fonction d'un édifice situé dans la partie méridionale de la zone fouillée; il pourrait s'agir du temple, dont la présence est déduite de la découverte d'éléments architecturaux en terre cuite et, toujours à l'intérieur du temenos (juste devant l'escalier d'accès!), d'un four destiné à la cuisson des tuiles en terre cuite. La principale période d'utilisation du sanctuaire se situe au milieu du VI s. av. J.-C.; au début du v ${ }^{e}$ s. av. J.-C., le complexe était déjà abandonné. Quoi qu'il en soit, l'existence d'une phase architecturale plus ancienne que l'autel et la couche de cendres avec les restes d'ossements et de céramique devant lui est attestée, mais non encore datée. M. Frasca a fait l'hypothèse qu'il pourrait s'agir d'un sanctuaire dédié au culte d'Héra.

B. BASILE, "Il Santuario di Scala portazza. Prime indagini », in M. Frasca (éd.), Leontini. Il mare, il fiume, la città, Catania, 2004, p. 99-116.

- Rapport préliminaire des découvertes faites à l'intérieur d'une pièce carrée appartenant à un sanctuaire fouillé en 1987-1988 et déjà attribué aux Dioscures grâce à une inscription sur un cratère attique à fig. r. (ChronARG [2004], 14.03). Dans l'attente de la publication définitive de l'intéressant complexe, on relève la mention, dans le même contexte, de la découverte de vases mêlés à des ossements d'animaux, interprétés comme les restes de dépôts sacrés. La céramique d'importation est protocorinthienne et corinthienne (aryballes, alabastres, kotyles, kylikes, lécythes, pyxides), gréco-orientale, rhodienne (aryballes, vases à onguents), étrusque (canthares in bucchero) et attique (kylikes et skyphoi); nombreuse céramique locale, avec une majorité de formes ouvertes (coupes et tasses) et la présence de céramique miniature (cruches, hydries, amphores). Le contexte, datable entre le $\mathrm{VII}^{e}$ et le $\mathrm{VI}^{\mathrm{e}}$ s. av. J.-C., comprenait peu de fragments de statuettes en terre cuite, fusaïoles et poids de métier à tisser; il y avait aussi des objets d'ornement en bronze qui apparaissent bien plus tard dans le reste des trouvailles $\left(2^{\circ}\right.$ moitié $\mathrm{IV}^{e}-\mathrm{II}^{e}$ s. av. J.C.

L. Grasso, "Il Santuario di Alaimo. Primi risultati dello studio della stipe », in M. Frasca (éd.), Leontini... (supra), p. 117-122.

- La découverte d'éléments architecturaux en pierre et d'une tête de korè laisse supposer l'existence d'un espace sacré d'époque archaïque à l'O de l'actuelle Piazza Umberto I.

B. BASILE, «Il Santuario... » (supra), p. 114.

14.02 - Grammichele - Università di Torino - Au cours des fouilles de 2000-2001 à l'emplacement de Terravecchia, sur le Poggio del Rullo, on a identifié les vestiges d'une structure qui se retrouve associée à des activités cultuelles, avec deux phases architecturales du VI $\mathrm{s}$. av. J.C. (saggio A). Des couches de cendres, avec des fragments d'ossements d'ovins et de caprins sont interprétés comme des restes de sacrifices et de consommation rituelle de repas qui auraient eu lieu tout d'abord dans un petit enclos de $2,50 \times 2,10 \mathrm{~m}$. Ensuite, un édifice rectangulaire fut construit, long d'au moins $8 \mathrm{~m}$ (détruit entre le $1^{\text {er }}$ et le $2^{e}$ quart du $\mathrm{v}^{e} \mathrm{~s}$. av. J.-C.), à l'intérieur duquel se trouvait une base cylindrique en pierre (autel ou base de statue ?). L'interprétation cultuelle de l'ensemble se fonde également sur la découverte de céramique miniature; une phiale attique à vernis noir contenant des graines de céréales est mise en relation avec des pratiques sacrificielles en l'honneur de divinités de la fertilité agraire. Du matériel relatif à l'activité de culte, en particulier un petit autel en pierre, a été découvert un peu plus au S (saggio B). 
M. BARRA BAGNASCO, «Terravecchia di Grammichele: rapporto preliminare sulla campagna di scavo 2000 », Orizzonti 2 (2001), p. 27-35, 46-47.

14.03 - Camarina - Soprintendenza ai Beni Culturali e Ambientali di Siracusa - Étude des trouvailles effectuées dans les fouilles de 1972-1973 dans la nécropole de Passo Marinaro: en particulier, on signale la présence de soutènements probablement liés à des autels et des vestiges de la fondation d'un grand édifice en appareil polygonal à côté d'une route à l'intérieur de la nécropole. Les structures sont mises en relation avec une fréquentation rituelle de l'endroit; une même explication est avancée pour les éléments découverts dans les couches superficielles de la nécropole, parmi lesquelles se trouve la majeure partie des tablettes de défixion.

R. SALIBRA, « La necropoli di Passo Marinaro a Camarina. Nuove acquisizioni dalla campagna di scavo 1972-1973», Kokalos 45 (2003) [2004], p. 41-110.

14.04 - Géla - L'analyse de la diffusion de la céramique attique à Géla, comparée à celle qui est connue dans d'autres centres de la Sicile (Agrigente, Himère, Lipari), met en évidence le fait que, dans les sanctuaires, l'utilisation de ce type de céramique serait liée à la pratique cultuelle. Un tel emploi se distingue de ce qui est attesté en milieu funéraire, où sont particulièrement mis en évidence les motifs peints qui illustreraient peut-être des mythes liés aux discours funéraires.

G. GRECO et alii, "L'incidenza della ceramica attica nei santuari: il caso di Gela », in R. PANVINI, F. GIUdicE (éds), Ta Attika. Veder greco a Gela. Ceramiche attiche figurate dell'antica colonia, Roma, 2003, p. 157-184.

14.05 - Polizzello - Università di Catania - En 2000, les fouilles ont été reprises sur le site déjà en partie exploré par Orsi et De Miro. Une structure rectangulaire du vI s. av. J.-C. a été mise au jour. Elle est constituée d'une pièce de $8,3 \times 5,6 \mathrm{~m}$. La découverte, à l'intérieur, d'une grande quantité d'ossements d'animaux laisse supposer que la structure aurait pu abriter des sacrifices animaux. On retiendra la localisation, dans la partie occidentale de la colline, de l'édifice où avaient été trouvés en 1926 deux petits modèles circulaires en terre cuite. L'A. souligne la ressemblance des ex-voto avec ceux qui sont en usage en Crète à la période minoenne.

D. Palermo, « La ripresa degli scavi sulla Montagna di Polizzello », Orizzonti 4 (2003), p. 9599.

14.06 - Agrigente - Soprintendenza ai Beni Culturali e Ambientali di Agrigento - Publication complète des fouilles menées entre 1982 et 1989, et en 2000, dans le sanctuaire naguère identifié comme celui d'Asclépios grâce à un passage de Polybe (I, 18) relatif au siège des Romains en 262 av. J.-C. Le sanctuaire aurait été construit au $\mathrm{IV}^{e}$ s. av. J.-C. La découverte de céramique des $\mathrm{VI}^{\mathrm{e}}$ et $\mathrm{V}^{e} \mathrm{~s}$. av. J.-C. près du temple est, à titre d'hypothèse, mise en relation avec un culte d'Apollon, représenté par une statue abritée dans le sanctuaire, due à Myron (Cicéron, Verr. IV); il manque toutefois des données concrètes pour soutenir cette hypothèse, étant donné le caractère banal des trouvailles (outre la céramique, une statuette féminine en terre cuite de style dédalique et des monnaies) et compte tenu de la fréquentation protohistorique connue de l'endroit, peut-être en relation avec un petit établissement près d'une source (P. MARCONI, Agrigento. Topografia e arte, Firenze, 1929, p. 92-93). Le sanctuaire, qui s'étend sur près de $18000 \mathrm{~m}^{2}$, était délimité par un mur de temenos, avec une ouverture au N, vers l'habitat; sa construction est datée du milieu du IV ${ }^{e}$ s. av. J.-C.

Au milieu du sanctuaire s'élevait le temple distyle in antis, également accessible par le $\mathrm{S}$ au moyen d'une rampe et doté d'un puits à l'intérieur. À l'E des marches d'accès au temple se trouvait un petit puits, au-delà duquel se trouvait un autel rectiligne et deux autres petits puits. Un second édifice de culte, appelé «Sacello Thesauros» se trouvait juste au N, entre le temple et l'autel; dans la partie $\mathrm{N}$ du sanctuaire - celle qui semble la plus largement investiguée - se trouvait une fontaine et, à l'O, une petite enceinte carrée, accessible par le S, qui renferme un autel. À l'O du propylon d'accès au sanctuaire se trouvaient des espaces délimités par un mur de temenos, parmi lesquels on identifie l'abaton, où intervenait l'incubation. Dans la restructuration romaine du sanctuaire qui suivit l'occupation durant le siège de 262 av. J.-C., l'édifice, devant lequel se trouvait une citerne, fut précédé d'un portique ( Portico N-O »); un second portique fut alors construit le long d'une série de pièces édifiées contre le mur occidental du temenos 
(«Portico $\mathrm{O} »)$ et identifiées comme hestiatorion et katagogeia. L'A., sur la base des analogies avec d'autres Asklépieia connus, reconstitue à titre d'hypothèse un itinéraire rituel qui va du propylon vers la source et, ensuie, après le dépôt de l'offrande dans le "Sacello Thesauros ", repart vers l'autel rectiligne, arrive au temple pour se diriger enfin vers l'enceinte avec l'autel et le Portique N-O. La présence de fragments de couteaux en fer et d'ossements d'animaux (outre des petites cruches, des vases à onguent, des figurines en terre cuite et quelques monnaies) dans les deux petits puits à l'E de l'autel rectiligne est mise en relation avec des offrandes sanglantes près du même autel; en revanche, le petit ensemble de l'enceinte avec autel était probablement utilisé, d'après l'A., pour le dépôt de gâteaux et de fruits, malgré l'existence de traces de combustion repérables à la surface des blocs. Un couteau en fer, un pinax avec une représentation de chien, de la céramique miniature font partie des découverte du «Sacello Thesauros». En général, on signale l'absence d'inscription d'action de grâce (on a seulement mis au jour une seule paire d'inscriptions fragmentaires) et la faible quantité d'ex-voto anatomiques. L'A. en déduit qu'à la période romaine, le culte d'Asclépios pourrait avoir été en partie transféré dans le temple d'Héraclès, même si le sanctuaire d'Asclépios a continué à fonctionner, au moins partiellement, jusqu'au IV s. ap. J.-C.

E. DE MIRO, Agrigento II. I santuari extraurbani. L'Asklepieion, Roma, 2003.

- La céramique découverte dans le sanctuaire de S. Anna est interprétée comme un indice d'actions rituelles (comme la cuisson et la consommation de repas) qui avaient lieu dans l'espace sacré. Il faut mentionner la présence massive de vaisselle et de céramique miniature (en particulier des cruches, des puisettes et des vases à onguent).

V. CALÌ, «Ceramiche votive e ceramiche di uso votivo e rituale dal Santuario extra-urbano di

S. Anna ad Agrigento », Quaderni di Archeologia. Università di Messina 3 (2003), p. 145-164.

14.07 - Salemi (Monte Polizzo) - Stanford University, Santa Clara University, Soprintendenza Beni Culturali ed Ambientali di Trapani - Présentation des données de la fouille menée entre 1998 et 2002 (ChronARG [2003], 14.20). Tout particulièrement intéressantes sont les découvertes effectuées dans la partie $A$, où une structure circulaire d'un diamètre de $6,4 \mathrm{~m}$ (A1), construite vers 550 av. J.-C., pourrait être un édifice de culte. À côté de l'édifice, au point le plus haut de la colline, il y a deux structures rectilignes interprétées comme des autels, une stèle, et des parties des murs qui semblaient délimiter cet espace. Des traces de combustion et de nombreux restes de cornes de cervidés, en particulier (cervus elaphus), indiquent le sacrifice de ces animaux, dont les viandes étaient probablement consommées ailleurs; les fragments de coupes découvertes sont mises en relation avec la consommation de vin. La structure circulaire est restée en usage jusque 500-475 av. J.-C.; une fosse contenant des cendres fut soigneusement scellée avec de l'argile, comme un foyer placé à l'intérieur du même édifice. On avance l'hypothèse que les ossements humains d'un individu de 12 à 14 ans, trouvés dans les environs de A1 pourraient appartenir à une sépulture qui détermine le lieu pour le développement des pratiques cultuelles qui sont reconstituées. L'attention est tout particulièrement attirée sur le très fort pourcentage d'ossements de cervidés, dont les cornes sont les matériaux ostéologiques de loin les mieux représentés sur le site (5141 fragments). Les A. affirment que les cervidés auraient été chassés (en automne, sur la base du point de développement des cornes) dans les bois alentour du Mont Polizzo, pour être sacrifiés sur les autels mis au jour, où l'on trouve des restes brûlés de crânes et de pattes. Les cornes pourraient avoir été portées durant des rituels (par exemple des danses) peut-être documentés dans l'iconographie contemporaine (œenochoé de Polizzello). Le large pourcentage d'ossements de cervidés ( 5347 fragments sur 5402 de mammifères sauvages) trouve peut-être un parallèle dans les pratiques cultuelles en l'honneur d'Artémis (sanctuaire d'Artémis Elaphèbolia à Kalapodi).

I. MORRIS et alii, "Stanford University Excavations on the Acropolis of Monte Polizzo, Sicily III: preliminary report on the 2002 season", MAAR 48 (2003), p. 251-259, 273-290.

14.08 - Entella - Dans les fouilles menées entre 1999 et 2001, juste en dehors du circuit d'enceinte de l'établissement, près de la porte $\mathrm{N}-\mathrm{O}$, on a mis au jour un dépôt de matériel certainement lié à des pratiques cultuelles; une couche contenant des ossements d'animaux 
(bovins, ovins, caprins, porcs et sangliers) et du matériel votif recouvrait une fosse constituée en particulier de nombreuses statuettes en terre cuite, parfois déposées en ordre, les unes à côté des autres, comme dans le sanctuaire de Déméter et Korè de la piazza della Vittoria à Syracuse ou dans le Thesmophorion de Bitalemi à Géla. La pente de la colline a probablement été terrassée pour accueillir des structures «mobiles et provisoires » liées à la fréquentation du sanctuaire. Une des activités qui s'y est développée est la cuisson de repas, à en juger par la présence de nombreux fragments de marmites, de petites fosses remplies de cendres et d'ossements animaux, et de petits foyers. Le matériel, datable entre la fin du $\mathrm{VI}^{\mathrm{e}}$ et le $\mathrm{III}^{\mathrm{e}} \mathrm{s}$. av. J.-C., comprenait des bustes et des statuettes féminines en terre cuite (du type dit « de l'Athéna Lindia », fidèles avec flambeau et porcelet), des lampes, des kernoi, un fragment de pinax en terre cuite, des vases en terre cuite dont quelques exemplaires miniatures. La documentation archéologique (comparable à celle de Bitalemi à Géla) conduit à interpréter ces vestiges comme ceux d'un Thesmophorion, situé à une courte distance de la nécropole (la B) de l'établissement.

F. SPATAFORA, «Entella. Il santuario delle divinità ctonie in contrada Petraro », in F. SPATAFORA, S. VAssallo (éds), Sicani, Elimi e Greci. Storie di contatti e terre di frontiera, Palermo, 2002, p. 13-15, 23-35; F. SPATAFora, A. Ruvituso, G. Montali, «Entella: un santuario ctonio extra moenia », in Quarte giornate internazionali di studi sull'area elima (Erice, 1-4 dicembre 2000), Pisa, 2003, p. 1189-1201.

- L'A. ajoute quelques remarques supplémentaires sur le dépôt votif déjà connu et mis au jour dans les fondations du grenier (principalement des statuettes en terre cuite avec porcelets et des coupes: M.C. PARRA, in Seconde giornate internazionali di studio sull'area elima, Pisa, 1997, p. 1203-1214). Les pièces découvertes au N du grenier étaient probablement liées aussi à l'édifice utilisé à des fins cultuelles au $\mathrm{V}^{\mathrm{e}}$ s. av. J.-C. Elles ont continué à être utilisées à la période hellénistique, parfois avec la présence d'un autel intérieur (pièce A1/D1). L'A. suggère que le complexe, outre la fonction de magasin, aurait accueilli un culte chthonien, attribué à Déméter ou à Hestia.

M.C. PARRA, «Ad Entella, tra un granaio ed un oikos: nuovi dati sulla thysia di fondazione », in Quarte giornate... (supra), p. 1029-1048.

14.09 - Marineo - Soprintendenza ai Beni Culturali e Ambientali di Palermo - Confirmation du caractère votif du dépôt de trois casques, de jambières et d'un bouclier dans un espace peut-être couvert près du mur de l'habitat (ChronARG [2002], 14.13; [2004], 14.13) identifié, grâce à la découverte de quelques tuiles inscrites, comme le centre de Makella. Présentation analytique du matériel en question, datable de la $2^{\mathrm{e}}$ moitié du vi ${ }^{\mathrm{e}} \mathrm{s}$. av. J.-C. Le dépôt votif d'armes (associées à des vases pour la cuisson) est isolé dans le cadre de la Sicile archaïque. Mais les A. n'examinent aucune explication alternative qui ne concernerait pas la sphère religieuse.

F. SPATAFORA, «La Montagnola - Makella», in Sicani, Siculi e Greci (supra 14.08), p. 87-97.

14.10 - Colle Madore (Lercara Friddi) - Soprintendenza BB.CC.AA. di Palermo - Récapitulation des découvertes déjà publiées (S. VAssalo [éd.], Colle Madore. Un caso di ellenizzazione in terra sicana, Palermo, 1999), avec une nouvelle présentation des données relatives au petit sanctuaire identifié sur la pente méridionale et datable au milieu du vi s. av. J.-C. Entre les blocs de fondation de l'édifice (à l'intérieur duquel se trouvait une stèle avec une représentation interprétée comme Héraclès à la fontaine), il y avait un dépôt de fondation constitué, outre de fibules et d'une lame en métal à décor anthropomorphe, de vases en céramique de production indigène, étrusque et grecque; parmi ces derniers, on remarque la présence de vases miniatures.

S. VAssallo, "Colle Madore. Terra di frontiera ", in Sicani, Siculi e Greci (supra 14.08), p. $99-113$.

14.11 - Cozzo Spolentino (Corleone) - L'A. mentionne la découverte, à l'extérieur de l'habitat antique, d'un groupe de matériel du $\mathrm{IV}^{\mathrm{e}} \mathrm{s}$. av. J.-C. interprété comme l'éparpillement des ex-voto d'un sanctuaire. Outre une statuette et des bustes féminins en terre cuite sont présentés des boucles d'oreille et des perles de collier en bronze, des monnaies et des vases de production siciliote et italiote. 
F. SPATAFORA, «COzzo Spolentino », in Sicani, Siculi e Greci (supra 14.08), p. 147-156.

14.12 - Sélinonte - L'A. discute l'hypothèse que les nombreuses figurines en terre cuite retrouvées à l'O du temple du sanctuaire de Zeus Meilichios soient en relation avec le rite de purification mentionné dans les premières lignes de la lex sacra, par analogie avec ce qui est prescrit par la lex cathartica de Cyrène (M.H. JAMESON, D.R. JORDAN, R.D. KOTANSKi, A lex sacra from Selinous, Durham, 1993). Le Campo di Stele est plutôt identifié comme un lieu sacré réservé aux cultes de groupes familiaux.

A. Brugnone, « Riti di purificazione a Selinunte », Kokalos 45 (2003) [2004], p. 11-26.

14.13 - Lylibaeum (Marsala) - Soprintendenza ai Beni Culturali e Ambientali di Trapani - Les fouilles menées dans la via Quarto ont mis au jour un édifice à vasques près de la ligne de côte en usage entre le IV ${ }^{\mathrm{e}}$ et le III $^{\mathrm{e}}$ s. av. J.-C. (ChronARG [2004], 14.16); la structure pourrait avoir eu un usage cultuel, une hypothèse fondée sur la proximité de la "Grotte de la Sibylle ». Une telle hypothèse permettrait d'expliquer la découverte récente d'une réplique de l'Aphrodite du type 'syracusain' (janvier 2005), rapportée par les journaux locaux.

R. Giglio, «Lilibeo (Marsala): recenti rinvenimenti archeologici in via Quarto », in Quarte giornate (supra 14.08), p. 730-731.

14.14 - Mozia - Università "La Sapienza" di Roma - En 2002, à l'E de Kothon, les vestiges d'un édifice déjà fouillé en partie ont été identifiés comme ceux d'un temple (Temple C) dont ont été mis au jour des niveaux postérieurs à 397 av. J.-C. (sanctuaire C3). Il faut remarquer la présence d'un autel en pierre, d'une cour intérieure avec un puit et d'un espace de stockage.

L. Nigro, «Nuovi scavi a Mozia dell'Università di Roma "La Sapienza" (XXII campagna, agosto-ottobre 2002)», Sicilia Archeologica 36 (2003), p. 87-88.

- Sur les pentes occidentales de l'acropole, à l'intérieur d'une maison (dès lors appelée « Casa del sacello domestico »), a été retrouvée une petite niche qui, vu la présence d'un petit autel et d'un astragale, pourrait avoir accueilli un culte domestique. Une colonnette cannelée avec un chapiteau éolique (fin $\mathrm{V}^{\mathrm{e}}$ - début $\mathrm{IV}^{\mathrm{e}}$ s. av. J.-C.) pourrait lui être associée.

L. Nigro, « Nuovi scavi ... », ibid., p. 90-91.

14.15 - Kossyra (Pantelleria) - Scuola di Specializzazione in Archeologia di Matera, Université de Greifswald, Soprintendenza ai Beni Culturali e Ambientali di Trapani - Sont rendus publics les résultats des fouilles menées en 2003 sur l'acropole de S. Marco où une citerne était remplie de matériaux probablement liés à un édifice sacré du II ${ }^{\mathrm{e}} \mathrm{s}$. av. J.-C., avec une phase d'utilisation à la période impériale. À cette structure sont associées les trois têtes en marbre identifiées comme César, Antonia la Jeune et Titus, découvertes à l'intérieur de deux autres citernes. La fouille a particulièrement mis en évidence le fait que les têtes de César et d'Antonia furent soigneusement déposées (dans le $3^{\text {e }}$ quart du I ${ }^{\text {er }}$ s. av. J.-C.) entre les ossements des bovins dans la citerne 861 à la fin d'un rite qui comprenait des sacrifices d'animaux, attestés par l'abondance des cendres, du charbon de bois et des ossements consumés de bovins et d'ovins. Ces derniers appartiennent au moins à sept ovins et à quatre bovins qui furent abattus. La grande quantité de vaisselle en céramique (assiettes et coupes) retrouvées dans le remplissage de la citerne doit probablement être mis en relation avec la consommation des chairs des animaux, accompagnée de libations. La présence des ossements d'un chien, tué mais non abattu, permet d'envisager que l'enterrement des têtes impériales associées aux parties non consommées des animaux découpés, au chien sacrifié et à la vaisselle en céramique utilisée pour la consommation des repas aurait été effectué au cours d'un rituel d'expiation (peut-être en relation avec des vicissitudes locales dont on ignore la teneur).

M. OsAnNA, T. SCHÄFER, S. TuSA, «I ritratti imperiali dell'antica Cossyra (acropoli di S. Marco, Pantelleria) », Sicilia Archeologica 36 (2003), p. 79-84. http://www.unibas.it/ssa/pantelleria.htm 


\section{Index géographique (Alexis d'Hautcourt)}

Acarnanie : 05.01; Palairos 05.01

Asie Mineure : Carie : Çanagik Tepe : 12.07; Cnide : 09.07; 09.23; 12.08; Halicarnasse : 09.07; 12.09; Iasos : 09.07; 12.07; Cilicie : 12.04; Ionie : Claros : 12.10; Ephèse : 12.03; Magnésie du Méandre : 05.12; Phocée : 12.11; Lycie : Tlos : 12.02; Tyberissos : 12.01; Mysie : Pergame : 05.08; Pamphylie : Kaunos : 12.03; Pergè : 12.03; Pisidie : Pednelissos : 12.05; Sagalassos : 12.06; Troade : Troie : 09.03

Attique : Eleusis : 13.02

Carthage : 11.00

Chypre : 09.23; Achna : 11.04; Agia Irini : 11.00; Amathonte : 11.00; 11.06; Arsinoè : 11.10; Athienou : 11.01; Geronisos : 11.09; Golgoi : 11.02; 11.06; Idalion : 11.00; 11.03; Kition : 11.00; 11.05; 11.07; Kouklia : 11.07; Kourion: 11.00; 11.10; Lapethos : 11.00; Malloura : 11.01; Marion : 11.06; 11.10; Mersinaki : 11.00; Mersineri : 11.00; Neapaphos : 05.08; 11.09; Palaepaphos : 11.00; 11.07; Paphos: 11.08; Pegeia: 11.08; Salamine : 11.00; Tamassos : 11.00; Vouni : 11.00;

Crète : 14.05 ; Lissos : 05.08

Cyrénaïque : Balagrae : 05.08; Cyrène : 14.12

Épire : 05.02; Achéron 05.03; Acherousia (lac) 05.03; Agia Paraskevi 05.04; Ambracie 05.02; Arta 05.02; Bouthrôtos : 05.08; Chaones : 05.07; Cuka : 05.07; Dodone 05.05; Finik : 05.07; Malathre : 05.07; Mesopotamon : 05.07; Passaron : 05.06; Phanari (plaine) 05.03; Phoinikè : 05.07; Thesprôtie 05.04

Eubée : 09.18

Grande Grèce : Caulonia : 13.01; Herakleia : 13.02; Lagaria : 13.04; Métaponte : 13.03; Paestum : 13.05; Poseidonia : 13.05; Siris : 13.02; Sybaris : 13.04; Tarente : 13.06; Thourioi : 13.04; Vésuve : 13.05

Îles de l'Égée : Amorgos : 09.24; Andros : 09.24; Astypalaia : 09.06; Délos : 09.25; 09.26; Despotiko : 09.26; Ialysos : 09.18; Ios : 09.24; Kos : 09.07; 09.08; 09.09; 09.10; 09.11; Kythnos : 09.27; Lindos : 09.19; 09.20; 14.00; Melos : 09.24; Mykonos : 09.24; Nisyros : 09.07; Paros : 09.24; 09.26; Rhodes : 09.11; 09.12; 09.13; 09.14; 09.15; 09.16; 09.17; 09.18; 09.19; 09.20; 09.21; 09.22; 09.23; Samos : 09.03; Samothrace : 07.00; 07.28; 09.03; 09.04; 09.05; Syros : 09.24; Ténos : 09.24; Thasos : 09.01; 09.02; Théra : 09.24

Iles ioniennes : Céphalonie : 05.13; Poros : 05.13; Corcyre : 05.10; Palaiopolis : 05.10; Ithaque : 05.12; Leucade : 05.11

Illyrie méridionale : Apollonia : 05.07; 05.09; 05.11; Dermenas : 05.07

Macédoine : 07.00; Abdères : 07.00; Aiani : 07.05; Aigai : 07.09; Aiginion en Tymphée : 07.02; Aineia : 07.16; Ainos : 07.00; Amphipolis : 07.00; 07.25; 07.26; Archontiko : 07.12; Asprovalta : 07.24; Beroia : 07.00; 07.07; Bormiskos : 07.22; Dion : 07.13; Eordée : 07.04; Herakleion : 07.15; Kalindoia : 07.00; 07.16; Kastoria 07.01; Kozani : 07.03; Leibethra : 07.14; Lété : 07.00; 07.20; Leukopetra : 07.08; Maronée : 07.00; Ménèis en Bottiée : 07.06; Mygdonie : 07.22; Nea Kerdyllia : 07.25; Olympe (Mt.) : 07.14; 07.15; Pella : 07.00; 07.10; 07.11; Philippes : 07.00; 07.17; 07.29; Polyneri : 07.02; Profitis : 07.21; Serrès : 07.00; 07.27; 07.28; Stagire : 07.23; Thessalonique : 07.00; 07.16; 07.17; 07.18; 07.19; Vergina : 07.09

Mer Rouge : 09.23

Péloponnèse : Argolide : Epidaure : 05.08; Corinthie : Corinthe : 05.05; 05.11; Pérachôra : 05.11; Élide : Olympie : 07.17; Messénie : Messène : 05.08; 05.11

Phénicie : 09.23; 11.05; 11.07; Sidon : 11.05; Tyr : 11.05

Phocide : Delphes : 05.08; Kalapodi : 14.07

Rome : 09.24 
Sicile : 14.00; Adranone (Mt.) : 14.00; Agrigente : 14.00; 14.04; 14.06; Camarina : 14.03; Colle Madore : 14.10; Cozzo Spolentino : 14.11; Entella : 14.08; Géla : 14.00; 14.04; 14.08; Grammichele : 14.02; Heloros : 14.00; Himère : 14.04; Kossira : 14.15; Lentini : 14.01; Lipari : 14.04; Lylibaeum : 14.13; Makella : 14.09; Marineo : 14.09; Mozia : 14.14; Pantelleria : 14.15; Polizzello : 14.05; Polizzo (Mt.) : 14.07; Salemi : 14.07; Sélinonte : 14.00; 14.12; Solonte : 14.00; Syracuse : 14.08

Thrace : 08.00; Abdères : 08.03; Haemus (Mt.) : 08.01; Plotinopolis : 08.04; Polystylon : 08.03; Sofia : 08.02

Via Egnatia : 07.00

\section{Index thématique (Alexis d'Hautcourt)}

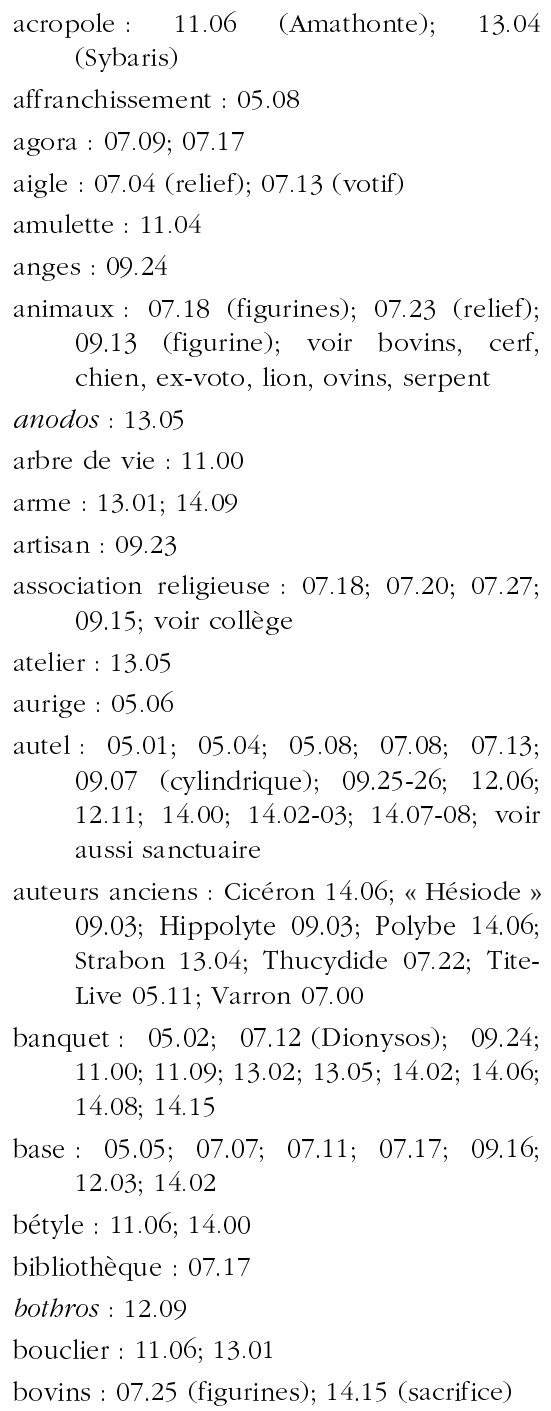

calendrier : 09.10

centaure : $11.00 ; 11.06$

céramique / «vaisselle»: 09.10 (inscription); alabastre 09.21 (argent); 14.01; aryballe 14.01; bol mégarien 12.07; canthare 14.01; coupe 13.04; coupe miniature 13.04; cratère 14.01; cruche à embouchure plastique 11.00; hydrie; 09.21; 13.04; hydrie d'Hadra 09.21; kotyle 14.01; kylix 05.05; 13.02; 14.01; lécythe 14.01; oenochoé 12.10; phiale 05.05; 09.21 (or); 14.02; phiale à omphalos 09.21 ; pyxis 13.05 ; 14.01 ; rbyton 11.00; skyphos 05.05; 14.01; vase $05.02 ; 09.18$ (bronze); 14.01 ; vase à boire 05.05; vase à onguent 13.05 ; 14.01 ; vase miniature 05.04; 14.01; $14.02 ; 14.06 ; 14.08 ; 14.10$; voir aussi ex-voto

céréales : 14.02

cerf : $12.03 ; 14.07$ (ossements et cornes)

chapiteau : 05.05; 11.00

chasse : 14.07

cheval de Troie : 13.04

chien : 14.15

chôra: 05.11; 12.01; 12.07

christianisme : 09.24

Chronique de Lindos : 09.20

chthonienne (divinité) : 14.00

citerne : $09.13 ; 14.15$

collège : 09.25; voir association religieuse colonie : $05.11 ; 09.03 ; 13.03 ; 13.04 ; 13.05$

Compitalia : 09.25

concours : 09.15; 09.18; voir jeux

consécration : $05.06 ; 09.25$

coquillage : 09.23

corinthien (ordre) : $12.01 ; 12.04$ 
cornes : 14.07 (cerf)

couronne : 11.03 (voir aussi ex-voto)

culte des princes thraces : 08.00

défunt représenté sous les traits d'une divinité : 07.07

départ (scène de) : 11.00

divinités/ héros

Achélôos : 05.11

Achille : 11.06

Ajax : 11.06

Alexandre le Grand : 07.16

anges: 09.24

Aphrodite : 05.08-09; 07.07-08; 07.16; 07.18-19; 09.12-13; 09.24; $11.05-$ 07 ; 12.10; 13.05; 14.13; Aineias 05.11; Euploia 12.03; Ourania 07.24-25

Apollon : 05.11; 09.10; 09.25-26; 11.03; $12.01 ; 12.03 ; 12.05 ; 12.10 ; 13.03$; 14.06; Agyeus 05.10; Erethimios 09.22; Hylatès 11.00; 11.10; Karneios 09.24; Pythien 13.01

Arachtos (fleuve) : 05.02

Archiloque : 09.24

Artémis : 05.07-08; 05.11; 07.04; 07.07; 07.15-16; 07.20; 09.12; 09.26; $11.01 ; 12.03 ; 12.10 ; 13.01 ; 13.03$; 14.07; Agrotera 07.04; Bendis 13.03; Elaphèbolia 14.07; Lochia 07.04

Asclépios : 05.08; 07.00; 07.07; 07.16; $09.16 ; 09.24 ; 14.06$

Astarté : $11.05 ; 11.07$

Athéna : 05.08; 05.11; 07.16-17; 09.18; $09.20 ; \quad 09.23-24 ; \quad 11.00 ; \quad 12.11$; 13.03-05; 14.00; Erganè 13.04; Lindia 14.00; Polias 05.12

Auguste : 07.16

Aulonitès : 07.16

Bacchus : 07.26

Basileus Kaunios : 12.03

Bès : 11.00

Cybèle : 07.16; 07.24; 12.03; 12.11

Danaos : 13.03

Darron : 07.10

Dea Roma : 07.00; 07.16

Déméter : 07.07; 07.13; 07.16; 07.20; $12.08 ; 13.02 ; 13.03$

Dieu-fleuve : 05.11
Dieux Syriens : 09.25

Dionysos : $05.07-08 ; 07.00 ; 07.06$; $07.12 ; 07.16 ; 07.18 ; 07.20 ; 07.22$ 23; 07.29; 09.24; 13.03; Pseudanôr : 07.00

Dioscures : 14.01

Énée : 07.00; 07.16; 09.03

Enodia : 07.20

Épeios : 13.04

Epona : 07.16

Éros : 07.07-08; 07.18; 08.04; 12.10; 13.05

Eukleia : 07.09

Europe : 11.06

Fulvus : 07.16

Gè : 13.02

Géryon : 11.06

Gorgone : 11.06

Grande Déesse : 11.03; 11.07

Grande Mère : 07.16; 09.04-05; 12.03

Grands Dieux : 07.00; 07.28; 09.03

Hadès : 07.00

Hékatè : Stratia : 09.10

Hélios : 09.06; 12.03

Héra : $05.11 ; 07.01 ; \quad 13.01 ; 13.03$; 14.01; Hoplosmia 13.01; Teleia 05.12

Héraclès : 05.11; 07.00; 07.09; 07.16; $11.00 ; \quad 11.03 ; \quad 11.05-07 ; 13.05$; $14.06 ; 14.10$

Hercule : 09.25

Hermès : 05.07-08; 05.11; 07.01; 07.16

Héros : 07.16 (ou Héron)

Héros cavalier : 07.16

Hestia : Isthmia : 09.26; Phamia : 09.10

Hippalkmos : 07.16

Hygie : 05.08

Ilythie : 09.24

Io : 13.03

Isis : 07.13; 07.16; 07.20; 09.24

Jules César (Divus Julius) : 07.16

Kabeiros : 07.16

Kabires : 07.00; 09.03; 09.24

Korè : 07.20; 13.05

Korybantes : 07.16

Lares : 09.25

Melqart : $11.05 ; 11.07$ 
Mère des Dieux : 07.00; 07.09; 07.20

Mère des Dieux Autochthone : 07.08 Mithra : 07.16; 09.24

Muses : 12.08

Némésis : 07.16

Nikè : 05.09; 12.03 (voir Victoire)

Nymphe : 05.11; 05.12;05.13

Orphée : 07.14; 07.26

Pan : 05.11; 05.13;07.08

Pénates : 07.00

Persée : 11.06

Perséphone : 07.00; 07.19; 13.02; 13.03

Phryxos : 11.06

Poséidon : 05.02; 05.08; 07.14; 07.16; 09.24

Psychè : 07.18

Sarapis : 07.16; 07.17; 07.20; 09.24; 09.25

Satyre : 05.11

Silène : 05.11

Sobazios : 13.03

Télesphore : 07.18

Theoi Megaloi : voir Grands Dieux

Theos Hypsistos : 07.16

Thétis : 05.11

Tychè : 07.16; 09.12; 11.03

Ulysse : 05.12

Vénus : 13.05

Victoire : 07.18; 09.03 (voir Nikè)

Zeus : 05.05; 05.08; 07.00; 07.09; 07.13-14; 07.16; 13.03; Aréios : 05.06; Cassios : 05.08; Damatrios : 09.24; Eleutherios : 07.00; 07.16 ; Homarios : 13.01; Hypsistos : 07.01; 07.03-04; 07.13; Meilichios : 14.12 ; Olbios : 12.04 ; Polieus : 09.10 ; Sôter : 05.08

dorique (ordre) : 05.07; 05.08; 07.02; 09.27; $13.01 ; 13.05$

eau : $\quad 05.05 ; \quad 05.08$ (sulfureuse); 05.11 (source); 07.22; 13.01 (rite)

enceinte : voir rempart

enfant : 09.09

étrangers : 09.20

expiation (rite) : 14.15

ex-voto et mobilier cultuel : aigle 07.13; armes 14.09; bague 09.27; baignoire 07.10; banquettes 07.10; bijoux 07.02 boucles d'oreille 05.04; 14.11; catalogue 09.20; clé 07.04; collier 14.11; coquillage 09.23; couronne 09.17 (or); 11.00; couteau 14.06; deinos 13.01; exvoto anatomique 13.05; fibule 09.27 ; $11.00 ; 14.10 ;$ figurine $05.02 ; 05.04$; 05.10-11; 07.07-08; 07.12; 07.15; 07.18; $07.21 ; \quad 07.24-25 ; \quad 09.04 ; \quad 11.00 ; 13.02$; 13.06; 14.12; kernos 14.08; lame 13.01 (bronze); 14.10; lamelle 07.26 (or); 09.27 (or); lamelle oraculaire 05.05; lampe 14.08; marmite 14.08; métal (objets en) 13.04; monnaies $07.02 ; 14.11$; pendentif $09.27 ; 11.04$ pinax 14.08 ; plaque 05.02 ; plateau à offrandes 11.09; protomé 05.04; 07.08 ; racloir 09.18; relief 07.01 $07.04 ; 12.05$; rosette 09.27 ; sceau 09.27; stèle 07.03-04; $07.18 ; \quad 07.27$ 14.10; terre cuite 13.03 ; $13.05-13.06$; thymiaterion 07.08; trépied 13.05 vases 07.02 ; xoanon 07.14; voir céramique

famille : 14.12

faune : $05.02 ; 05.04 ; 09.02 ; 11.08-09 ; 14.05-$ $06 ; 14.08$

fertilité : $11.01 ; 11.04 ; 13.03 ; 14.00 ; 14.02$

fête : 09.25

fosse : 05.02

four : 14.01

foyer : 13.04

fragmentation rituelle : 13.06

fruit : 14.06

funéraire (contexte) : 07.18; 07.19; 07.25; $09.19 ; 09.21 ; 11.00 ; 14.03 ; 14.04 ;$ en chytrismos 09.06; 09.09; monument 08.02; 12.04; osthéothèque 09.19; 09.21; relief 11.00 ; rite 11.08 ; rupestre 12.04; tholos 09.08; tombe 07.07; $07.12 ; 09.17$

gâteau : 14.06

grenouille : 12.03

griffon : 13.03

gymnase : 05.05

hermaphrodite : 13.05

héros guérisseur : 07.10

impérial (culte) : 07.00; 07.17

importation : 13.04

incendie : 05.04

incubation : 14.06

indigène (divinité) : 12.07; 13.04 


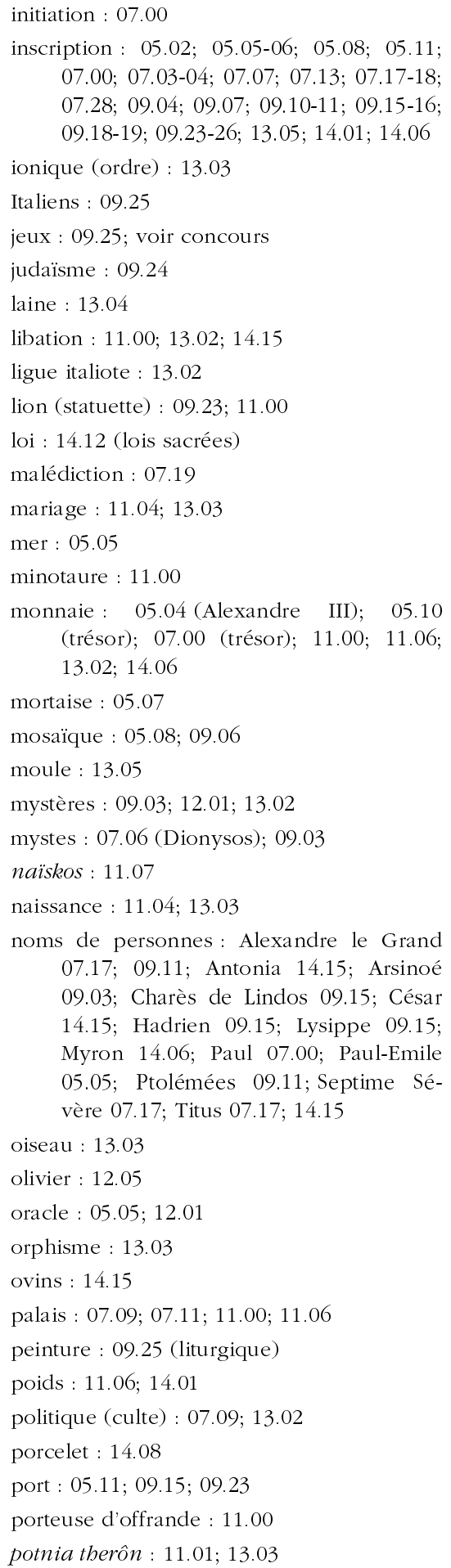

pottier : 07.13

procession : 05.01; 05.09; 09.15

propagande : 07.00 (romaine); 13.03

prytanée : 05.05

pschent : 11.00

relief : 05.06; 07.01

rempart : 05.02; 05.07; 07.02; 07.23; 08.01; 08.03

remploi : 07.05; 07.17

réoccupation d'un sanctuaire par une église chrétienne : 07.05

revenus du dieu : 05.08

rite : 05.02 (consécration de fondations), 13.01 (chthonien; de passage); 13.06 (de passage; funéraire)

roi : $\quad 07.11 ; \quad 09.11$ (Ptolémées); 11.06-07 (Chypre)

rose : 13.03

sacrifice : 09.02; 09.10; 11.07 (humain ?); 12.10 (hécatombe); 13.02; 14.01 ; $14.02 ; 14.05 ; 14.07 ; 14.15$; sacrificateur : 11.00

sanctuaire: abaton 14.06; à ciel ouvert 09.04; 09.05; administration 11.06; adyton 09.27; 12.03; Alexandreion 09.11; anaktoron 09.03; analema 09.27; antéfixe 13.03; archives 09.20; Artémision 13.03; Athénaion 05.12; autel $07.13 ; 07.23 ; 09.25 ; 09.27$ (monumental); 11.09; 14.01; 14.06; 14.14; bassin 09.15 ; en bois 12.01; boutique 09.25; cella 07.13; 09.27; 12.03; colonnade 05.05; "creusé dans le sol» 08.02; Délion 09.26; diadromos 05.05; domestique 07.08; entonnoir 13.02; escalier $05.05 ; 13.01 ; 14.01$; eschara 13.02; extra-urbain 09.23; favissa 05.08; fontaine 14.06; fosse 08.02; fosse sacrificielle 07.23; frise 14.01; funéraire 07.06; grotte 05.11-13; 07.14; gerôon 07.14; grenier 14.08; 14.14; hécatompède 07.23 ; hestiatorion 14 . 06; inventaire 09.20; katagogeia 14.06; koilon 05.08; krepis 05.08; métope 14.01; naos distyle in antis 05.07-08; 14.06; naos tétrastyle 05.08; nekyomanteion 05.03; Odysseion 05.12; orthostate 05.07 ; péribole 05.05 ; podium 05.09; pompeion 05.09; portique 05.05; 07.02; 07.13; 07.18; 09.25; 11.10 ; 14.06; Poseidonion 09.01; Propylées 09.25 (Délos); 11.09 (Chypre); 14.06 
(Agrigente); Ptolémaieion 09.11; puits 13.01; 14.06; 14.14; pyra 09.27; rampe 14.06; réfection 07.13; 09.27; rupestre $12.01 ; 12.03$; 12.11; Sarapieion 09.25; de sommet 08.01; stéréobate 05.05; 13.01; stoa 05.05; 09.22; taphet 11.00; temenos 14.01; 14.06; terrasse 14.01; Thesmophorion 07.23 ; 14.08 ; Timacheion 09.10; triglyphe 08.03; 09.27; 14.01 ; tympan 05.07 ; vasque $13.01-02$; 14.13

scorpion : 12.03

serpent (statue) : $11.00 ; 13.01$

sphinx (statuette) : 09.23; 11.00; 11.06

statue de culte : 07.13; 07.17

statue / statuette: 05.07-08; 07.17; 07.20; $07.23 ; 08.04 ; 09.12-13 ; 11.00-01 ; 11.03$; $11.05-06 ; 12.03 ; 12.10 ; 13.01 ; 13.03$; $13.05 ; 14.01 ; 14.06 ; 14.08 ; 14.11$; acrolithe 07.17; argent 07.14; bétyle 05.10; bronze 05.05; 05.07; 07.15; colossale 07.17; 09.15; ithyphallique 09.03; korè 14.01; kouros 05.10 ; 11.00 ; voir exvoto figurine stèle funéraire : 05.09; 07.07; naiskos 08.00 synagogue: 09.06

syrinx: 11.00

tablette de défixion: 07.19; 14.03; tablette de malédiction: 09.25

taureau : 05.02 (figurine); 05.05 (statue);

$$
11.00 \text { (statue); } 11.06
$$

temple boy : 11.00; 12.10

théâtre : 05.02; 05.08; 07.09; 07.29; 09.03

tiare : 11.00

tissage : 13.04

torche : 13.02

tour : 05.07; 07.02

trittoia : 09.02

tuile : 05.05 (estampillée); 09.27; 13.01; $14.01 ; 14.09$ (inscrite)

tumulus : 08.00

vêtement : 11.04

vie après la mort : 11.00

vin : 14.07

zodiaque : 09.06 